\title{
Enhancing Student Perceptions of Middle Eastern People and Culture through Music, Dance, Folk Literature, Culture, and Virtual Field Trips
}

Jason A. Noland

Follow this and additional works at: https://researchrepository.wvu.edu/etd

\section{Recommended Citation}

Noland, Jason A., "Enhancing Student Perceptions of Middle Eastern People and Culture through Music, Dance, Folk Literature, Culture, and Virtual Field Trips" (2017). Graduate Theses, Dissertations, and Problem Reports. 6326.

https://researchrepository.wvu.edu/etd/6326

This Dissertation is protected by copyright and/or related rights. It has been brought to you by the The Research Repository @ WVU with permission from the rights-holder(s). You are free to use this Dissertation in any way that is permitted by the copyright and related rights legislation that applies to your use. For other uses you must obtain permission from the rights-holder(s) directly, unless additional rights are indicated by a Creative Commons license in the record and/ or on the work itself. This Dissertation has been accepted for inclusion in WVU Graduate Theses, Dissertations, and Problem Reports collection by an authorized administrator of The Research Repository @ WVU.

For more information, please contact researchrepository@mail.wvu.edu. 
Enhancing Student Perceptions of Middle Eastern People \& Culture through Music, Dance, Folk Literature, Culture, and Virtual Field Trips.

Jason A. Noland

Dissertation submitted to the College of Education and Human Services at West Virginia University in partial fulfillment of the requirements for the degree of

Doctor of Education

In

Curriculum \& Instruction

Joy Faini Saab, Ed.D., Co-Chair

Sam Stack, Ph.D., Co-Chair

Nathan Sorber, Ph.D.

John Oughton, Ed.D.

Michael Vercelli, D.M.A

Roxann Humbert, Ed.D.

Department of Curriculum \& Instruction/Literacy Studies

Morgantown, West Virginia

Keywords: multicultural education, music education, cross-curricular education, racism, Middle

East, prejudice, anonymous polls, virtual field trips

Copyright 2017 Jason A. Noland 


\begin{abstract}
Enhancing Student Perceptions of Middle Eastern People \& Culture through Music, Dance, Folk Literature, Culture, and Virtual Field Trips.

This study aimed to build on previous research by creating a multidisciplinary unit of study incorporating music, dance, folk literature, and cultural highlights that originate from the Middle East - coupled with virtual field trips to areas in the region to give greater depth to the students' understanding of the Middle East and its people. The study was completed with rural upperelementary students in West Virginia who were participating in a summer program aimed at lowincome students to assist them in increasing or maintaining reading levels over summer break, as well as providing two meals a day. Initial and endpoint data were collected using an anonymous poll delivered through PollEverywhere that was meant to measure participant perceptions of the Middle East at each of those points, with audio transcripts of the lessons, field notes, and surveys collected by the researcher. An observer and the camp site coordinator provided observations which served as additional sources of data to track perceptions throughout the study. Results did indicate a positive change in participant reactions to the lesson activities related to Middle Eastern culture after participation in these educational activities.
\end{abstract}




\section{DEDICATION}

To my husband, Daniel

Without your unwavering love, support, devotion, and admiration my journey to this point would have been much more difficult. You never complained about all the time I spent on coursework, the late nights attending class, or having to go solo to numerous social gatherings (though, we both know I am not fond of many social gatherings, anyway). You gladly dealt with my irrational moodiness when I had late nights of reading, researching, and writing without complaint, and picked up the slack when I was overwhelmed with work. You have been my

loudest cheerleader, and biggest supporter. For all of this, I am truly grateful. I am so blessed that you came into my life. I love you. 


\section{ACKNOWLEDGEMENTS}

Countless thanks to Dr. Joy Faini Saab for sticking with me throughout my doctoral journey. You are a true inspiration for the professor that I aspire to be. From our first conversation during my phone interview through to this point you have been an incredible source of knowledge and insight that has made me a better academic, teacher, and human. You encouraged me to step outside my comfort zone and take an incredible, eye-opening trip to Italy - something I likely would not have done otherwise. Even in your "retirement," you have offered unwavering support and guidance, for which I am truly thankful. I cannot imagine having completed my journey without you along the way. Thank you! I look forward to continued discussion and knowledge sharing.

Thank you to the other members of my committee, past and present. Dr. Sam Stack, Dr. Nathan Sorber, Dr. John Oughton, Dr. Michael Vercelli, Dr. Roxann Humbert, and Dr. Eva Toth. I appreciate the time you gave me throughout the various stages of my doctoral journey, and your collective knowledge, expertise, guidance, and patience that combined to truly solidify this project.

Thanks to all of the professors in the College of Education and Human Services, as well as the School of Music whom I have had as instructors. Each of you opened my eyes to a larger world of knowledge, and made your own impact on who I am as a scholar and teacher. Your dedication to student learning is acknowledged, and appreciated more than you can know.

Thanks to my Simpson Elementary family, as well as my Fairmont State University family for your support and encouragement throughout this journey. Thanks, also, for my 
students at Fairmont State this semester. Your support and understanding for slower than normal feedback while I finished this project is extremely appreciated!

Finally, thanks to my family and friends. My parents always made sure I was wellequipped to succeed in school while growing up, giving me a solid foundation on which to succeed in higher education and in life. A luxury that you learn is all too uncommon once you work in the public schools. Thanks to both family and friends for your understanding in my “absence" many times over as I completed my masters and doctorate programs, and your unwavering support. 
Table of Contents

Abstract.

.ii

Dedication. .iii

Acknowledgements. iv

Chapter 1: Introduction. .1

Background \& Importance for the Study. .2

Intergroup and Racial Attitudes in Children. 3

Researcher Conception of the Middle East. .5

American Islamophobia....................................................

Statement of Purpose and Research Questions................................ 10

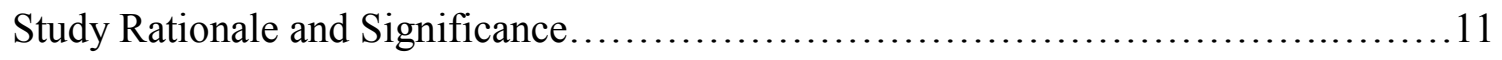

Overview of Methodology.................................................. 12

Chapter 2: Literature Review..................................................... 16

Multicultural Education..................................................16

Multicultural Music Education.................................................. 19

Middle Eastern Music....................................................23

Music Teacher Preparation Programs......................................... 26 
Using Live Polls via Mobile Response Systems as

Discussion Starters \& Data Collection..........................................28

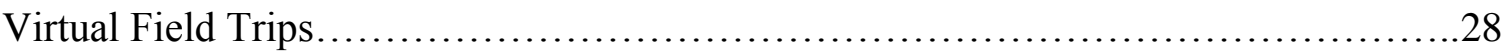

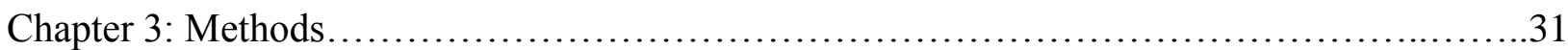

Research Questions.................................................................... 31

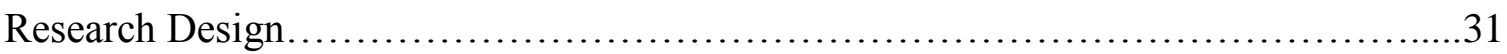

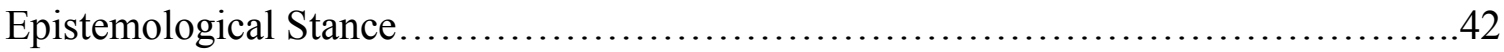

Role of Researcher \& Researcher Bias.............................................43

Participants \& Sampling Procedure..............................................44

Data Collection......................................................................... 45

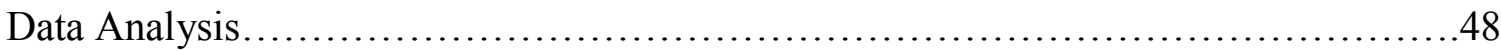

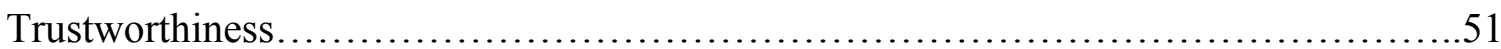

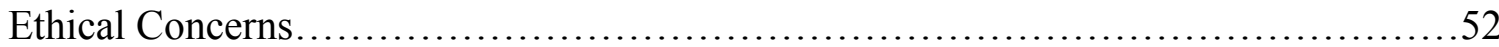

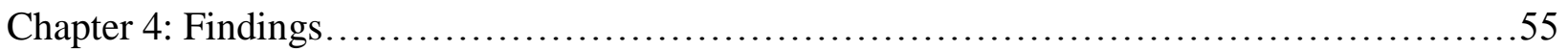

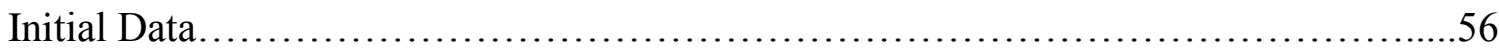

Cultural Highlights \& Observations................................................59

Instrument Activities...........................................................60 
Musical Listening \& Dancing...............................................61

Folk Tales...............................................................63

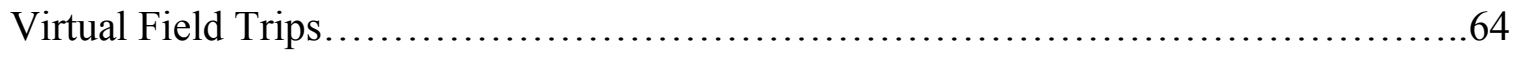

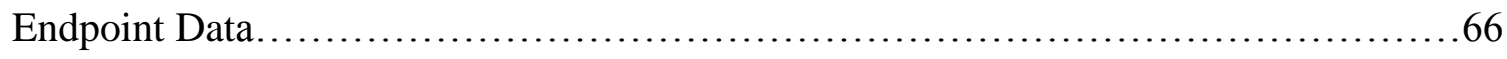

Narrative Portraits of Participants...........................................69

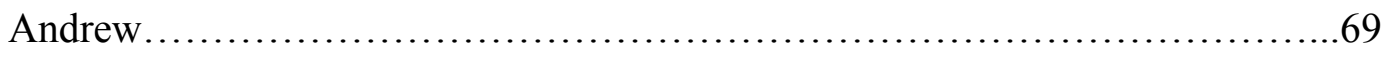

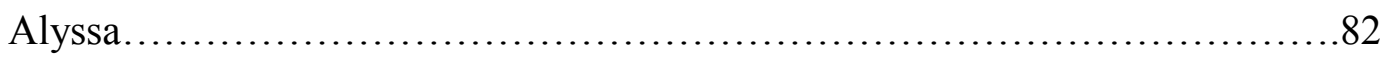

Heather.......................................................99

Megan.......................................................... 103

Chloe.......................................................... 112

Observer and Site Supervisor Surveys........................................ 119

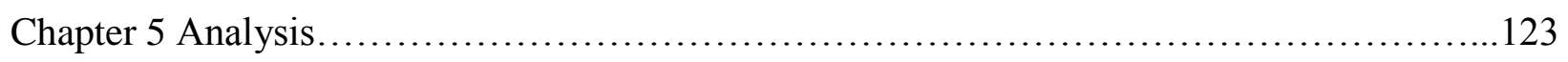

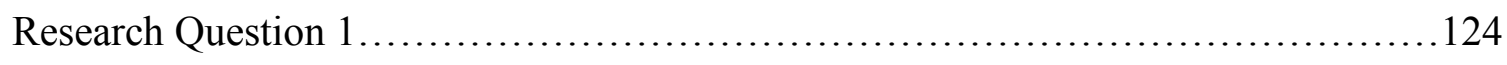

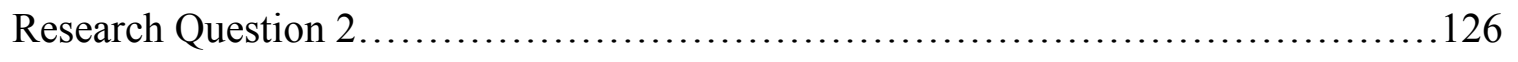

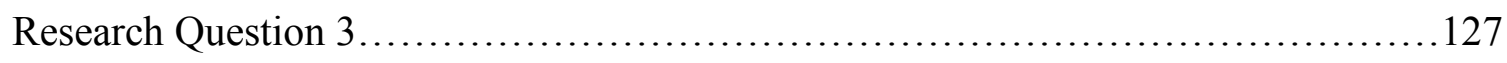

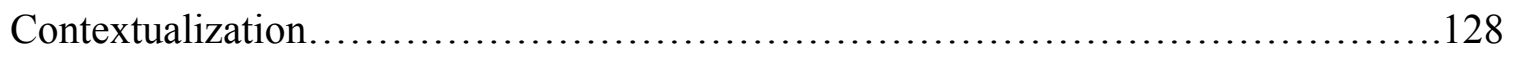

Discussion........................................................... 136 
Barriers

Implications

Limitations and Future Research

References.

Appendix A: Lesson Standards Alignment

Appendix B: Researcher Compiled Map - Session 1

Appendix C: Parent Consent Letter.

Appendix D: Participant Assent Letter.

Appendix E: Observer Consent Letter. 170

Appendix F: Sample Data Matrix Excerpts. .171

List of Tables 179

List of Figures 180 


\section{Chapter 1}

\section{Introduction}

The idea of multicultural education has been a part of American education since before the nation, and a formal educational system, was officially established (Urban \& Wagoner, 2014). After all, “'American' culture has always been mixed and multiple, a cast of expressive people in a vast and varied land" (Campbell, 2014, p. 11). The methods, philosophy, and desired outcomes of multicultural education have shifted throughout the centuries, however. From the time the first European settlers arrived up until the early $20^{\text {th }}$ century, the major focus of multicultural education was to "civilize" any resident who was not European, where civilize would be defined as eliminating their non-western customs, traditions, and language to bring everything in line with the western customs. In other words, they attempted to make everyone the same.

Multicultural education has come a long way since the first Europeans came to North America. On the whole, no longer is the ultimate goal to make everyone the same (assimilation), but rather to focus on cultural pluralism (Janzen, 1994). The struggles of the Native Americans in the early days of colonization, as well as African Americans through the mid-1900s -and arguably to an extent today, are certainly the foremost examples of the needs and changes that took place when it came to multicultural education. However, we cannot discount the impact the floods of immigrants into Ellis Island through the $19^{\text {th }}$ and into the $20^{\text {th }}$ century (mainly from Austria, Hungary, Bulgaria, Greece, Romania, and Turkey), as well as the impact that the large number of Asian immigrants into California had on the education system in the United States (Urban \& Wagoner, 2014). Following the 9/11 attacks, we saw an increase in anti-Muslim, and 
anti-Middle Eastern sentiments. These feelings were heightened with the rise of the Islamic State (ISIS), coupled with the controversial primary election campaigns in 2015-2016 with Donald Trump (Republican nominee) "making it okay" to speak against "the other" and vowing to close the borders to Middle Eastern people, deport Muslims, and put tight surveillance on Mosques and Muslim communities as widely reported by the media.

\section{Background \& Importance for the Study}

This study aims to facilitate increased cultural understanding of the Middle East by introducing Middle Eastern Music, Dance, and basic customs in the elementary music classroom, paired with virtual field trips to see portions of the Middle East for themselves. The most recent rise in anti-Islamic rhetoric swelled in the post 9/11 United States with the rise in Islamic terrorist notoriety, as well as the 2016 Presidential Election, then subsequent Inauguration of Donald Trump. These events have created an environment where this type of multicultural education is needed in order to make a dent in the stereotype that all Middle Eastern people are Muslims, and all Muslims are violent by nature (Naumenko \& Naumenko, 2016). In reality, the Muslim population residing within the United States consists of citizens of more than 22 nations, speaking different languages, and representing a multitude of cultures (El-Atwani, 2015; Pew Research Center, 2012a)

There are inconsistent data concerning the number of Middle Eastern and ArabAmerican, people living in the United States, though there is consensus that the numbers are on the rise (Pew Research Center, 2012). In the 2011 Census American Community Survey, there was an estimated 1.8 million Arab-Americans living in the United States (U.S. Census Bureau, 2012a), a 47\% increase in the population from reported populations in 2000 (Pew Research 
Center, 2012). The Arab-American Institute estimates the population to be 3.6 million in 2014 (Arab-American Institute, 2014).

Part of the reason behind the inconsistent population measures could be because the United States Census does not currently have a category specifically for people of Middle Eastern origin as defined in the 1997 revised standards, and there is also a lack of consensus on what the definition of an Arab or Middle Eastern ethnic category would be but research on creating this category was suggested (Adamy \& Overberg, 2015). It has been reported that the U.S. Census has sent a survey to 1.2 million households exploring the creation of a category for inclusion on the 2020 Census that would enable those residents who identify themselves as Middle Eastern or North African as such, though there is fear that many that identify within this category would choose to withhold their heritage following recent terrorist acts and calls from Trump to ban Muslims (Adamy \& Overberg, 2015).

\section{$\underline{\text { Intergroup and Racial Attitudes in Children }}$}

Cristol \& Gimbert (2008) assert that "racism is a negative attitude based on faulty assumptions and that attitude is developed early in a person's life" (p.202). While no research was found that pertained specifically to attitudes in American children toward people of Middle Eastern descent, there is significant research that highlights the development of intergroup attitudes as a whole in children and adolescents particularly when it comes to measuring perceptions of individuals of European descent v. African American. The results of these studies fall in line with a study conducted by Bar-Tal (1996) that measured the acquisition of "the concept of the Arab by Israeli-Jewish kindergarten children" (p.348) and two unpublished studies discussed by Bar-Tal written as masters theses at Tel-Aviv University. These historical 
studies have studied racial identification and stereotyping and found children as young as 3 months old can identify visual differences between races, and found that racial attitudes begin showing as early as 3 years old (Aboud, 2003). Historical studies also note the role that properly designed education (covered in Chapter 2), as well as interactions with people from diverse backgrounds, can influence racial attitudes even after negative racial attitudes are observed in children (Aboud, 2003; Cristol \& Gimbert, 2008; Katz, 2003; Vietz \& Hildebrandt, 2009).

The validity of the findings of many of these historical studies is often called to question in literature reviews on the topic, particularly when it comes to the studies that are superficial in nature. Hailey \& Olson (2003) note that studies in infants (3 months old) that found the infants prefer to look at photos of people from the race they see most often (generally their own) can be most reasonably interpreted "that infants prefer the most familiar race group rather than their own group per se" (p.460). Other studies note infants (10 months old) equally accept toys from individuals of two different races, while still preferring a toy offered by an individual with a native rather than foreign accent (Hailey \& Olson, 2003). Studies that require children to answer questions identifying a white or black individual as a "certain way" including "clean," "naughty," "good," “cruel," "stupid," are also called into question as they may show a tendency toward in-group favoritism or attachment rather than out-group bias (Aboud, 2003).

Phyllis Katz of the Institute for Research on Social Problems (2003) discusses how people generally believe that children inherently do not see color differences until they are pointed out to them and that children would not develop racial bias if they are not taught it by their parents. She continues on to note that historic research has, in fact, not found a correlation between children's racial attitudes and their parents and that "prejudice (or individual racism, as 
it might be called today) is multiply determined and that its roots arise from many possible domains" (Katz, 2003, p.898). Katz updates historical research that constructs five factors that are involved in racism: Historical, Sociocultural, Psychological, Act, and Object of Prejudice (Allport, 1954; Katz, 2003). These factors combine aspects of society including historical concepts, legal and politically motivated legislation, socialization, media, childhood factors (direct and indirect), peers, personality factors, fear (e.g. fear of the dark, the unfamiliar, or self-esteem), categorization (ingroups and outgroups), etc. to provide a basis for why racism develops. The impact of these factors may change during each developmental level from childhood through adulthood depending on personal experiences, including television shows watched regularly, peer group changes or development, etc. (Aboud, 2003; Bar-Tal, 1996; Katz, 2003) .

\section{$\underline{\text { Researcher Conception of the Middle East }}$}

The concept of the Middle East seems to represent different things to different people and organizations. There is not a wholly accepted list of countries included in what would be deemed as the Middle East. The list of countries that is included in this region will vary based upon what resource you are looking at, but normally spread from lower Europe, across northern Africa, and over to Eastern Asia.

The Middle East Policy Council (n.d.) states that:

Regions are subjectively determined (and thus debatable) areas that we perceive to have certain characteristics in common. They may be defined by physical geography; for example, areas bordered by mountains or rivers or seas, or areas which share a similar climate. They may also be defined by characteristics of human geography, such as shared historical experience, the same language, the same religion, or similar cultural practices. In the case of the Middle East, both physical and human geographic considerations are brought to bear to define the region. 
The researcher in this study believes that the Middle East is just like any other region of the world, having a variety of histories, landscapes, cultures, etc. that make up each country. While many people in the United States seem to jump to the conclusion that any individual that physically (in body features or attire) resemble a stereotypical person of Middle Eastern origin is a Muslim or Islamic person (generally with a negative connotation), the researcher for this study operates with the understanding that multiple religions are practiced within the Middle East, with many residents likely not practicing a religion at all. The researcher also understands that, similar to in the United States, individual churches or groups with the same named denomination may carry on different customs from other churches of the same denomination. Some of these groups may even operate under completely different philosophical bases.

The researcher believes that, like any region of the world, there are varied economic, political, and developmental landscapes in different areas of the region. There are areas of modern development like Dubai, there are areas of poverty and lesser development that are more commonly shown through movies and media, and everywhere between.

The researcher believes that just like you cannot develop a list of characteristics that a person of American origin has and expect it to be applicable to every person of American origin, you cannot develop a list of characteristics that a person of Middle Eastern origin has and expect it to be applicable to every person of Middle Eastern origin. Similarly, you cannot develop a list of characteristics that only a person of American or Middle Eastern origin has and expect people with those characteristics to only be from the respective origin.

The researcher chose the activities for the research sessions in this study based on their origination in countries that are widely discussed as being included in the Middle East. The intent was not for the participants to become experts on the Middle East, rather, to plant the 
seeds to enhance their understanding and perceptions of the people and region of the Middle East.

\section{$\underline{\text { American Islamophobia }}$}

Mohamad Emara (2017) describes Islamophobia as "fear, hatred or demonization of Islam by distorting its essential truths and true image"

Looking back through history, the idea of "Islamophobia" has resounded within American culture since before the official creation of the colonies (Hutson, 2002; Johnston, 2016; Saladin, 2016). These prejudices are grounded in various political, economic, identity, and theological ideologies in varying degrees depending on the prominent issues of the period discussed (Rauf, 2016; Saladin, 2016). These prejudices rise and fall through various times in history and are often fueled, grounded, and shaped by the religious leaders, politicians, and the media (Emara, 2017; Rauf, 2016).

Relationships between predominantly Christian European nations, and predominantly Muslim nations were friendly in pre- $11^{\text {th }}$ century times. This rhetoric began to change around the time of the Crusades, when in 1095 Pope Urban II called Christians to "embark on a crusade to the Holy Land" (Saladin, 2016). During his speech, he called for war against Turkish people, suggesting they are "linked to the devil through their Muslim religion" (Saladin, 2016; The Editors of the Encyclopaedia Britannica, 2007). These anti-Muslim feelings continued to be carried on and spread through the globe. Christopher Columbus used his expedition to the Indies as an effort to combat Muslim expansion by spreading Christianity (Saladin, 2016; Social Psychology Network, n.d.). Similarly, the British colonists carried their anti-Muslim views to the Americas. Captain John Smith served in combat against the Ottoman Empire and was captured 
as a Turkish slave. Upon escaping, he returned to England and was praised for his combat against the Muslims. His coat of arms depicts the severed heads of three Turkish men, which came about as a gift for his service (Hindley, 2007; Saladin, 2016). Anti-Muslim rhetoric, viewing Muslims as "unchanging, irrational, and barbaric” (Johnston, 2016; Rauf, 2016; Saladin, 2016), continued past American separation from Europe during the American Revolution. Thomas Jefferson, in his autobiography, discusses the debate that took place within the Virginia legislature over a proposed religious freedoms bill. He supported Islam being included in the bill based on his legal understanding of religious freedom, but noted it was a unique exception based on the fact that it was largely not accepted as an equal religion by other citizens (Hutson, 2002; Saladin, 2016).

Anti-Muslim ideals once again gained popularity during the Greek Revolution against the Muslim Ottoman Empire in the 1820s. Secretary of State John Quincy Adams in an 1832 essay noted his support of Greece's independence and discussed his view of Christian teachings as compared to Muslim. He touted that Christian doctrine is concerned with human good, while Islam is the exact opposite - focusing on evil and violence. He insinuates that the world will not be at peace while Islam exists (Saladin, 2016; Samuelson, 2002).

During the annexation of the Philippines at the turn of the $20^{\text {th }}$ century, the United States first knowingly ruled practicing Muslims, though this is only because the religious identities of African slaves were not recognized. In his address, President McKinley stated that the goal was to educate, civilize, and Christianize the inhabitants of the islands (though $90 \%$ of them were already Roman Catholic) (McKinley, 1900; Saladin, 2016). Many Americans opposed nonChristian people living in U.S. territory; even more believed that Muslim's could not live in the same manner as other Americans. Eventually, Christian controlled areas of the Islands were 
allowed to govern themselves, while the Military oversaw predominantly Muslim areas (Saladin, 2016).

The early $20^{\text {th }}$ Century brought about xenophobia against all minorities in America. To quell the fear of immigrants taking over their communities, Congress passed the Emergency Quota Act in 1921. This act restricted the number of immigrants allowed to enter by nationality, and restricted anyone of Asian (including Arab) descent from entering the U.S. The Naturalization Act of 1790 already restricted citizenship rights to European immigrants, and eventually African's after emancipation (Saladin, 2016; U.S. Congress, 1790; U.S. Congress, 1921).

1944 brought the first Muslim being granted U.S. citizenship. Courts granted this citizenship on the basis that this man could be considered white as Arabs had lived in Europe and picked up European traditions (Saladin, 2016; U.S. District Court for the District of Massachusetts, 1944). There is some speculation that this change was prompted for economic reasons with the U.S. having increased interests in the Middle East that began with Saudi Arabia becoming a major oil supplier during World War II.

The most recent surge in anti-Muslim rhetoric came about after the September 11 attacks. The leader of the terrorist group "Al-Qaeda" claimed responsibility for the attacks in order to promote Islam. However, devout Muslims condemn terrorist acts of violence. Following the attacks, President Bush delivered a speech explaining that the "war on terrorism" was not a war on the Islamic religion as the Islamic religion holds beliefs vastly different from the radicals (Johnston, 2016; Saladin, 2016). 
The President's statements did little to quell the fears of many American's in regard to people of the Muslim faith. Anti-Muslim rhetoric continued through the 2016 election following reports beginning in 2014 (along with primary election season) that the extremist group most commonly known in the United States as "ISIS" was rapidly expanding. The issue was largely discussed from both Democratic and Republican candidates, each with varying messages and suggestions on how to combat extremist threats to the United States (Saladin, 2016; Woodrow Wilson International Center for Scholars, n.d.). Particularly on the Republican side of the primary elections ISIS was discussed in a way that framed attacks by ISIS as "religious violence", especially targeting Christians (Saladin, 2016, p.27), though the majority of practicing Muslims do not condone extremist actions.

\section{$\underline{\text { Statement of Purpose and Research Questions }}$}

The purpose of this study is to combine musical and cultural activities from the Middle East, as well as virtual field trips to the region to begin to break down some of the prejudice against people of Middle Eastern heritage. The focus of the activities will be to counter some the stereotypes of the people, culture, and geographic features of the Middle East and its people.

The attempt will be to combat these stereotypes by focusing on the similarities between Middle Eastern folk tales, music, traditions, and civilization and our own in the United States. The design of the sessions throughout the study build on previous literature that focuses on multicultural education, music education, and virtual field trips; the combination of which is difficult to find in current literature particularly in regard to the Middle East.

Students were through hands-on activities of music making on authentic instruments, interactions with two Middle Eastern Folk Tales, alongside learning traditional dances of the 
region, and creating their own ostinato patterns to modern Israeli Pop music based on traditional rhythms. Throughout these experiences discussions centered on cultural similarities and differences, surprises that the students encounter, and virtual field trips to give them a glimpse of life and communities in the Middle East.

Leading this study was the following questions:

1. What impact, if any, does student activity in traditional Middle Eastern customs have on the students' ideas or beliefs about the region and people?

2. What impact, if any, do virtual field trips to the Middle East have on students' ideas or beliefs about the region and people?

3. Is there a notable overall shift in opinions about people of Middle Eastern origin, or the region itself, after participation in the aesthetic experiences and discussions?

\section{$\underline{\text { Study Rationale and Significance }}$}

This study aims to educate elementary-aged students about culture and society from the Middle East, with the ultimate goal of reducing any pre-established stereotypes and prejudices. Ideally, it will also establish a foundation for continued discussion about the subject and curricular change within the specific research environment once the study is complete. The curricular lessons in this study are built with the focus of a pluralistic framework for multicultural education in mind.

This study is especially timely given the current climate in the United States, as Naumenko \& Naumenko (2016) state: “The problem of Islamic extremism in the modern world has determined the necessity to find ways to counteract this phenomenon" (p.336). Historical research encourages beginning to counter societal prejudice in schools, especially with children, 
as their attitudes are still being formed, rather than having been long-established. Thus, they are easier to change than adults (Banks, 1988; Glock, Wuthrow, Piliavin, \& Spencer, 1975).

While the main focus of the study involves music and dance to "facilitate the understanding of near and distant people and places" (Cantarelli Vita, 2016), the study follows the guidance of previous researchers (Banks, 1988) in building an interdisciplinary approach to the overall curricular unit. Threads from Social Studies, Literature, Geography, and Science are intertwined to give students a deeper understanding that music and dance alone would not allow.

This study follows the guidance of previous researchers as it aims to bring to focus the common characteristics of our cultures by retaining the values of the cultures through class activities, while empowering the students to construct common themes and connections (Banks, 1988; Janzen, 1994; Pizzillo, 1983; Tiedt \& Tiedt, 1990) to assist the students to "not only develop appreciation for the perspectives of others, but sustain a value-tolerant acceptance of diverse cultural understandings, belief systems, customs and (perhaps) sociopolitical traditions" (Janzen, 1994, p.10).

The qualitative research approach to this study, along with the researcher being a participant observer, will allow greater insight into the thought processes of the participants throughout the research period. It is important to understand how the thoughts of the participants evolve throughout the process, rather than simply their beginning and endpoint.

\section{Overview of Methodology}

This study is designed as a qualitative ethnographic study, with the researcher posing as a participant-observer. Hays and Singh (2012) describe qualitative research as studying a phenomenon in context, with the researcher collecting and analyzing data collected within the 
natural setting. Further, they describe ethnography as a "research paradigm in which the researcher describes and provides interpretations about the culture of a group or system" (p.60). Hammersly (as cited in Crotty, 2015) continues that statement in saying that an ethnographic researcher strives to "document the culture - the perspectives and practices - of the people in these [social] settings. The aim is to 'get inside' the way each group of people sees the world" (p.76).

Christine Bennett (2001) offers an analysis of historical research in multicultural education from which twelve genres emerged that are grouped into four clusters (curriculum reform, equity pedagogy, multicultural competence, and societal equity), each with their own unique assumptions. This research falls most closely within cluster three, Multicultural Competence, and falls within the Prejudice reduction and Ethnic Group Cultures genres. Research within this cluster are based around the assumptions that "the reduction of racial and cultural prejudice is possible and desirable" (p. 192), and "individuals can in fact become multicultural; they need not reject their familial worldview and identity to function comfortably in another cultural milieu" (p.192). James A. Banks (1988) would put the curricular activities within this study within the multiethnic ideology, rather than assimilationist (total integration) or pluralist (separated) ideologies. Banks believe that the assimilationist and pluralist ideologies have extremes within them that allow for "distorted views of societal realities" (p.122). The multiethnic ideology works toward "an open society, in which individuals from diverse ethnic, cultural, and social class groups have equal opportunities to function and participate" (p. 122). This ideology respects individual ethnicity, and uses it in positive ways by discussing unique cultural characteristics, while stressing that "minority and majority groups share many cultural traits, values, and behavior styles" (p.122). Banks' work is solidified by other researchers who 
have studied and stress the importance of the basic assumptions discussed previously (Pizzillo, 1983; Tiedt \& Tiedt, 1990).

The researcher will serve as a participant-observer, facilitating the lessons for the participants (students and their formal music teacher), while simultaneously collecting data and observations. This role is best suited for the study given the specific knowledge and experience required in order to effectively facilitate the lessons for data collection.

Results from anonymous electronic polls conducted during the first and last lessons were saved as documentation of beginning and endpoints in participant understanding. Students will be led in six lessons focused on music \& culture of the Middle East, as well as short virtual field trips to various locations within the region. Individual lessons will be audio recorded, transcribed, and coded in order to better document the discussions, and track potential changes in the structure of participant questions, responses, and thought processes. While video recording may be able to document nonverbal communication more efficiently (Hays \& Sing, 2012), in an elementary classroom setting, it often creates distraction and changed behaviors which may significantly alter the observations. Following the study's completion, a follow-up interview with the participants' music teacher will be conducted to gather information from conversations with the students that may have occurred after the researcher completed his work with the participants.

Audio transcripts will first be coded using a combination of "In Vivo" and "Descriptive" coding, to more accurately capture and emphasize the voice (by means of beliefs, understandings, and questions) of the adolescent participants throughout each phase of the study (Saldaña, 2012). The transcripts will then be coded using "Focused Coding" to bring out the 
"most frequent or significant codes" (Saldaña, 2012, p.213) that developed during the In Vivo coding process. The "Holistic" coding method is appropriate for the data from both polls, as well as the follow-up interview with the music teacher as these represent "snapshots" at certain periods of time during the study (beginning and endpoints), instead of looking for changing themes throughout a period of time (Saldaña, 2012). 


\section{Chapter 2}

\section{Literature Review}

\section{$\underline{\text { Multicultural Education }}$}

The field of modern multicultural education within the United States came into being largely in post Brown v. Board of Education times, but has and continues to be viewed as lacking a specific definition and purpose (Bennett, 2001; Gibson, 1984; Sleeter \& Grant, 1987). It was developed to combat the prejudices that were shown during desegregation including non-white students being placed in special education courses, or being expelled at the teachers' discretion, and still others placed in schools where the curriculum was entirely focused around EuropeanAmerican ideals and perspectives (Bennet, 2001). Today, the manner on how to go about educating the youth about different cultures/religions is a matter of considerable debate, especially when centered within the public school system. Ideally, this teaching will begin in early childhood through parenting, and discussing these types of differences in a child's first years in order for the child to be more likely to develop non-biased views toward a certain skin color, gender, religion, etc. (Hildebrandt, \& Vietze, 2009). Bindewald \& Rosenblith (2014) charge that "Pluralistic democratic states have the responsibility of developing civic identities in students so that the project of liberal democracy itself might be maintained" (p. 599). The American Psychological Association (American Psychological Association, 2008) encourages its members to adopt a multicultural perspective within them, and suggests diversity (ethnic, cultural, etc.) needs to be represented and respected in education and work settings outside specific occasions and holidays that focus on it. This can be especially challenging where you

have students in the public school, still under the trust of their parent's, that come from varying 
religious, ethnic, socioeconomic, etc. backgrounds (Bindewald \& Rosenblith, 2014; Brandt, 1994). Often, schools will receive pushback from parents on teaching about topics that tend to be controversial, or potentially go against their personal ideologies. Arguments are made that schools should remain as neutral as possible on these issues, while others claim this is a threat to maintaining a "meaningful existence of cultural minority groups" (Bindewald \& Rosenblith, 2014, p. 590). The majority of research behind multicultural education either focuses on teaching "tolerance", teaching "respect", or instilling "tolerance as mutuality" (Bindewald \& Rosenblith, 2014; Brandt, 1994). Tolerance is seen to be the easiest position to take, where you simply accept that there are people that are different than you and leave them be without doing them harm. Respect takes multicultural education a step further where you actually engage with people that are different than you, get to know them, and build healthy relationships with them. The aim of the tolerance as mutuality (Bindewald \& Rosenblith, 2014) model of multicultural education goes beyond simply "tolerance" and "respect" for the other, rather, the focus is on developing the "will to relationship" (p.600), despite differences among individuals to allow for “collective, inclusive decision making", where focusing on open communication is the central focus of making tolerance as mutuality a reality. While Bindewald \& Rosenblith (2014) believe that tolerance as mutuality is a great starting point for overcoming challenges that arise between peoples with different backgrounds, viewpoints, and beliefs they also point out it is especially difficult within the public schools to engage in steps to overcome prejudices while discrimination exists. James A. Banks in an interview with Ron Brandt (1994) further acknowledges the challenges in teaching multiculturalism within public schools, particularly when religious conservative parents do not want their children to be taught to accept and/or respect religions other than their own. Banks goes on to state: 
"Schools are public institutions that should promote the common good and the overarching values of the nation-state. While we value diversity and are committed to that ideal, the diversity we value must exist within the framework of American democratic values" (p.31).

He notes these values are justice, equality, human rights, freedom of expression, and freedom of choice.

Banks pushes for "three orientations to multicultural education” (Brandt, 1994, p. 28). These orientations include contributions (noting contributions by people of a specific group), additive (adding supplemental literature to existing curriculum), and transformative (helping students to look at reality differently). While Banks prefers the transformative approach, he emphasizes that most schools operate under the contribution and additive approaches. Those schools see those approaches as necessary stepping stones to being able to move toward the transformative approach (Banks, 2013; Brandt, 1994).

James A. Banks (2006) offers a review of notable research since the 1940s on curriculum strategies to combat negative racial relations within elementary aged students. Each study showed reduced prejudice within students after teaching units that incorporated multicultural textbooks (including multiethnic readers), role-play, folk dancing, Sesame Street episodes, and other relevant curriculum materials. Going forward, Banks (2006) stresses that it is:

“essential for teachers to: (1) restructure their curriculum and teaching so that students from different ethnic, racial, language, and social-class groups will have equal opportunities to learn; (2) implement prejudice-reduction strategies that are effective for different individuals and different racial/ethnic groups; and (3) promote social inclusion, in addition to prejudice-reduction so that both teaching practices and school climates foster relationships that build across differences so that all students will develop the knowledge, attitudes, and skills needed to function as effective citizens in our diverse, complex, and troubled world" (p.613). 


\section{$\underline{\text { Multicultural Music Education }}$}

The National Association for Music Education (NAfME) began to put focus on promoting multicultural music in music education in the 1940s, primarily through folk/ethnic songs (Humphreys \& Wang, 2009). In 1994 the NAfME created the National Standards for Music Education through a grant funded by the U.S. Department of Education. There are nine national standards on this list, all of which are the basis of each state's content standards for Music. Out of these nine standards, at least five are such that easily align with the study and performance of multicultural music, four of these include implied language to suggest multicultural uses.

While I think it is safe to assume that every Music Educator finds value in teaching multicultural music to their students; the extent to which it is taught, and the context vary greatly from teacher to teacher. Overall, it appears that multicultural music education methods normally fall into one of two categories: 1) exposure by performing a song from another culture - this may or may not be an "authentic" performance and is normally a segregated experience, and 2) Deeper study of the music \& culture of a different ethnic group through multiple means and normally involving more than one subject.

\section{Matt Robinson in his article Crossing Borders: Adding Cultural Diversity to Music}

Education Expands Horizons for All” (2010) gives perspectives on including multicultural music into curriculum from five different music educators from various specializations. He credits Jeremy Cohen, founder and director of This World Music (thisworldmusic.com) as giving five steps to follow when beginning to incorporate multicultural music into the music classroom that I think are quite valuable. These include: 
1. Seek out high-quality professional development- from those who have studied in the culture and have adapted traditional music for classroom use.

2. Choose depth over breadth- pick one or two world music traditions and make them your focus.

3. Strive for balance- with world music and western music traditions.

4. Teach aurally- to help reach "non-music" students, and ensure you remain faithful to traditional pedagogical methods.

5. Provide context- about the culture the music derives from that you are studying.

From my research to this point, the two methods I find fit most closely to an authentic multicultural music education would be categorized as a "Virtual Field Experience" (Bartolome, 2013), and school-wide cross-curricular studies (Damm, 2006; Hoffman, 2012).

Adria Hoffman describes a program that she implemented along with her colleagues at an American middle school that she describes as a "racially homogeneous yet linguistically, ethnically, and socioeconomically diverse school community" (Hoffman, 2012). She goes on to describe the student population as:

Some of our students were new to the United States, and some had had family in the area for generations. Our school housed an increasing population who identified themselves as Asian, Caucasian, Latino, and Middle Eastern. Additionally, the number of English language learners, representing diverse ethnicities increased significantly from year to year. (Hoffman, 2012)

The project was developed because the school staff saw an increasing problem with stratification between groups of students. They saw themselves - the "Related Arts" teachers who teach across grade levels - as the teachers in the best position to create change in creating a more cohesive school community. The program they designed was a grant-funded artsintegrated curriculum through which students learned about each other and the core content areas while also creating a safe place for all of their students. Opportunities were provided for core groups of students to meet with teaching artists each week to disseminate information through community performances. These opportunities not only impacted students through learning, but 
provided useful continuing education to faculty, and informed the community. This project not only opened the door to students' understanding and appreciation of each other, but also positively impacted behavior and engagement of troubled students from the ethnicities being studied.

Another example of quality multicultural music instruction is termed as a "Virtual Field Experience (VFE)" (Bartolome, 2013). She attests the VFE "Is designed to immerse students in a multisensory, cross-cultural learning experience that provides opportunities for them to engage with a single musical culture, in-depth, for an extended period of time” (Bartolome, 2009). Bartolome wanted her students to learn West African Drumming. Since she did not know anything about the subject, she decided to spend a month at the Dagbe Cultural Institute in Kopeyia, Ghana to learn drumming, dancing, handicrafts, and participating in local ceremonies and cultural events. She took what she learned and recreated some of her experiences for her students over a six-week period using immersive and multidimensional approaches. Although I do not believe it is necessary for a Music teacher to travel to a foreign country to study their music and culture in-depth in order to create a meaningful VFE — nor does the author of this article from how I interpret the article-I strongly believe that the extended, multidimensional study of a culture and its music serve well in the process of creating a multicultural music education that has meaningful and lasting impacts on the students' lives.

Along a different spectrum, there are also cases as described by Cam Cobb in Throwing out the Culturally Unresponsive Cookie Cutter: Collaborations, Concessions, and Curricula in a Ramadan Music Accomodation (2012). This paper is written from the perspective of a sixthgrade general education teacher in Toronto, Canada. This school has a number of Muslim students who are allowed on their parents' accord to live by the customs as the religion as they 
see fit when appropriate. Historically, these students have selected certain customs to adhere to and certain ones not to at school during the month-long period of Ramadan. In this particular year, four students decided to strictly adhere to all customs which included not listening to or participating in the creation of secular music. The students spoke with their teacher privately about their plans, and he set out to try to set up accomodations for these students. Unfortunately, he received negative feedback on the idea from other colleagues who "expressed doubts as to whether the girls would successfully observe Ramadan in this manner during the entire month" (Cobb, 2012). A search of district policy fell short of including language that would support accommodation of an alternative curriculum, but did allow for students with religious views that do not allow music to be excused from taking any such classes - on a permanent, not temporary basis. Through conversations with colleagues, especially the Music teacher, he was "Attempting to foster a robust form of inclusion... [drawn] from an equity-oriented vision of education and human relations" (Cobb, 2012). What ended up coming about from these discussion was an agreement that the students would be pulled out of Music, put in a conference room, supervised by the principal or counselor, and given research projects to complete during the celebration of Ramadan. What was desired from the sixth-grade teacher, and would have been a wonderful result of the situation that arose, would have been to use the opportunity to steer the Music curriculum to studying about varying religious views in regard to Music, and use the time to give the students some deeper knowledge of Muslim and other religious practices that do not allow (at certain times or at all) the enjoyment of secular music. There is no ban on listening to Muslim religious music during Ramadan, and perhaps some of the parents would have been willing to come in to speak to the children about their customs. This would allow the students not to have 
been isolated from the rest of the group, and helped their peers understand more about the cultural backgrounds of the other students that may be different from theirs.

\section{$\underline{\text { Middle Eastern Music }}$}

My interest in studying Middle Eastern Music stems from the fact that the school I teach at is comprised of a number of students from the Middle East. Early in my research about multicultural education, I came across an article by Adria Hoffman (2012) that quotes Beverly Tatum (2007) as saying:

If we think about our school environments as an illustrated book in which students look to see themselves, we have to ask, what story is being told, and who is included in the illustrations? ... [Students] may not be seeing themselves in the curriculum in meaningful and substantive ways.

This quote is really what drove home the fact that many of our students are not seeing themselves as being an important part of our school. A number of our students' families moved to the United States recently to get away from the wars that are ongoing on their countries. I realized at that moment that we are doing these students a real disservice by not acknowledging their cultural backgrounds. I do not feel that this is on purpose, rather, it's just not something the staff does not think about. Our multicultural plan mostly consists of phrases that encourage "acceptance" that there are other belief systems than our own, and focuses on issues regarding students with disabilities. I have always made a point to include songs of different cultures in my curriculum, as well as learning to play instruments from different countries. However, the songs I chose to teach were more often than not included in some sort of book, and the instruments we learned were essentially all African originated -- because I am familiar with it.

Beegle \& Shehan (2003) state it perfectly that: 
In practice, the "movement" of world music and multicultural music education has mostly excluded the musical cultures of a vast population stretching from Morocco, across North Africa, through Iraq, over to Turkey, and all the way east to Afghanistan. Multicultural education in and through music has been colored by convenience. The musics of the Middle East are not conveniently attainable, comfortable for many on their first hearing, or clearly understood without considerable study.

Weidknecht (2009) outlines several reasons that music teachers are often unwillingalthough I would prefer to say "unmotivated"- to include world music education in their curriculum. Some of the issues she states include:

1. Lack of time to include world music study within an overloaded curricula.

2. Linguistic Challenges

3. Lack of ethnically authentic materials and equipment available.

With the historic, and current complicated relationship the United States has politically with the Middle East it is easy for American music educators to shy away from touching anything that has to do with that region. I, however, believe that that is a perfect reason to teach about the Middle East! To quote Beegle \& Campbell (2003): "Even as contemporary world events continue to unfold unpredictably, the power of music is called upon to strip away discord, shape a united courage, and remind Americans of prospects for peace and living together in harmony."

There is no doubt that the Middle East is just like any other region of the world, having a wide variety of histories, landscapes, cultures, etc. that make up each country. It is also true that Middle Eastern music differs greatly from western musics - especially in regard to tonalities (Middle Eastern music incorporates quarter flats as well has traditional "western flats") so it is rather uncomfortable for westerners to try to emulate at first. Study of Middle Eastern music is complicated in many ways due to the fact that the region as a whole has a distinct sound to its music, but each country has minor differences in their styles (even if they use the same name). 
Additionally, each country may have a different name for the same instrument (e.g. the goblet drum is referred to as a "Darbuka" in Egypt, but a "Tablah" in Egypt) that also may be made with slight differences.

In general, Middle Eastern music has several common features no matter where the country of origin is. As described by Beegle \& Campbell (2003) these characteristics include:

- Complex melodic and rhythmic ornamentation

- Absence of harmony

- Ensembles of instruments that perform in unison or octaves

- Highly improvised melodies with ornamentive features based on motifs (maqam's- similar to western Tetrachords)

Through my research I have concluded that, once someone takes the initiative to learn about Middle Eastern music — it is probably one of the most affordable world musics to perform on authentic instruments. The instruments are very basic, historically being made from mostly found materials including reeds, pumpkins, gourds, clay, and skins. Even today you can very affordably invest in a wide variety of Middle Eastern instruments made in the historic fashion. Additionally, in a pinch many western instruments can be used to create the same general rhythms and pitches necessary to perform this style of music. Fretless guitars or violins can be used in place of the Rebab (possibly the precursor to the western Violin), and the Oud. Tambourines can be used in place of the Riqq, which is actually an instrument a person can get a performance degree on in the Middle East. Finally, frame drums which are popular in elementary music classrooms can replace the Middle Eastern frame drum to give a nearly identical sound if made of the right materials in the right sizes. Doumbeks (Tablahs, Darbukas, 
etc.) are available in varying sizes to accommodate different size children-sizes are used for other purposes in adult Middle Eastern bands — and are some of the least expensive drums I have seen in my years of teaching. All it takes is a teacher getting over the roadblock of apprehension to learn something different to them.

\section{$\underline{\text { Music Teacher Preparation Programs }}$}

\section{In Multicultural and Popular Music Content in an American Music Teacher Education}

Program, Humphreys \& Wang (2009) examined the course requirements for music education majors at one large university music school in the southwestern United States. According to the authors:

"The principal accrediting agency for American college and university music departments and schools, the National Association of Schools of Music (NASM), added to its standards a requirement for a multicultural repertoire for undergraduate music majors in 1972, and it specifically mentioned popular and non-western musics in new competency-based standards for pre-service music teachers inaugurated in 1974" (Humphreys \& Williams, 2009)

Although I could not independently verify this information easily from the NASM website.

This study focused on the coursework focusing directly on studying or performing music of the 80 students enrolled as undergraduate music education majors. The instructors of the classes, studio lessons, and ensembles were asked to estimate the percentage of time students dealt with each of 13 styles of music - including time outside of class. The study found that only .23 percent of a students' time was spent on musical styles of non-western origin!

It is important to note that Humphreys \& Wang (2009) do note that: 
The results of this study are not generalizable, but the fact that the music school examined in this study is fully accredited by the NASM suggests that its teacher education curriculum may be similar to those of many other large music school in the USA.

On a personal note, the findings of this report do echo the experiences I had during my undergraduate studies. While I did perform multicultural pieces in the choral setting from time to time, the overwhelming majority of music I performed was of western-origin. In my Music History, Music Appreciation, and other coursework I do not remember discussing any forms of music outside of the western realm.

Fast forward to when these pre-service teachers are employed for their first teaching positions and you have a number of new teachers with little experience with multicultural music, trying to find their own in their teaching. Many of these teachers will rely on their supplied textbook to guide their curriculum — as they may not be comfortable making their own curriculum from supplemental and/or original materials. Emily Mason (2010) in her study: Multicultural Music Represented in Current Elementary Music Textbooks: A Comparative Study of Two Published Music Series analyzed the songs included in the kindergarten through fifth grade music textbooks published by two of the biggest textbook publishers in three publication years. The contents of these textbooks echo what was found in the curriculum for undergraduate Music Education majors, it is overwhelmingly western in nature. The first publisher, Macmillan McGraw-Hill's textbook included songs from 100 countries, 46.05\% of which were from the United States, 5.78\% African American, 4.28\% English, and 3.21\% German. The second series published by Silver Burdett Ginn contained songs from 107 countries. Of these, 53.12\% were from the United States, 5.10\% African American, 3.07\% German, and 2.80\% French. However, they did see an increase in the number of countries represented as the subsequent new series' were published. 


\section{$\underline{\text { Using Live Polls via Mobile Response Systems as Discussion Starters \& Data Collection }}$}

Technology advancement has allowed for easier, more efficient gathering of anonymous data. Modern platforms, including Poll Everywhere, allow students to anonymously input their thoughts to specific questions through various question-type formats (multiple choice, open ended, etc.) using modern cellular devices they are already familiar with (Shon \& Smith, 2011). These systems are particularly helpful for gathering information about sensitive, or "hot-topic" concepts where anonymity is important in gathering the most accurate information without participant fear of fallout from peers or instructors for their opinions (Blood, 2010; Chandler, Hamm, Hudson, Smith, \& Tucker, 2010). These response systems have proven effective in previous studies on increasing student engagement (especially with students who are often reluctant to participate), while allowing students to immediately see how their response compares to the others, and allows the instructor to give immediate feedback on the results (Bhatia, K., Kirthi, P., \& Wijetunge, T., 2016; Blood, 2010; Blood, E., \& Gulchak, 2012; Hwang, C., Lacroix, D., \& Usova, T., 2012).

\section{$\underline{\text { Virtual Field Trips }}$}

Advancement in digital technologies and online tools have allowed teachers across disciplines to easily "enrich cultural and language studies with an exploration of geography and travel" (Johnson \& Lamb, 2010), allowing for the ability to "bring locations across the globe into the classroom learning environment" (Cook, Bell, Walters, \& Smith, 2016). By allowing places and concepts to be visualized, this type of global exploration provides for and engaging interdisciplinary approach to teaching and learning (Dodsworth \& Nicholson, 2012; Johnson \& Lamb, 2010). Global awareness is significantly impacted by allowing students to interact with the interface, by allowing students to better establish the relationship between location, culture, 
and events (Adam \& Mowers, 2010; Davinroy \& Williams, 2015), as well as allow students to "develop an appreciation for the differences among cities, towns, and countries across the globe" (Cook, et al, 2016).

Google Earth is one such platform that allows users to search for a location, and interact with it using satellite images and photographs. Students can interact in 360 view with the terrain of a geographic location, or even tour museums, colleges, and other places of interest without leaving the classroom (Davinroy \& Williams, 2015; Johnson \& Lamb, 2010; Meyer, 2016). Teachers have used this platform to bring to life stories from famous literature, effects of volcanic eruptions, "walking" historic routes including the Oregon Trail, more abstract concepts like economics, as well as combating assumptions like Alaska being entirely covered in ice with its residents living in igloo's (Adam \& Mowers, 2007; Johnson \& Lamb, 2010; Meyer, 2016). Davinroy \& Williams (2015) discuss a lesson in which Google Earth was used within a French Culture class. Before the advent of systems like Google Earth, students learned about the culture through photographs. Updating to this method of teaching allowed her students to more acutely notice similarities with French and American culture (housing, property boundaries, signs, graffiti, etc.) and traditions that had not happened using only photographs. The impact on this class was that students played a much more direct role in their learning, guiding the lessons beyond what the teacher had planned and expected. Particularly relevant to the current study, another teacher described having students use Google Earth to study the history of the Middle East Palestinian and Israeli conflicts. Students teamed up to use Google Earth to create two separate tours of the Middle East, one from each perspective. Through this project they learned about the important events that have taken place throughout the conflict, and developed an 
appreciation for how propaganda and censorship may have been used to impact perceptions of the events (Tarr, 2006). 


\section{Chapter 3:}

\section{Methods}

\section{$\underline{\text { Research Questions }}$}

As stated in chapter one, the activities within this study were designed to engage elementary students in activities that combined music and culture from the Middle East, as well as virtual field trips to hopefully, reduce prejudice and stereotypes toward people of Middle Eastern ethnicity.

Leading this study will be the following questions:

1. What impact, if any, does student activity in traditional Middle Eastern customs have on the students' ideas or beliefs about the region and people?

2. What impact, if any, do virtual field trips to the Middle East have on students' ideas or beliefs about the region and people?

3. Is there a notable overall shift in opinions about people of Middle Eastern origin, or the region itself, after participation in the aesthetic experiences and discussions?

\section{$\underline{\text { Research Design }}$}

Participants were led through a series of six lessons designed to engage the learners in activities relevant to Middle Eastern music, culture, and society. These lessons can be mapped to WV and National Science, Social Studies, Dance, Music, and Theatre standards (Appendix A). The first session began with a poll which participants responded to using an iPad that each 
participant was assigned. The poll was created using Poll Everywhere, to allow for anonymous participation in order to allow for a more accurate measure of where the students were in their understanding at the current point. This information was also used to guide discussions as the study progressed. Another poll was given in a similar fashion at the end of the last session to give a snapshot of participant understanding at the end of the study. A follow-up interview was conducted with the observer who was present during the lessons, and the site supervisor for the camp after the study had ended in order to gather information about observations and insights that they had come across from student discussions once the researcher left the environment.

Sessions were designed as follows:

Session 1: Middle Eastern Geography, Cultural, \& Percussion Introduction

Materials: iPads, Laptop, Projector, Doumbek/Darbuka/Tablah mixture (total amounts to 1 for each student), Riqqs, Zils, Jug Drum, 2 large bottles of water.

Overview: This session was designed to establish the beginning point in the students' understanding and thoughts about the Middle East. Students were then introduced to the location of the Middle East on the world map, as well as the first cultural highlights that were shared during the study: customary greetings and leg crossing norms. Finally, students were taught how to play basic traditional rhythms on their drum to accompany a traditional Turkish Folk Song.

Order of events:

1) This session began with participants responding to an anonymous poll using an individual iPad. A QR code was projected that students could scan for easy access to the poll. Poll questions included:

A) Using one word, describe what you think of when you think of the Middle East. 
B) When you think of music from the Middle East, what do you think of?

C) When you think of houses and communities in the Middle East, what do you think of?

D) When you think of popular stories from the Middle East, do you think the storylines, morals and characters would be similar to ours in the United States, or very different?

E) Overall, do you think people from the Middle East share a lot of common interests, ideals, and thoughts that we have in the United States?

2) Participants discussed each of the questions, the answers, and how their perceptions were formed.

3) Using a researcher-compiled map (Appendix B) that included country boundaries, names, and thumbnails of famous places (Great Pyramids, Dubai, etc.) participants were oriented to where the Middle East is located, some of its famous places/sights, and its location compared to the United States and West Virginia.

4) Discussed the Interesting Cultural highlight for the day (above).

5) Introduced basic Middle Eastern percussion instruments including the various drums from different countries. Discussed the materials each was made from. Additionally the Riqq and Zils. Discussed similarities to instruments common to us in the United States, as well as how each instrument makes its sound. Using the Jug Drum, discussed the science behind the changed sound when it is filled with water.

6) Introduction to Doumbek playing:

a. Basic playing technique/posture

b. Playing technique for "Dum" and "Tek"

c. Basic Doumbek rhythm "Maqsum"

i. Practiced rhythm using only hands (no instrument) 
ii. Transferred rhythm to instrument when the majority of participants were comfortable performing with few errors.

7) Closing Discussion: What did we learn today?, initial student reactions to the activities, overview of the next lesson.

Session 2: Introduction to Traditional Middle Eastern String Instruments \& Turkish Folk Song.

Materials: Gopichands, Ektars, and Dotara; Percussion instruments from session 1, computer, speakers, "Katibim” recording (from “Girizgah”: Alaturka Records).

Overview: During this session students were introduced to examples of traditional Middle Eastern string instruments. Students discussed similarities to these instruments and traditional Appalachian \& Western instruments in regard to materials and sound production. Students reviewed basic rhythms on the Middle Eastern drums, and accompanied a folk song from Turkey using these instruments, adding frame drums, riqqs, and zils for added dimension and interest. Students compared the storyline of the Turkish folk song to the storylines of traditional Western folk songs.

Interesting Cultural Highlight: Discussed how in this part of the world it is important to practice proper posture. You should always sit up straight, and it is considered rude to slouch and put your feet out in front of you when sitting. When you are standing during conversation it is considered disrespectful to lean against a wall, and put your hands in your pockets.

Order of Events:

1) Open review/discussion about the previous session. What do we remember? What was most interesting? What was most surprising? (about the previous session) 
2) Reviewed posture and procedure for playing Middle Eastern drums. Reviewed "Maqsum" rhythm, learned "Ayub" rhythm.

3) "Katibim"

a. Using hands only, participants practiced accompanying the recording using the Maqsum rhythm.

b. Discussed: What do we notice about the sound of this song? What emotion(s) do we think this song is portraying? What do we think the singer is singing about? After reading the translation, discuss the overall theme of the song (love), how is this similar or different to Western folk and popular songs?

c. Accompanied the song using instruments. Once students were comfortable maintaining the Maqsum rhythm on their own, researcher assisted in layering in frame drum, riqq, and zill parts- demonstrating playing each instrument and their rhythm for specific students and layering them in while playing continued. Participants traded instruments periodically until everyone had the chance to play every instrument.

4) Closing Discussion: What did we learn today? What was interesting or surprising about today's activities? Overview of activities for the next session.

Session 3: Virtual Field Trip to Istanbul \& Traditional Israeli Wedding Dance

Materials: iPads, laptop, speakers, "Nigun Atik" recording (Shenanigans: Bush Dances of New Holland, Vol. 2), Shehnai, Mizmar, and Duduk. 
Overview: During this session students were introduced to traditional Middle Eastern wind instruments, as well as learned a traditional Israeli wedding dance. Students also took a selfguided virtual field trip to Istanbul, Turkey through Google Street View.

Interesting Cultural Highlight: Discussed that while considered an odd practice in the United States, using vehicles (especially large trucks) as a canvas for art is popular in the Middle East, particularly in Afghanistan, India, and Pakistan. Paint, mirrors, brass, and chrome are often used to decorate vehicles. Animals, airplanes, ships, and mosques are popular depictions.

Order of Events:

1) Introduced traditional Middle Eastern wind instruments using actual instruments as well as recordings compiled by the researcher. Discussed similarities and differences between these instruments and traditional Western instruments.

2) Using iPad's, participants were allowed to explore Istanbul, Turkey using Google Street View (Turkey was chosen because they learned a Turkish folk song learned in session 2). Participants shared out and discussed things that were interesting and/or surprising in our adventures.

3) Discussed the interesting cultural highlight (above).

4) "Nigun Atik"

a. Introduce "Nigun Atik", a traditional wedding dance from Israel. Discuss with the students American traditions at weddings. Are there any traditional dances? Are there families from a different culture or religion that have special traditions? Note to students that this dance is performed in a circle, with the newlyweds in the center of the circle. As the guests are dancing around the couple they are 
wishing blessings upon them as they begin their lives together. What are some ways we give our good wishes to newlyweds?

b. As students listened and danced to the song, they were asked to identify some of the instruments they heard. What similarities are there between this song and ones we are accustomed to? What are some differences? What are their initial thoughts about the song? This is also a wonderful song to discuss form, dynamics, etc.

c. Using hands only, researcher demonstrated dance motions for the students. Students were asked to mirror the hand motions once they are comfortable.

d. When most students had mastered the movements using hands, we discussed how those motions will be transferred to feet, etc. to perform the dance. Researcher demonstrated the dance moves in full motion, and asked the participants to follow.

5) Closing Discussion: What did we learn today? What was most interesting or surprising? Overview of activities for the next session.

\section{Session 4: Virtual Field Trip to Israel \& Hoy Nergis/Toy Nergis Folk Dance}

Materials: iPads, Computer, Projector, speakers, recording: "Hoy Nergis/Toy Nergis" from Folklife Records, book: "The Magic Apple” as told by Rob Cleveland

Overview: In this session participants explored Israel on a self-guided tour through 360 Street View. Participants were introduced to the first Middle Eastern folktale "The Magic Apple", and were introduced to the traditional Armenian dance "Hoy Nergis/Toy Nergis".

Order of Events: 
1) Using iPads participants were allowed to explore parts of Israel using Google 360 Street View (Israel was chosen because the participants learned an Israeli wedding dance during the previous session). Participants were asked to share out and discuss things that the they found surprising or interesting from their adventures.

2) Introduce "The Magic Apple" as told by Rob Cleveland.

a. Read "The Magic Apple", which tells the story of three brothers whose father is dying. The father tells the sons he wishes them to go on a journey and each one of them find one thing that would bring them happiness. In the end, they save the life of a princess with their collective items. The king decides the man who saved his daughter should marry her, the brothers argue about which of their gifts actually saved the princess, in the end, the princess decides the man who gave up everything he had (the apple) would marry her.

b. Discussion of the tale. What was the moral of the story? Are there any similar stories in American/western culture? Etc.

3) Discuss the backstory of the dance Hoy Nergis/Toy Nergis, which is that Narcissis asks her mother to find her a good husband, but decides to marry a musician instead. Students will learn the dance steps by rote.

4) Closing Discussion: What did we learn today? What was interesting or surprising? Overview of activities for the next session.

$\underline{\text { Session 5: Introduction to Folk Literature, Israeli Pop Music Introduction, Perfect Hoy }}$ Nergis/Toy Nergis

Materials: "Joha Makes a Wish" book adapted by Eric A. Kimmel, speakers, "Hoy Nergis" recording, "Lealy Nahary” by Amr Diab recording, Middle Eastern Percussion Instruments. 
Overview: In this session students were introduced to another traditional folk story from the Middle East, and compared/contrasted it with our popular folk stories. They reviewed traditional drum patterns and "arranged" an ostinato accompaniment to an Israeli Pop song. They also continued to learn and perfect the Armenian dance "Hoy Nergis" from session 4.

Interesting Cultural Highlight: Discussed how similar to the western custom of putting a child's tooth under a pillow for the Tooth Fairy when a child loses it, in the Middle East it is often wrapped in cotton and thrown into a body of water (a garden is used if there is no water) so the child will receive good luck.

\section{Order of Events:}

1) Folk Story “Joha Makes A Wish” as adapted by Eric A. Kimmel:

a. Introduce the book

b. Read the story. This story tells the story of Joha, who comes into possession of a wishing stick. A note that came with the stick claimed it could make his wishes come true. He uses the stick, but, his wishes always ended up turning out to be the opposite of what he had wished for. The Sultan passes by in a procession, with everyone wishing him a long life as he passed by. The guards notice Joha did not wish the Sultan a long life, and stopped to inquire. Joha explained that he was having bad luck with wishes and didn't want anything bad to happen to the Sultan should he wish him a long life. The Sultan agreed he can wish for something else, and forced Joha to wish for a wart on his face to disappear... which only got worse with the wish. The guards tried to take Joha prisoner, but he ran away. He ran into a shopkeeper 
who hid him until the guards passed. The shopkeeper explained to Joha that he had been holding the wishing stick upside down all day, which is why his wishes end up backward. Joha went to the palace, to make things right with the Sultan. The Sultan took the wishing stick as his own, without listening to Joha trying to explain how to use it.

c. Discuss what elements of the .story are similar to our folk stories (fairy tales).

2) Participants arranged an accompaniment to "Lealy Nahary" by Amr Diab using traditional percussion instruments and traditional rhythms.

a. Participants listened to the song, while patting the steady beat on our lap

b. Discussed the sound of the song" What was interesting? Was there anything you didn't expect? Are there any songs we know that have similar sounds? What do you think this song is about, why?

c. Read translation of lyrics, discuss similarities and differences with songs in American/Western culture:

Day and night come around, my love, none will blame you, take me to you Day and night come around, my love, none will blame you, take me to you. I wish I can see you right in front of me, I wish your love was not that special. My life with you is so beautiful. What can I say, you already know. Without saying anything, you must be knowing. There is a lot I feel like saying. And there is a lot I wish you can say. My life with you is so beautiful.

d. Participants were given time to arrange their accompaniment on their own, then eperform for the group, then teach it to all of us. After everyone was done, they were 
given time to revise their accompaniment based on how they felt about it following their performance.

3) Closing Discussion: What did we learn today? What was interesting or surprising?

\section{Session 6: Wrap-up, Endpoint Data Collection, Selected Musical Activity}

Materials: iPads, laptop, projector, instruments and recordings as decided by participants.

Overview: During this session the participants responded to questions in Poll Everywhere to gather ending data in regard to their thoughts on the Middle East. We discussed how their thoughts compared to what was shown in the beginning poll. Participants were also be able to choose a few activities to do again before the researcher left.

\section{Order of Events:}

1) This session began with participants responding to an anonymous poll using an individual iPod touch. A QR code was projected that students could scan for easy access to the poll. Poll questions included:

a. Using one word, describe what you think of when you think of the Middle East.

b. When you think of music from the Middle East, what do you think of?

c. When you think of houses and communities in the Middle East, what do you think of?

d. When you think of popular stories from the Middle East, do you think the storylines, morals and characters would be similar to ours in the United States, or very different? 
e. Overall, do you think people from the Middle East share a lot of common interests, ideals, and thoughts that we have in the United States?

2) Discussed poll results and how they compared to the initial poll given during the study. If there was a change in the overall trends of the poll, what to participants think were the activities in class that led to this change?

3) Participants chose to go on another virtual field trip, and create their own ostinato accompaniments to additional Israeli Pop songs to complete the research sessions.

\section{Epistemological Stance}

It is important for the researcher to describe the epistemological stance from which the research is conducted. In its simplest form, epistemologies deal with knowledge and how it is constructed, which can lead to different interpretations of the same event (Ajjawi \& Tai, 2016; Crotty, 2015; Hays \& Singh, 2012; Sandars \& Tavakol, 2014).

This research was conducted through a 'social constructionist" viewpoint. Social constructivists believe that all knowledge is socially constructed, what is known is only known through interaction (Ajjawi \& Tai, 2016; Crotty, 2015; Walker, 2015). Crotty (2015) points out that knowledge construction through a social constructionist viewpoint may not involve other people at all, but knowledge may simply be acquired through interaction with nature and the world.

In this study, data from the first data collection (initial poll) were based on knowledge socially constructed from the participants' interactions with their families, community, school, and various forms of media. Throughout the study, knowledge was constructed through 
participant interaction with objects, multimedia tools, physical activities, and group discussions with the goal of expanding their initial (presumably limited) knowledge base.

\section{$\underline{\text { Role of the Researcher \& Researcher Bias }}$}

It is important for a researcher to practice "researcher reflexivity" or reflection on their personal interaction with the research before and during the research process in order for the audience to gain a better understanding of the credibility of the study, as it is to be considered an additional lens on the process. The role of the researcher, their relationship with the community and/or the participants being researched, and their own personal values and beliefs may play a role in the validity of the outcome of the findings (Hays \& Singh, 2012; Hellawell, 2006; Sandars \& Tavakol, 2014).

This study was conducted within a public elementary school I have not personally taught in, through the cooperation of a state-wide camp program, but within a county that I used to teach in. From this perspective, Hellawell (2006) would argue that I lay in the middle of the insider-outsider spectrum. I was an outsider in the sense that the students had not interacted with me before on a personal or teaching level, as I do not live in their community, and had never taught in their schools. However, I was also an insider as I had direct knowledge of the overall political and social ideals the residents of this community hold. Additionally, I had experience in teaching elementary students, which gave me insider knowledge of their developmental level, thought processes, etc. To that effect, Armstrong \& Tinker (2008) would argue that "researchers are always both insiders and outsiders in every research setting, and are likely to oscillate between these positions" (p.54) during any given study. They go on to stress that in order to combat criticisms of outsider research, responses from each participant must be counted as equally valid, context specific responses instead of inaccurate or distorted views. 
In regard to the multicultural aspect of this research, Banks (1988) stresses it's important for educators and researchers to be aware of their own biases when presenting lessons with a multicultural emphasis. The emphasis of the study is to decrease prejudice against people of Middle Eastern descent. Being that I have designed this study, and am passionate about decreasing prejudice, it should be a given that I believe whole-heartedly that people are equals no matter their sex, ethnicity, religion, socioeconomic status, etc. I believe that diversity is an important part of society, and that in the end, we are all humans with the same basic human needs. Although we may look different, practice different religions, dress differently, etc. more often than not we can find common grains in our ethnic and religious practices. In order to combat prejudice, I believe it is important to focus on those common grains, bring out the similarities between us and then you can begin to appreciate the differences. When it comes to data collection and analysis, it was important that I not ask leading questions (toward a certain answer) and take participant responses as they were.

\section{$\underline{\text { Participants and Sampling Procedure }}$}

This study was conducted with cooperation of a statewide summer program in West Virginia at one of their community-based sites. This summer program aims to assist lowincome, rural students to maintain or gain reading levels throughout the summer using daily lessons incorporating art, drama, vocabulary, and creativity. The program also assists the families by providing the participants two meals a day throughout the 6-week program. This was a purposeful sample of convenience given the geographic proximity to the researcher. The lessons were conducted once a week for 4 weeks, and twice the $5^{\text {th }}$ week (original plan was once a week for 6 weeks). Out of 25 consent and assent forms distributed, only 5 students returned 
their forms and were allowed to participate. The returned forms were from four females and one male, ranging from $3^{\text {rd }}-6^{\text {th }}$ grades, all of Caucasian descent.

The community-based site was located in Sunrise County, WV at Narrow Hollow Elementary School, though participants of the summer camp only had to live in the surrounding community that feeds into South Sunrise County High School - not necessarily attend Narrow Hollow Elementary school.

Sunrise County, WV had a population of 69,099 during the 2010 Census of which $96 \%$ were white (U.S. Census Bureau, 2010), with a median household income of $\$ 43,987$ (U.S. Census Bureau, 2014), and $16.7 \%$ of individuals were living below the poverty level. Narrow Hollow, WV, during the 2010 Census, had a population of 496 people (Census, 2010), of which $95.8 \%$ were white, with a median household income of $\$ 53,250$ (Census, 2014), with $8.7 \%$ of individuals living below the poverty level.

\section{$\underline{\text { Data Collection }}$}

Data were collected using start and endpoint live polls using mobile devices and Poll Everywhere, classroom observation/discussions, and surveys sent to the lesson observer and camp site supervisor after the study had ended. Field notes were collected to capture enhance the other forms of data and aid in the analysis process during which analytical memos were used to track the thoughts of the researcher, keep track of emerging trends, and keep important notes of pathways to explore. The information gathered from the four data types helped to triangulate the data and better ensure trustworthiness of the findings (Amankwaa, 2016; Hays \& Singh, 2012; Sandars \& Tavakol, 2014). Triangulation helps to minimize the effect of potential researcher bias within the analysis, brings out potential inconsistencies within the data and/or analysis, and 
may result in a broader understanding of the phenomenon (Amankwaa, 2016; Carter, BryantLukosius, DiCenso, Blythe, Neville, 2014; Hays \& Singh, 2012; Sandars \& Tavakol, 2014).

\section{Live Polls}

Live polls using individual iPads and Poll Everywhere served as the data collection tools for the beginning and endpoint of the study. Using this system allowed for anonymous, honest responses from participants on their thoughts to each poll question (previously listed). It is found in historical literature that this anonymity often opens the door for participants giving honest answers on sensitive matters, something that may not happen during the classroom discussions (Blood, 2010; Chandler, Hamm, Hudson, Smith, \& Tucker, 2010).

\section{Classroom Observation/Discussion}

Throughout each session, participants engaged in discussion about the activities of the day, especially in regard to what was interesting to them and what surprised them. Each session was audio recorded and transcribed for analysis, as personal experience has shown the researcher that video- taping elementary students normally ends up with the students being distracted and showing behavior they would not normally which may result in less or skewed data. Given that audio recordings do not allow for recording of nonverbal communication, field notes were integral in completing the picture of each session. This focus-group style data collection allowed for participants to share perspectives, build on other participants' views, in an interactive setting that is more relaxed that one-on-one interviews (Carter, et al.; 2014; Hays \& Singh, 2012). However, these situations may also have caused some with differing opinions from the overall group to remain quiet about their true feelings (Hays \& Singh, 2012). It is noted that at the 
beginning of the research project there were a couple participants who were leery to say much verbally, but opened up as the weeks went on.

\section{Observer Survey}

The purpose of the observer survey was to gather information from a different point of view about the study that may not have been evident during each of the sessions. This addition further solidified the triangulation, better ensuring the trustworthiness of the data analysis (Amankwaa, 2016; Hays \& Singh, 2012; Sandars \& Tavakol, 2014). The interview was intended to be a semi-structured in-depth-interview using a base set of questions as a script, with field notes and initial responses being used to create additional and follow-up questions. However, in reality, it turned out to be more of a survey as the observer and site supervisor were difficult to communicate with so the questions had to be delivered through e-mail and they did not return responses to questions beyond the initial set. The resulting responses were limited in depth, and not as insightful as the researcher had hoped. The questions on the survey included:

1. How frequently did the students participate in other activities that involved different cultures throughout this camp (including literature, art, music, dance, etc.)?

2. How in depth were the discussions surrounding those activities in regard to the other culture?

3. What were some of the most interesting or notable things you witnessed (from the students) through the activities in the study?

4. Were there continued discussions about the activities after I left the classroom each week? 
5. If so, what were the nature of those discussions?

\section{$\underline{\text { Data Analysis }}$}

Unlike quantitative data analysis where the focus is using numbers and correct formulas to interpret data that can be generalized to a larger sample, quantitative data analysis does not have a correct formula or rule for analysis of data (Hays \& Singh, 2012; Sandars \& Tavakol, 2014). The goal of qualitative data analysis is being able to gain enough insight and deep understanding in order to provide a thick description of the phenomenon being studied (Hays \& Singh, 2012; Sandars \& Tavakol, 2014). Hays \& Singh stress that "thick description" does not mean providing a lot of detail, but providing a "comprehensive and focused picture of a behavior or occurrence" (p.8) that allows the findings to be generalized to a narrowed context, or replicated.

Miles, Huberman, \& Saldaña (2014) describe three coinciding steps in qualitative data analysis: reducing data, displaying data, and drawing conclusions/verification. Reducing data involves "selecting, focusing, simplifying, abstracting, and/or transforming the data that appear in the full corpus (body) of written-up field notes, interview transcripts, documents, and other empirical materials” (Miles, Huberman, \& Saldaña, 2014, p.12). This process likely begins in the planning stages of a study, before data collection begins by means of deciding what data to collect and how (Hays \& Singh, 2012). Once data collection begins, researchers constantly evaluate what data to code, which labels to use for chunks of data, and which story to tell (Hays \& Singh, 2012; Miles, Huberman, \& Saldaña, 2012). The process of coding, defined by Saldaña (2013) as: "a researcher-generated construct that symbolizes and thus attributes interpreted meaning to each individual datum for later purposes of pattern detection, categorization, theory building, and other analytic processes" (p.4), should begin even during data collection by means 
of pre-coding, or bringing visual attention to portions of interest, or preliminary jottings during the process of writing field notes, transcribing interviews, etc. (Saldaña, 2013).

Audio transcripts were first be coded using a combination of "In Vivo" coding and "Descriptive" coding. Manual coding was used on hard-copy printouts to facilitate the coding process, with Microsoft Word/Excel being used when it comes to step 2 (data display). Saldaña (2013) stresses that mental energies may be better used in this way with researchers with little experience with coding software programs, as well as small scale research designs. In Vivo coding to more accurately capture and emphasize the voice (by means of beliefs, understandings, and questions) of the adolescent participants throughout each phase of the study, better enabling me to attune myself to "participant language, perspectives, and worldviews" (Saldaña, 2012, p.64). Descriptive coding is used to identify "the basic topic of a passage" (p.88) of data. Descriptive coding is often used to create the basic vocabulary for data, to assist the researcher in better visualize the general view of what was seen and heard in the study (Saldaña, 2012).

The transcripts were then be coded using "Focused Coding" to bring out the "most frequent or significant codes" (Saldaña, 2012, p.213) coupled with Pattern Coding to group the “initial codes into a smaller number of categories, themes, or constructs” (Miles et al., 2014; Moffa, 2016 p.69) that developed during the In Vivo and descriptive coding process. Using Focused Coding as a second cycle process aims to develop categories from the initial data properties identified in the first cycle of coding (Saldaña, 2012). These codes can then be compared across data to "assess comparability and transferability" (p.217) to solidify the view of the participants' experience.

Given the small sample size and the nature of the data collection method of the initial and endpoint data, as well as the observer and camp site supervisor surveys, the data from these data 
sources were analyzed using identical practices as the audio transcriptions. The data from the initial poll were put into the matrix with the audio transcript data in separate rows, with the data from the observer and camp site supervisor being used to solidify the findings for the analysis.

Throughout the research process, fieldnotes and analytical memos were used to better facilitate and solidify the concepts and relationships being observed within the data, and allowing analysis and description in greater detail. Emerson, Fretz, and Shaw (2011) emphasize that in "writing fieldnotes the field researcher should give special attention to the indigenous meanings and concerns of the people studies...fieldnotes are an essential grounding and resource for writing broader, more coherent accounts of others' lives and concerns” (p.15). Saldaña (2013) describes analytic memos as being comparable to a researcher journal, facilitating researcher reflexivity on the data, reflecting on the coding process, the methods being used, patterns being observed, reflecting on personal assumptions and how they may be shaping the research and research decisions.

Step two in data analysis as described by Miles, Huberman, \& Saldaña (2014) involves displaying the data that have been collected and coded. These displays enhance the credibility, trustworthiness, and generalizability of the analysis. These displays should be "focused enough to permit a viewing of a full data set in the same location... arranged systematically to answer the research questions at hand" (Miles, Huberman, \& Saldaña, 2014, p. 108), and serve four interconnecting purposes of assisting the researcher to "explore, describe, explain, and predict phenomena" by outlining the intellectual journey through the study (Hays \& Sing, 2012; Miles, Huberman, \& Saldaña, 2014). During data analysis, data were compiled into a matrix for each data type to better visualize the emerging patterns, and then combined into an all-encompassing matrix of all data sets. 
As Miles, Huberman, \& Saldaña (2014) emphasized, the last step of drawing conclusions and verifying the data will happen simultaneously with the first two steps. Throughout data collection, field notes, coding, and displaying the data emerging ideas and themes should emerge across data that shape the final analysis in answering the research questions.

\section{$\underline{\text { Trustworthiness }}$}

The value of a qualitative research study is enhanced by its trustworthiness (Lincoln \& Guba, 1985). They outlined four criteria for establishing trustworthiness: credibility, dependability, confirmability, and transferability; which Hays and Singh (2012) argue have become the "gold standard in judging trustworthiness in qualitative research" (p.194). Procedures for establishing trustworthiness should be established in the research design and narrative (Amankwaa, 2016).

Credibility is viewed as the "believability" of the study (Amankwaa, 2016; Connelly, 2016; Hays \& Singh, 2012; Lincoln \& Guba, 1985). Two techniques employed by this study were suggested by Lincoln \& Guba (1985) in order to establish credibility: triangulation of data (multiple sources of data) and member-checking (observer and camp site supervisor surveys).

Dependability goes beyond credibility in evaluating the interpretations and conclusions of data over time and across researchers (Amankwaa, 2016; Connelly, 2016; Hays \& Singh, 2012; Lincoln \& Guba, 1985). This study attempts to establish dependability by reviewing previous literature applicable to each element of the study, completing the study over the course of six sessions with participants, and discussing data and findings with the observer and camp site supervisor. The observer, while not a formal researcher, was undoubtedly doing his own informal analysis of the phenomenon as the study commenced. The camp site supervisor was 
also tracking the progress of the study as he is the music teacher in the building the camp was housed in, and has interest in multicultural music teaching.

Confirmability emphasizes that study findings be accurate reflections of participant views and responses, free from researcher bias and motivation (Amankwaa, 2016; Connelly, 2016; Hays \& Singh, 2012; Lincoln \& Guba, 1985). In this study the researcher provided a statement of bias, bringing to focus his personal views in regard to subjects related to the study. During data collection field notes reflected a separation of researcher opinion points and participant responses/opinions. Emphasis was placed on open ended questions rather than leading questions given to participants.

Transferability in qualitative research places emphasis on providing thick descriptions of the research process employed so that future researchers and consumers can judge the applicability to their own personal contexts (Hays \& Singh, 2012; Lincoln \& Guba, 1985). The more times similar findings are reported from multiple groups, the more confidence there can be in transferability (Hays \& Singh, 2012). Throughout the research process, ample attention was placed on gathering sufficient information to generate complete descriptions of every component of the research process to facilitate future researchers and practitioners in establishing if the results are relevant to their context, and/or allow for replication.

\section{$\underline{\text { Ethical Concerns }}$}

Codes of ethics serve the "primary goal of promoting the welfare of others" (Hays \& Singh, 2012, p.74). Ethical concerns are particularly important and potentially complicated with additional protections for vulnerable populations, including minors and members of low socioeconomic status as are represented in his study (Bos, Tibboel, Tromp, \& Pinxten, 2012; Hays \& 
Singh, 2012). Three overarching themes represent the basic cornerstones of ethical research practices which are (1) informed consent, (2) research interests do not overrule personal interests, and (3) participants shall not be exposed to unnecessary risks (Bos, Tibboel, Tromp, \& Pinxten, 2012).

This study sought the approval of the West Virginia University Institutional Review Board (IRB) prior to data collection. The main function of an IRB is to protect human subjects (Hays \& Singh, 2012). The purpose of IRB review is to have an outside audit of the planned research to ensure proactive procedures are in place to ensure ethical guidelines are instituted during the study.

Given that minors cannot, alone, consent to being involved in research (Hays \& Sing, 2012; Nelson \& Quintana, 2005), parents were notified of the planned study and its procedures with the option of allowing their child to opt-out at any time without penalty. The Superintendent of the county school system, principal of the school, leadership at the local and state level of the camp, as well as the observer were similarly be informed of the study and its goals. No potential risks outside of those experienced during the regular camp was expected, but parents and participants were similarly informed of these should they have arisen.

Participant confidentiality is another notable consideration of ethics. All identifying information of the location of the school, the school itself, and the session observer was changed to pseudonyms. Sessions were audio-taped, therefore there is no potential for faces and other identifying features of participants to be recorded and distributed. Student names were not be collected during the research sessions, as I did not feel the need to track individual student responses through the anonymous polls or in group discussion. All electronic data were collected on a password-protected computer. Poll Everywhere uses a password-protected user 
account to collect information, the results of each poll were saved using screen shots that were saved on the password-protected computer, and deleted from the Poll Everywhere webpage.

Physical data were kept in a locked file cabinet to which only the researcher has access. 


\section{$\underline{\text { Chapter } 4}$}

\section{Findings}

This chapter reports the study's findings as discovered through transcripts of each of the sessions, anonymous poll responses from participants, survey responses from an observer of the lessons and the camp coordinator. These data sources were coupled with observations and field notes made by the researcher to better facilitate greater understanding of the data. Throughout the coding and analyzing process, analytic memos were kept by the researcher to reflect on the process, note patterns, as well as note other avenues to explore. These data sources and methods also assisted in greater triangulation of the data to help ensure trustworthiness, as well as enhancing the credibility and believability of the findings (Lincoln \& Guba, 1985). Initial In Vivo and Descriptive coding was done on hard copies of the transcripts and poll results. The transcripts were then reviewed again, with Focused and Pattern coding used to determine the significant codes to be put into a matrix that categorized them by the type of activity they related to (virtual field trip, cultural highlight, etc.) as well as the day that specific code corresponded to. This matrix was then printed in large-scale format, the researcher then went through the matrix to continue Pattern coding with different color highlighters to note codes that were inherently participant reflections of things that they found "weird/different/odd," "cool/interesting," "expected," "unexpected/surprising," or "similar". Some codes received more than one color. This color coding assisted the researcher in getting a more holistic view of the trend of the data codes, thus the trend of the participant thoughts throughout the duration of the study.

The findings are discussed in this chapter beginning with initial data to get a glimpse of participants' initial conceptions about the Middle East and how those conceptions were formed. Findings are then organized according to the instructional activity they correspond to. The 
information is organized in this fashion to best illustrate student observations during each of the cultural experiences that attribute to the end results. I believe this contributes to a more holistic picture of the development of participant perceptions throughout the study, rather than partial snippets in time. Finally, data from the surveys completed by the adult observer and the site coordinator are reported at the end of the chapter, before each research question is addressed individually.

\section{$\underline{\text { Initial Data }}$}

Initial data were collected using a PollEverwhere that participants completed anonymously on an individual iPad. Five questions were asked, and the results were discussed after everyone had entered their responses.

Figure 1 shows the responses for the first question: "Using one word, describe what you think of when you think of the Middle East."

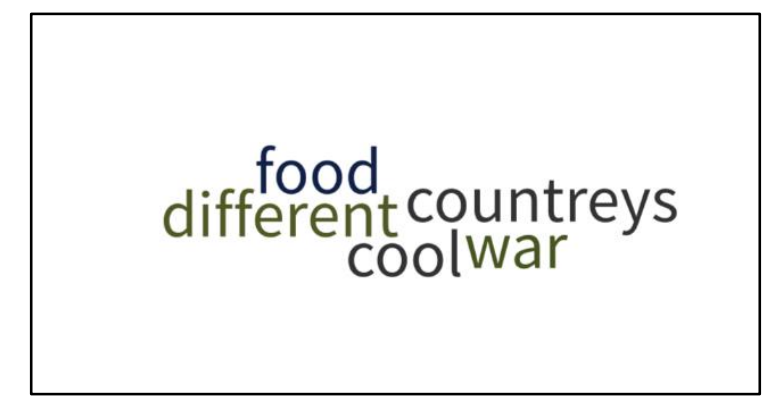

Figure 1: Initial Data Question 1 Responses 
Figure 2 shows the participant responses for question 2: "When you think of music from the Middle East, what do you think of?"

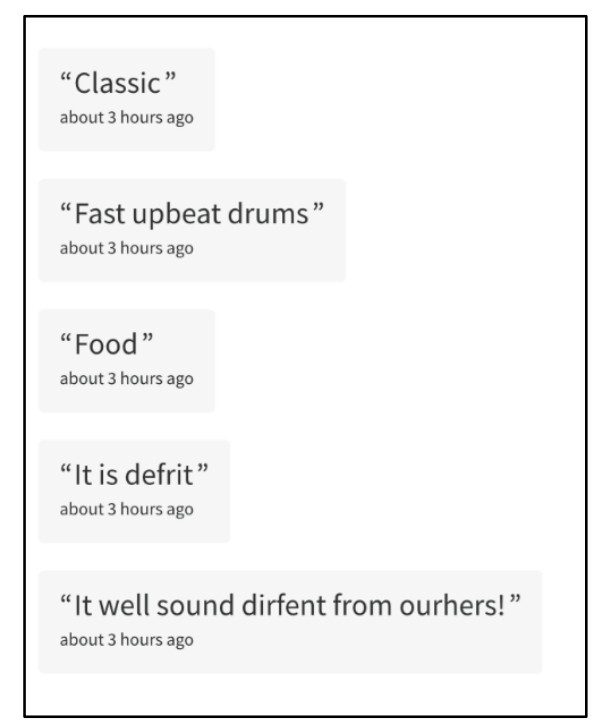

Figure 2: Initial Data Question 2 Responses

Figure 3 shows the participant response for question 3: "When you think of houses and communities in the Middle East, what do you think of?"

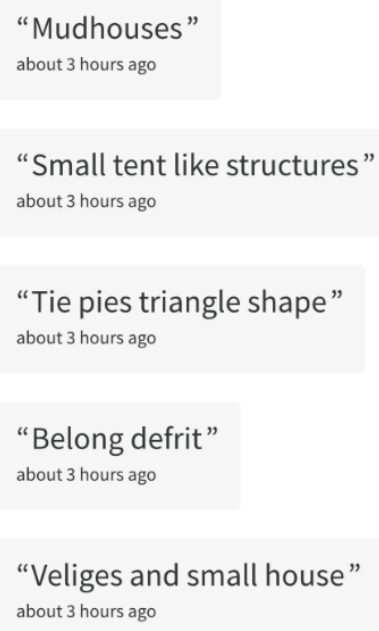

Figure 3: Initial Data Question 3 Responses 
Figure 4 shows the participant responses for question 4: "When you think of popular stories from the Middle East do you think the storylines, morals, and characters would be similar to ours in the United States, or very different?"

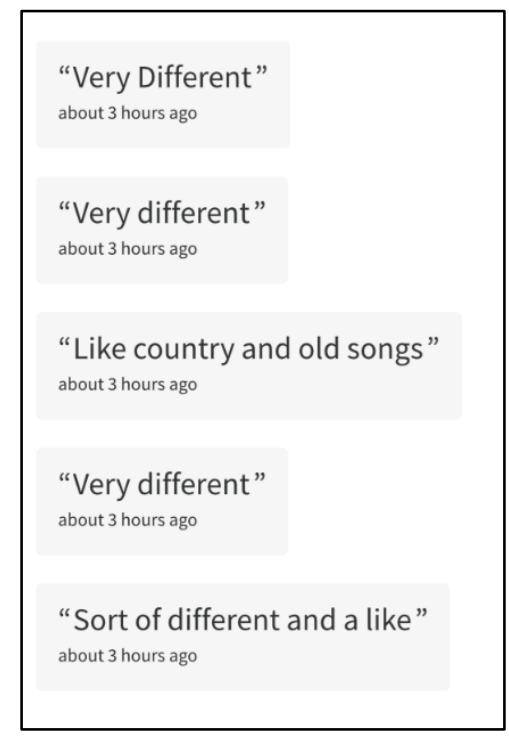

Figure 4: Initial Data Question 4 Responses

Figure 5 shows the participant responses to question 5: "Overall, do you think people from the Middle East share a lot of common interests, ideals, and thoughts that we have in the United States?"

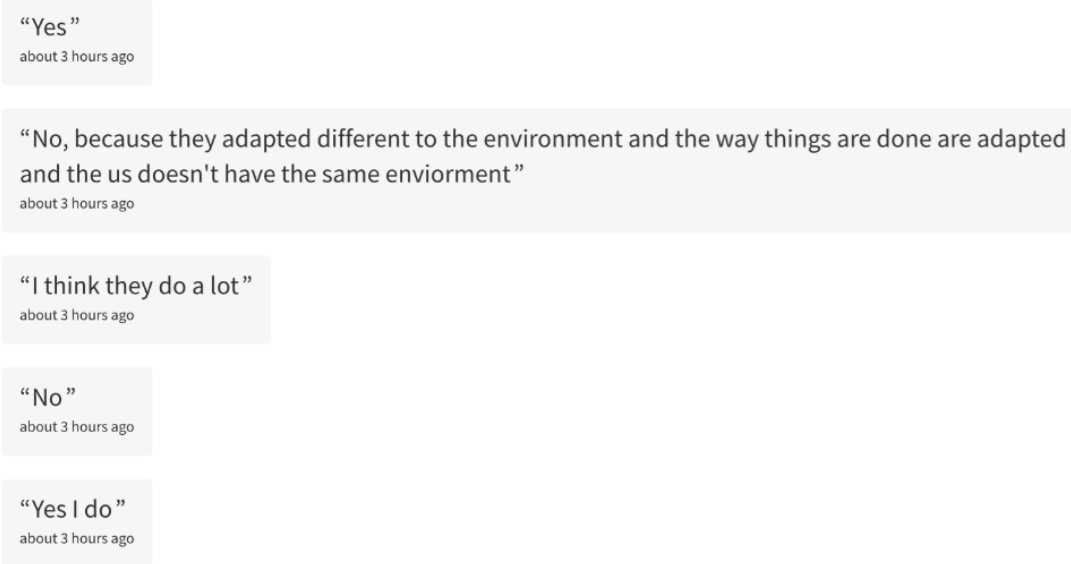

Figure 5: Initial Data Question 5 Responses 
During the discussion following completion of the survey, students discussed that their perceptions primarily stemmed from their "parents", "TV", and "Movies". Notably, one student has parents that are in the military and served in the Middle East and share their experiences with their son. The mother of one of the other participants frequently makes Middle Eastern food for their family. The participants also noted how "lots of wars" are discussed about the area on TV, and movies often depict the area as a "desert" and "looking old".

\section{Cultural Highlights \& Observations}

The dedicated cultural highlights portion of the lessons received mixed reactions. When discussing how the left hand should be reserved for sanitary purposes there was much discussion around how it was "weird", and "if you're left handed it's gonna be pretty difficult". They were more understanding of not pointing your feet at someone while you're in the Middle East.

However, they were very curious about what would constitute "bad posture" in the Middle East asking if specific posture examples would be appropriate in the region. The popularity of people creating murals on their cars was said to be "weird", but did not generate much discussion.

The custom of children wrapping their lost teeth in cotton and put it in a body of water or garden for good luck generated some discussion on how it was "different" than what we do according to one participant. Another participant noted it was "different, but kind of similar" to what we do, with another participant adding “...but it's kinda similar cuz they're wrapping it in cotton and keeping it safe" and a third participant expanding to note that "getting money [in our culture] is kind of good luck".

Another notable observation about the culture came while viewing a video for instrument demonstrations in day 3. It was during this activity that while the main instrument players were 
in "traditional" attire saying it "looks like it's from India", there were others who were wearing "Adidas" and other types of clothing considered normal in the United States.

\section{$\underline{\text { Instrument Activities }}$}

When introducing popular traditional Middle Eastern musical instruments, the most frequent items discussed were the materials used in creating the instruments, comparing their appearance to popular western instruments, and of course the sounds they create.

The riqq "looks like a tambourine!", but "sounds lower" and "sounds different" than the tambourine according to the participants. The jug drum was compared to "pottery" given the fact that it is made of clay. The students compared the traditional doumbeks to "African drums" given their similar (not identical) shape, noting the ones I brought in were "tiny and cute", and the "metal ones look more modern", all creating a sound that is "more high pitched" than what we use in western music.

The string instruments and their components were compared to a number of our western string instruments. The sound of the gopichand described as "weird", with its "tuners" being like a guitar. The ektar was "like a banjo" and "looks like a pumpkin" before the researcher stated that the base is made of a pumpkin. The spike fiddle was described as looking like a "violin", “guitar", and being "like a ukulele". One student said "they're evil [people]" considering many of the traditional instruments use animal skins as their membrane, but another student replied by saying they were "very conservative" as they used the entire animal.

The "wind family" instruments were noted to "look handmade" being mostly made of "wood". The shehnai "looks like a clarinet", and was said to sound "like a fog horn", "weird", 
"like an elephant", "sounds like a koala", and "cool". The shehnai sound was heard in a video along with the oud, tablahs, and a harmonium. The combination of these sounds "sounds like it's from Egyptian times", "makes you feel like a snake", and was "so cool”. The participants discussed the "really long things [notes]" played on the shehnai and that it "must be really hard to keep the breath". They also pointed out how the oud "sounds like a guitar", and the tablah player's fingers move fast, noting he "must practice a lot". The mizmar was also shown in a video performing along with a riqq player and was said to "sound different", with the overall song sound reminiscent of a "spy movie" and "cops and robbers" due to the "fast tempo", with one student exclaiming "I love this!". The duduk was shown in a solo video. It was described as "bigger", with a reed that looks like a "tooth", "shark tooth", "swimming fins", and overall "weird". The sound was described by the participants as "Indian", "bedtime", "fantasy", "loud", reminiscent of a "clarinet", and sounding "like it would come from a much bigger instrument".

During day 6, the students chose to create their own rhythm (ostinato) to perform along with modern Middle Eastern songs. During this session, they were very curious about the cost of the instruments, and requested to learn an additional traditional sound on the instruments beyond the two they originally were taught. It seemed apparent that they didn't have much practice with this kind of self-exploration due the complexity of the ostinatos they first created. As each example went on, however, they began to create ostinato that were more simple and fit better into the overall rhythm of the songs.

\section{Musical Listening \& Dancing}

The first musical listening example was a folk song from Turkey called Katibim that the participants accompanied on traditional percussion instruments. Folk Song was defined by one of the participants as "like country, like the original passed down". The students first listened to 
the song and described it as "cool", "weird", "really fast", "like opera [high pitched]", and using "long notes". One participant stated it was "different than what we do", while another stated it was "sometimes similar", and another reflected that "their folk [songs] sound more modern, I think [than ours]". Participants thought it was "sad [sounding]", "boring”, "kind of cool", and "interesting". When asked what they thought it was about based on the sound they replied it was likely "about a person", or "maybe it's religious". After reading the translation to them a participant expressed it's a "love song", and that it was "not surprising [that they would have love songs]".

During day 5, participants were exposed to an Egyptian Pop song, Lealy Nahary, which they accompanied with an ostinato on the doumbeks. While listening to this song, students noted that it "sounds like an American song" "because of the kind of music it is" as well as "the beat", with one participant noting it "sounds like music I like to listen to". One participant didn't expect the "computerized sound", while others did "because of the modern buildings" that they had discovered in the earlier sessions. The overall consensus was that the "song was good", one "liked the instrumental interlude", and another thinking that the interlude "sounds Asian". When asked to put this song into a category, responses ranged from "it's like a pop song", to "classical mixed with a little bit of pop", and another saying it was "classical, with a little bit of country". When asked to describe the sound of the song participants said it "sounds like a happy song" and "like a dance party song".

The dancing activities themselves didn't prove to be fruitful for deep conversation beyond the musical descriptions. One participant described the music for the first dance, Nigun Atik, as "like a snake". Notably, participants began to snap the steady beat on their own part-way through the listening session. After being read the translation, one participant noted that the 
lyrics "don't rhyme", as she expected them to. Participants were apprehensive about their ability to learn the dance before being taught the movements, with one asking "How are we supposed to do it when there's no video?", what I took to be a notable sign of the times and students' reliance on technology. During the learning process when students were mimicking the movements using only hands, one participant expressed frustration saying "I can't do it". However, as time went on and they caught on, one noted "that was easy" and the participants expressed excitement over being able to perform the dance accurately. The participants expressed less apprehension when it came to the second dance, they "liked this song" and wanted to take the movements to the next level by doing the proper group hand-hold throughout the routine, though it was difficult given the small number of participants. During session 5, a dance was not planned, but the participants requested to do the dance from session 4 again, Hoy Nergis.

\section{$\underline{\text { Folk Tales }}$}

Participants discovered some similarities between the folk stories that were shared with them and some folk stories we have in the United States. They noted similar morals, characters, and personal aims depicted within the stories. The storylines were said to be "unique...in a good way", similar to the type of storylines we would have in the United States, and were not expected from stories originating from the Middle East. The Magic Apple was described as a "Reverse Snow White" where the "father wanted happiness for the sons", with the overall moral being “don't be selfish". Joha Makes A Wish didn’t generate a lot of discussion due to time constraints, but the students were very attentive and engaged, making hypotheses of what would happen next while the story was being read. One participant mentioned that she thought the stories were different because they "revolve around one tiny thing" noting the "stick" and the "apple" were prominent figures in the stories. This prompted discussions with other participants 
who disagreed with her, noting there was more than one just "thing" in each of the stories, and stories they read throughout their camp often had a focus character but didn't necessarily revolve around those characters.

\section{$\underline{\text { Virtual Field Trips }}$}

The virtual field trips proved to be a fascinating experience for the participants. Once they learned how to navigate the app, their interest in exploring various parts of the Middle East, and the world, blossomed. At times, they needed to be refocused on the task at hand, getting caught up in some of the idiosyncrasies that occur within the app due to the nature of its creation. Of particular interest to them were the "ghost" appendages that occur due to the fact that the images are normally captured on by a camera on a moving vehicle (also discussed in particular spots due to the shadow) with moving humans within the image range.

During the virtual field trip to Turkey, participants pointed out that they have the "same cars we do", and "motorcycles", one noted seeing a "Police car pulled over a taxi", and a "bus". Of particular interest to one participant was fascination by the fact that they have gas stations similar to ours, noting he hadn't really considered that they would need gas stations. Other notable features that were unexpected were: developed streets that looks like ours, two named "Diaz Avenue" and "Kennedy Avenue", which generated discussion of surprise that "lots of stuff spelled [in] English". One participant noted seeing a "coffee place", and they were all surprised that one participant discovered a "Burger King". Participants discussed some surprise in seeing people wearing "shoes" and carrying "purses", and people wearing "Burkas". Other items noted included random "water bottles" laying around, "street vendors", "Palm Trees", and a "new house being built". During the closing discussion of the day, they noted interesting things about the virtual field trip including seeing "people in cars", seeing "signs in English", and seeing 
"Turkey on the tablet". Some surprising things they noted included seeing "a lot of people", "people dressed like us", seeing a "mixture of types of people", as well as people wearing "tshirts" and "Adidas".

During the virtual field trip to Israel, the participants saw a larger variety of types of areas than they did in Turkey. In Turkey, the participants mostly saw developed, city-type residential and commercial areas. In Israel, they saw a mixture of developed cities, historical sites, and recreational areas. Participants noted seeing "a whirlpool", "cars", "someone’s home", "parking lots", a "downtown area", and a "church". A lot of time was spent looking at and discussing an area that had "a bunch of people by the sea" and "in a desert". One participant noted the landscape in this area "looks like Florida" with "palm trees", "frozen sand", and a "pretty view". It was noted by one participant that it was likely a "hot climate" since this landscape reminded them of Florida. In other locations, a participant noted seeing an "archaeological dig", and the landscape in one area reminding them of the "Grand Canyon". During the ending discussion on this day, participants noted that the "Turkey virtual field trip [the day prior] was more interesting than Israel", noting that the Turkey virtual field trip had "more to walk through". At the same time, other participants noted this virtual field trip was "interesting" and included "awesome views".

During the last session, one of the participants' chosen activities was to do another virtual field trip. During this experience, participants were able to choose a country around and in the Middle East they wanted to explore on their own. Participants visited places including Iran, Syria, Armenia, and Georgia and had a tendency to jump around visiting different places and countries instead of spending focused time in one area like was forced in the first two virtual field trips. During these virtual field trips, some notable things participants identified included: 
"powerlines", "the sea", a "car", "palm trees", a "medical clinic", a "bridge", a "lawn mower", "lots of people", and a "playground".

\section{$\underline{\text { Endpoint Data }}$}

Endpoint data was collected using the same PollEverwhere that participants completed to collect the initial data. These survey responses were collected anonymously on an individual iPad. The same five questions from the initial survey were asked, and the results were discussed after everyone had entered their responses. It should be noted that due to last minute schedule changes by the camp the last session day had to be changed from the original planned date moving from the normal Wednesday each week to the day following session 5 (that Thursday). During this last session, two of the normal participants were absent, and the camp leader had the two absent participants complete the survey when they returned before the end of the camp week. Their responses are included in the endpoint data noted as the answers submitted within minutes of the screen shot, though they were unable to participate in the wrap up discussion surrounding the data collected in the endpoint poll.

Figure 6 shows the responses for the first question: "Using one word, describe what you think of when you think of the Middle East."

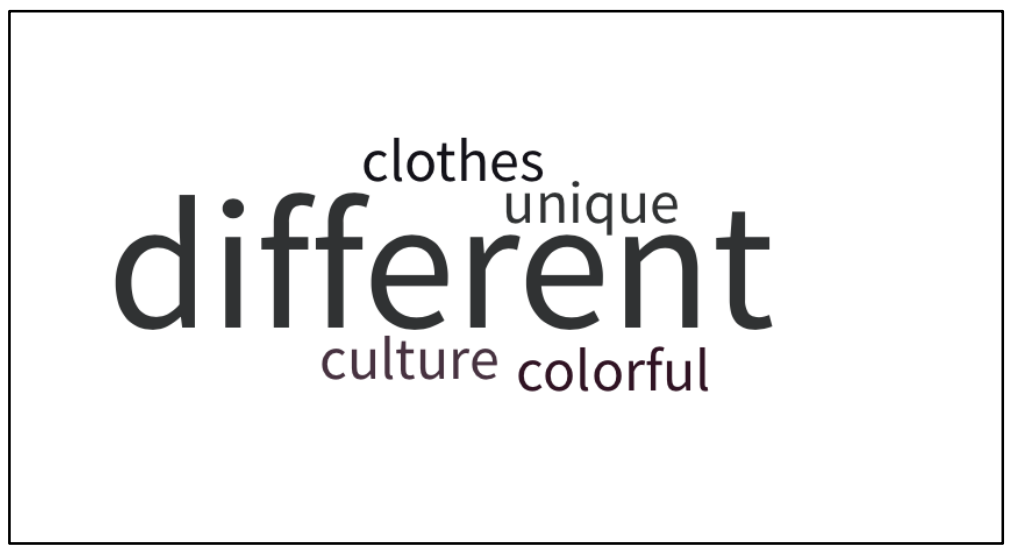

Figure 6: Endpoint Data Question 1 Responses 
Figure 7 shows the participant responses for question 2: "When you think of music from the Middle East, what do you think of?"

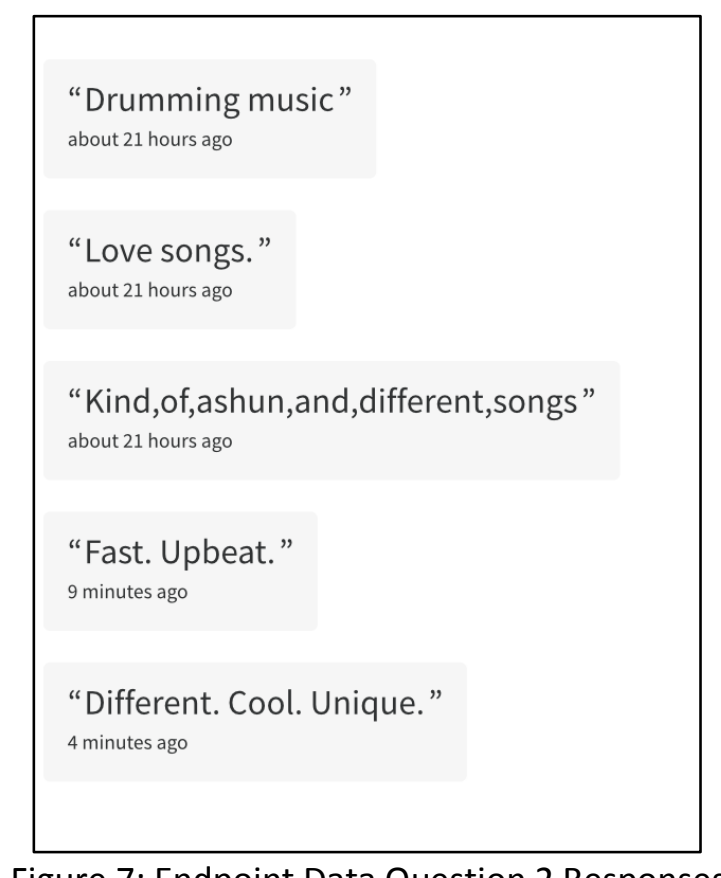

Figure 7: Endpoint Data Question 2 Responses

Figure 8 shows the participant response for question 3: "When you think of houses and communities in the Middle East, what do you think of?"

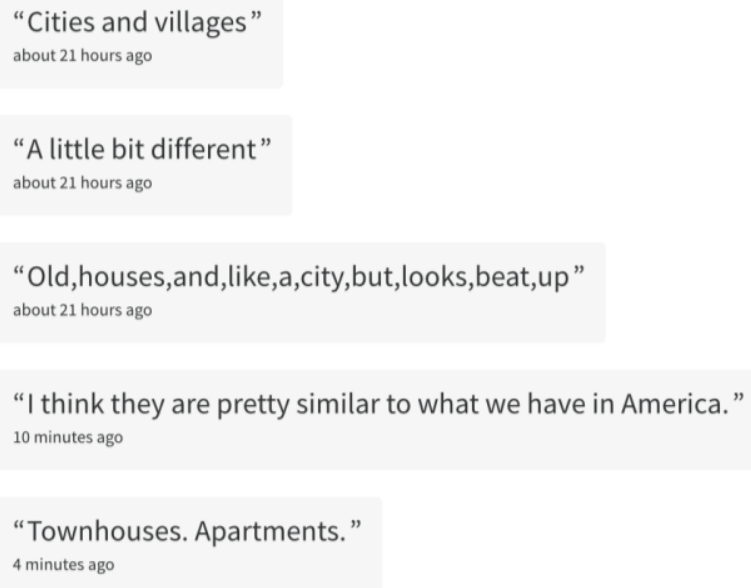

Figure 8: Endpoint Data Question 3 Responses 
Figure 9 shows the participant responses for question 4: "When you think of popular stories from the Middle East do you think the storylines, morals, and characters would be similar to ours in the United States, or very different?"

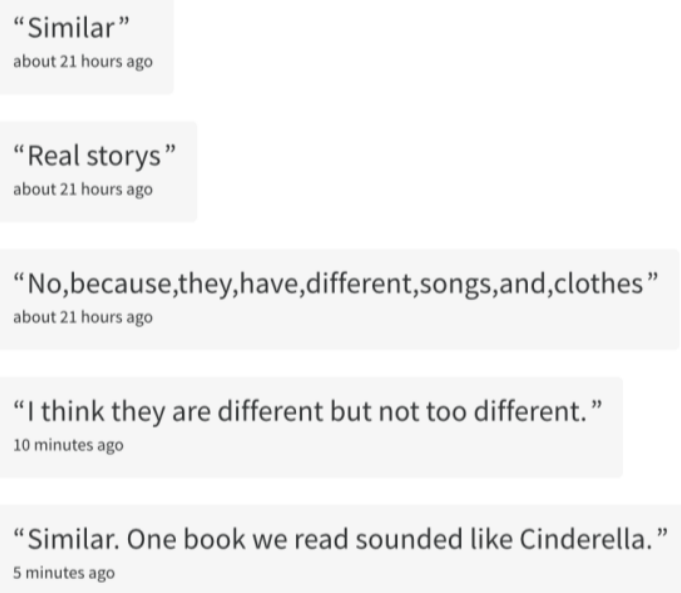

Figure 9: Endpoint Data Question 4 Responses

Figure 10 shows the participant responses to question 5: "Overall, do you think people from the Middle East share a lot of common interests, ideals, and thoughts that we have in the United States?"

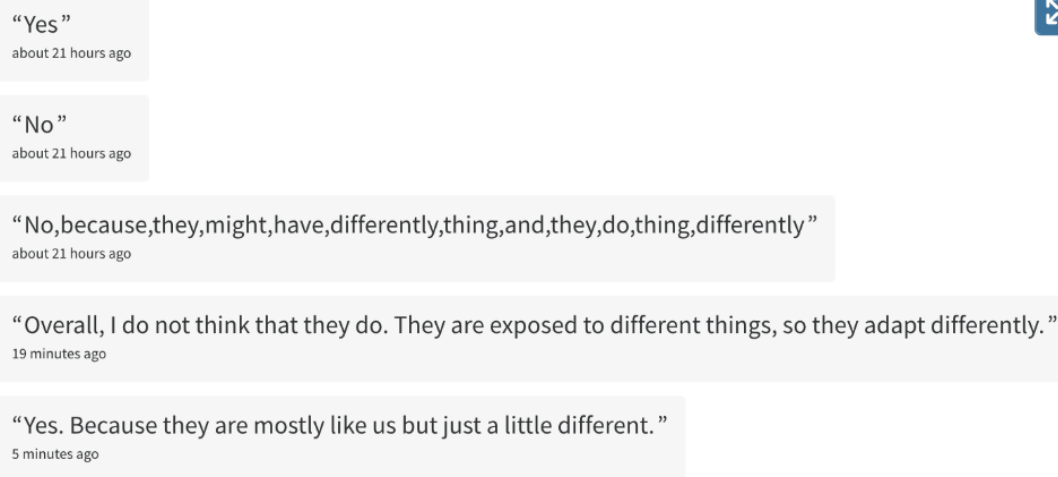

Figure 10: Endpoint Data Question 5 Responses 
Once each participant had completed the survey, we discussed the results as we had following the initial survey. Participants noted that the answers this were "mostly different" than the first time.

When discussing the impact virtual field trips had on their answers one participant stated they "learned all kinds of things". The discussion went on to discuss that "it looks different [than expected", one participant "didn't expect big buildings"... "I didn’t think walking into this room it would be like cities and all that kind of stuff", another participant adding they didn't expect to see “Burger Kings, Starbucks, or Moels [gas stations]”. One participant stated "I expected them to have cars, but not a gas station because I didn't think they were as developed as they are".

When discussing the impact the music (listening \& playing) had on their answers they noted that "the dancing and music [impacted opinions]". They noted it was "different than expected" with it being "more fast" and "a lot higher" than anticipated. They noted that the subjects of the songs were not surprising, but one added that the "combination of instruments and how it's made is kind of amazing, in a good way".

They didn't have much to add about the folk tales, but reiterated that the stories were "unique [in a good way]" and had "some unexpected" storylines.

\section{Narrative Portraits of Participants}

Andrew was one of the most outgoing and engaged participants from the start. He was average build and always came dressed in bright, clean, athletic-type clothes like he was about to go play basketball, though he was a football player. In the first session, he self-described himself as a "jokester," which certainly came out through each of the lessons. However, he was mostly able to remain on task and always participated seriously in discussions. 
During the first session when the anonymous virtual poll was being introduced and we discussed how the same questions that were on the information forms that they signed were going to be on the virtual poll, he offered that he thought he remembered one question being "what you think when we hear the word Iraq or something, and I said terrorism". He then relayed that his parents are in the military and were stationed in Iraq for a period of time, noting that they talk to him about their time there [a likely explanation for why he thinks of terrorism]. He also volunteered to identify where the Middle East is located on a map during the introduction following the initial poll.

While the other participants were quiet during the initial poll, he frequently made comments including how the Middle Eastern drums "look like bongos", and how he had "two ideas for the first question [of the poll]". The discussion that followed the initial poll centered around where their vision of the Middle East came from, he was the first to speak up and reiterated "I got my vision from what my parents say, they went there so they talk to me about it".

Following the discussion that followed the poll, students were shown a compiled map of prominent places in the Middle East. While looking at the map he commented that it showed “it's not [just old like in movies], there's huge cities". During the cultural custom discussion, he was the participant most interested in the correct posture practices. He put his body into various positions and inquired if they would be considered proper posture.

When it came time to introduce the Middle Eastern percussion instruments, he reiterated his statement that they "are like bongos", and assumed they would "sound like bongos" before he heard the sounds. When the jug drum was taken out of its box he let out an audible gasp with the other participants. As the various ways to play it were described and modeled including with 
rings and bracelets, he stated he believed "you have to wear rings to make it make noise," later finding that to not be entirely true. For the water experiment with the jug drum he hypothesized that the jug drum would "echo" after the water was put inside compared to without water. He discovered, however, that "it [the water] shortens it...it cuts it off [the sound]". He described the zills as "mini cymbals" that sound "echo-y" and "really high pitched".

He seemed to have good rhythm, catching on fairly quickly to the rhythms on the drums. The main times he messed up were when his hands were in the wrong place, not quite ready to start with the rest of the group. He took no time to volunteer the play the rhythm alone when the offer was made, eagerly raising his hand at the opportunity.

During the closing discussion for session 1, he relayed that he "learned that there are some cities, but it's not all city," and that "you can't touch people's heads" [cultural highlight]. As he was walking out the door he stated "I thought it was really fun hanging out like this".

During session 2, Andrew began a bit distracted by a ball he had brought with him that day. He was the first to speak up during the introduction discussion where we reviewed what was done the week before saying that "we learned about the Middle East," expanding to say that "we looked at some of the big places in the Middle East and we learned how to play the drums," and expressed that he thought it was "pretty cool" to see the different places in the Middle East. After another participant expressed that the buildings were "different" than originally expected, he expressed that he was surprised that "they're not that far behind [in development compared to the U.S.]". While reviewing the cultural norms discussed in the previous session he was one of the first to mention that you "don't point them at people" when reminded of etiquette with the feet. He then reminded everyone that "you have to shake with your left hand," correcting himself right after by saying "no, you don't shake with your left hand" before once again asking 
if certain poses would be considered proper posture. When asked what the most interesting thing was about the previous week he said "the drums". He said the most surprising thing to him was "[what] the city is like, I thought it was just mud houses and stuff [before]".

Most of the participants were less focused during session 2, including Andrew, though he also took the lead a few times in diffusing difficult situations between other participants [showing good leadership skills, and signs of a likely well-adjusted upbringing]. Andrew brought a ball with him that was distracting to him until he was asked to put it away, and got off track a few times during the introduction discussion for session 2. First, diverting the conversation by saying "and what are those things, what are those?" inquiring about the instruments for the day that he saw sitting around the room (string instruments). When told that we would talk about them later in the session he inquired "do you pull a string and it makes noise?". Then later by saying "I wanna play that guitar [referring to an ektar]".

When comparing the size of the gopichands, he predicted that "this one [pointing to the smaller one] is going to sound higher [in pitch]". When the researcher pointed to the top of the instrument with the tuning peg, Andrew said he thought it was "like...a handle," and said that guitars and violins also have tuners. He predicted "it's going to sound wavy" when the researcher would squeeze the sides of the gopichand, saying "I knew it, it's high pitched and goes [made wavy sound with his voice]" after it was played. During this time one of the participants wound the string too tightly and broke the string, Andrew stepped up to help diffuse the situation as the other participant was upset and tried to blame it on him. Andrew was curious about the ektar saying it "looks like a banjo because it has three strings," and after learning the body is made of pumpkin asked what did they put around it to make it hard?". He suggested the membrane on the body of the ektar was likely made of "sheepskin". 
Andrew described the spike fiddle as "it's like a guitar" when he learned you can put your fingers on the neck to make different notes, and said it's similar to a violin or cello "because it has a bow". When discussing the materials the instrument is made of he commented “everything we looked at so far has had some type of parchment or sheepskin" when it was time to discuss the membrane. Another participant then mentioned that they were evil for doing this, but, this is another situation where Andrew (and another participant) helped to diffuse the situation. Andrew assisted in this by replying “they don't kill them. It's with babies that are already dead when they're born," (though, this is not entirely true in this case), continuing to say “but they won't just automatically kill them...they don't just kill them for the skin...they eat the whole thing".

He recalled the drum activity from the week previously very well, being the first say "we learned two rhythms [sounds]" on the drums, and could pretty accurately recall the rhythm and the order that each of the sounds are played on. He was the only one to remember "tek was the higher pitch, and dum was the lower pitch". He was also able to accurately describe the proper playing posture and procedure. When other participants were having problems recalling the rhythm as we practiced, he described that he was actively analyzing his playing while we were reviewing the rhythm by saying "I was counting. I just wanted to see if I was actually doing a dum for a tek, cuz I kept on going like this [demonstration] and it sounded like it was low pitch". When comparing the ceramic and wooden drums he said '[the wooden ones] don't do tek that well, but they do dum better" and "[the ceramic ones] do tek better than dum". When the metal doumbeks were added to the comparison he said they "sound higher pitch [than the wooden and ceramic ones]". 
After listening to Katibim he said it "sounded cool," and may have been portraying a "sad, kind of" emotion before reiterating that it "sounded cool" and was likely about "a person". He scoffed at another participant who suggested they don't have itunes outside of the U.S. by saying “just cuz it's in the Middle East doesn't mean they don't have it [itunes]". After being read the translation, he confirmed it was "about a person," and that it was "a love song," which he stated was not surprising to find out of the Middle East. He did, however, ask "is there pop music?".

During session 2 the participants learned filler parts on the zills, riqq, and frame drum to accompany Katibim along with the doumbek. Andrew was apprehensive at first saying 'I don't know how to do this," but quickly caught onto each instrument part as they were introduced to him.

During the beginning of the closing discussion of session 2 another participant gave a silly answer to which he replied "that's not what we learned... We learned a new rhythm...well, it's not a new rhythm, but we learned how to combine different parts...put different instruments together and play". He stated he "liked the song," and thought the "spike fiddle is cool".

Andrew wasn't as interactive during session 3 as he had been previously (he had just become a big brother during the previous week, so maybe fatigue played a part). He recalled that during the previous session they "got to play new instruments". He also noted that the spike fiddle "plays the same [as a cello], it has one of those things [endpin]".

When asked to identify what family in western musical instruments the new instruments to be introduced that day would belong to he identified them as "wind" instruments, expanding to say "they look like a harmonica," with one made of "bamboo or wood". At the beginning of 
the video of the shehnai being played he commented "that sounds weird," followed shortly after with "sounds cool, though" later saying he "liked the beat to it [the example song]". While listening he commented "it's like really long things [notes]... Like, see his face starting to turn red". Speaking about one of the tablah players in the same video, he said the player must have “a lot of talent, because it's [he's] not even looking [at the instrument], he's looking at the other guy," and they must "practice a lot". Andrew also commented on the clothing of the players in the video, noting some were wearing "Adidas" which was unexpected.

He stated the mizmar "looks like a clarinet," and was excited (along with the other participants) that there was another video for a mizmar demonstration. While he did not comment on the sound of the mizmar itself, the music being played reminded him of "stealth music [in a movie]," as well as "cops and robbers".

He described the duduk reed as "a lot bigger [than the previous examples]," and asked if he could have it to "turn [himself] into a duck" due to the shape reminding him of a duck bill. While watching the example he described the sound of the duduk as "like a clarinet".

After being reminded that they would be taking a virtual field trip to Turkey he exclaimed excitedly "I forgot about that! I'm glad I came back this week!”. One of the first things that he noted he saw that was surprising was a "motorcycle," followed shortly after by a "police car," that "pulled over a taxi". A big surprise for him personally was when he came upon a "gas station called Moels". He later expanded on that by saying he "knew they had cars," but "never thought about them having gas stations [like ours]". Andrew joined the rest of the participants in what was the biggest outcry during the entire study period when they collectively yelled "Nooooooo!" when they were asked to put them away after the first virtual field trip. 
During the discussion about wedding traditions in the U.S. before the Israeli wedding dance portion of the session, he was first to speak up with "cake" and "kiss". The participants were asked if there were any dances that are common to do at weddings in the U.S., to which he replied the "Electric Slide". While he caught onto the moves for the Israeli wedding dance quickly and performed it accurately, he didn't have anything to say during that period of time (he seemed to need to focus a lot in order to do the moves correctly).

During the closing discussion, Andrew was the first to speak after being asked what was surprising or interesting that day, saying "the field trip and the dance," expanding to say "the people in the cars" were surprising. He said he was not surprised by the tall buildings "because we already talked about it," and continued to say "I just didn’t expect [so many people], because I saw 200 or 300 people!" and "they were dressed kinda like us". As another participant was questioning where else you could visit using Google Streetview, Andrew asked if it was available for "China" (potentially showing interest in learning about another culture).

Session 4 was a difficult session based on the fact that it was pajama day for the camp, and they were having a water day during recreation time after camp. All of the participants had difficulty maintaining focus, paying attention, and giving thoughtful responses. The only time everyone was quiet for a fair amount of time was while the researcher was reading the folk tale, The Magic Apple, as part of the activities. Andrew was the most engaged and often tried to help keep everyone else focused and on task, with little success.

During the opening discussion for session 4, he said the "virtual field trip to Istanbul/Turkey" was the most interesting thing about the previous week, noting that seeing "people that look exactly like us," "Burger King," and "gas stations" as things that were surprising in that experience. 
In session 4, participants went on a virtual field trip to Israel, participants had some difficulty focusing with this one as there were fewer options that you could move around using the interface- most of them were just 360 still photos instead of navigational 360 maps like they interacted with during week 2. Andrew was one of the more successful participants, noting he found "the perfect view!" in one spot, and was able to navigate on "highway 40," while also discovering the shadow of the "2015 Google Car" that collected the images. In another scene he mentioned finding "the Monster car," and again mentioning the amount of people he was seeing in the images as surprising by exaggerating that he saw "20 billion people there". He didn't give serious answers during the wrap up activity for this virtual field trip, saying "it was fun because we got to make mega people," (the researcher is still not sure what that meant) and "somebody's feet". He did say he thought the climate was hot, due to another participant noting they saw palm trees.

After being read The Magic Apple, Andrew said he believed the main point was that the father of the men wanted them "to find something to give them happiness and riches," which is "similar" to stories we have in the U.S..

Andrew's focus ebbed and flowed, along with the other participants, during the Hoy Nergis dance segment of the session. When he could tell the researcher was getting frustrated with the behavior that day, he would try to pull the others back on track by pointing out how rude they were being. Andrew had some difficulty catching onto the movements for the dance, especially while sitting and doing the movements with hands only, but did fairly well when the moves were transferred to standing with feet doing most of the movement.

During the closing discussion for session 4 he said he enjoyed the "new dance" saying he "thought it was pretty cool," self-reflecting that he "messed up a lot" while performing it. He 
disagreed with other participants who didn't think the virtual field trip to Israel was as interesting as the first one to Turkey in saying "I thought this one was interesting only because even the ones you couldn't move, it was really awesome views from the place [that he hadn't seen before]".

Session 5 was held at an earlier time than normal due to the participants taking a trip to the pool immediately after lunch. It was also shortened due to the county Superintendent of Schools reading to the campers just before the session. However, the participants remained much more focused than they were during session 4. Many of the responses, however, were still more limited than they were initially (perhaps the biggest realizations had occurred during the first few sessions, leading to lesser surprise during the later sessions).

During the introduction to session 5, Andrew recalled that they "learned a new song [dance]" the previous week, and summarized the storyline for The Magic Apple for the other participants. When asked if participants would have expected that storyline to come out of the Middle East prior to these sessions, Andrew responded "probably not".

Andrew was one of the most engaged with the folk story Joha Makes A Wish during this session, offering hypotheses for what he thought was going to happen as the story unfolded. He responded "that was good" after the story was completed, and began to say what he thought the moral of the story was, but was interrupted before he could finish.

The cultural highlight of session 5 discussed what people in the Middle East commonly do when children loose teeth. Andrew commented "When we lose them [teeth], we put them under our pillow... what do they do? Shove it up their ears?". He said children in the U.S. get money when they lose teeth as a way of saying "good job". After the Middle Eastern custom of 
wrapping lost teeth in cotton and putting it in a body of water or garden for blessings or good luck was described Andrew commented "it's a different way [of doing it]... but it's kind of similar cuz they're wrapping it in cotton and keeping it safe, and getting money is kind of good luck". He then relayed a story where his father wanted to tie one of his teeth to his four wheeler to pull it out.

Andrew was able to recall the sounds they learned to play on the drums during the first week, but not the exact order in which they came for the rhythm. As participants were learning a new rhythm introduced during session 5 he stated "I'm okay with the drums, it's easier [to play the rhythm correctly]". Participants were tasked with creating a rhythmic pattern to accompany the Israeli Pop song, Lealy Nahary, which Andrew described as sounding "like an American song," with a "pretty easy beat". He later expanded to say "it sounded American because of the kind of music it is, the beat, and how it sounds with the tempo and instruments," and that he did not expect computerized music from the Middle East. Andrew's initial rhythm patterns were very complex, and seemed to have no sense of a planned rhythm, mostly sounding like random banging on the drum. He was clearly enjoying the music as he was moving his head and shoulders as he played. As the researcher paused the music to offer helpful guidance to the participants, Andrew's patterns became much more planned and simple, eventually evolving into a rhythm that made sense with the music.

During the closing discussion for session 5, Andrew recalled that "we learned a new song and a new rhythm" and that he was surprised that the "song sounded American". When the researcher stated that they would have choices on the activities that were to be done on the last day he replied "I think everybody's going to want to go on a virtual field trip...to Turkey!". 
Andrew was the most vocal participant during session 6, particularly with the absence of two other participants (one of which was usually vocal). At the beginning of the discussion following the endpoint poll he commented "I don't think I put any of the same answers [as before]" (pointing to a change of at least some perceptions).

When comparing the answers submitted for each of the polls he said that overall the answers for question 1: "Using one word describe what you think of when you think of the Middle East" as being "mostly different" as a whole than they were in the initial poll. For question 2: "When you think of music in the Middle East, what do you think of" he said he thought the answers were "different" continuing to say "the only part that is kinda the same is 'different' and 'drumming"'. He did not comment on the answers to question 3: "When you think of houses and communities in the Middle East, what do you think of"'. He said "overall, we changed" in answers for question 4: "when you think of popular stories from the Middle East, do you think the storylines, morals, and characters of the stories are similar or very different?". For question 5: "overall, do you think people from the Middle East share a lot of common interests, ideals, and thoughts we have in the United States?" he did not comment on the group as a whole but explained "the only reason I put yes is because their children are their biggest... because they don't want their children to get hurt like we do [meaning in the same way]".

When asked if any of the activities during the sessions led them to change their answers, Andrew stated "Dancing" and "Music" led him to change his thoughts. He later said "I didn't think walking into this room it was going to be cities and all that kind of stuff [in the Middle East]...no Burger King, Moels [gas stations], or Starbucks". He said he "thought they had cars, 
but not a gas station" because "I didn't think they had that good of [infrastructure], how far they are...I didn't think they were as developed as they are".

In terms of the music, Andrew stated the music was "different [than expected]...it was faster than expected". He expanded to say "how it sounded [was surprising]... with how the instruments were and how they were made, I just think the combination of the instruments and how it sounds is amazing...in a good way". He later stated that "the subjects weren't that surprising, just how it sounded".

Andrew agreed with another participant that the folk tales were "unique," expanding to say the storylines were not what he expected. On this topic he engaged in a conversation with another participant who thought they were different because the Middle Eastern stories were said to revolve around one thing. Andrew disagreed with that statement and cited examples where the stories had multiple important characters or items within them, comparing them to other stories they had read in the morning camp sessions.

When asked for other thoughts on things that may have been interesting or surprising throughout the sessions, Andrew first said "I learned all kinds of stuff," and cited "that they have Burger King and Starbucks" when asked to expand on that.

There was a unanimous decision that the participants wanted to do another virtual field trip and play drums during the last session. Andrew initially asked if he could go to Belgium, before the participants were told they had to visit Middle Eastern countries only (the idea being they would choose one). Andrew then asked if he could visit Iraq (because his Dad lived there), then asked if he could go to Syria first. Later, he asked if he could visit Jordan, Armenia, and Georgia. As he was jumping from country to country his only comment was that he saw what he 
thought was a "creepy clown" (the researcher did not take much notice as he was busy assisting another participant who was having trouble navigating the iPad).

During the drumming portion, he asked if they could be taught another sound that is common on the drums in the Middle East. He was active and engaged, moving his body to the beat of the different songs as they created different rhythmic patterns on their own to accompany each song. By the end, he had improved tremendously on creating ostinato patterns that make sense.

Andrew self-reported that his parents are in the military and were stationed in the Middle East. It seems that through his comments and interaction throughout the sessions, that initial knowledge was limited to war and military experiences. Through the activities in each session, he seemed to develop a wider view of what the Middle East and its people are like. He acknowledged that all of his answers changed from the initial poll to the endpoint poll. The things he talked about the most through the sessions had to do with 1) the communities and how developed they are compared to what he believed, 2) the music was more upbeat and modern than he expected, and 3) it was common for him to tie philosophical threads together when it came to comparing the customs of the Middle East and the U.S..

Alyssa began the first session very quiet and timid. She was average built and her dirtyblonde hair was somewhat unkempt as if she had been playing outside all day. She normally wore dingy, faded jeans and t-shirts. While she was always attentive, she had a tendency to whine - particularly when she did not get to play the instrument she wanted right away. During the discussion following the initial poll she offered that there are "lots of wars" in the Middle East and this information came "from movies". 
She really came alive during the first session when the percussion instruments were introduced. She noted she did not know what African drums were when other participants compared the Middle Eastern drums to African [potentially pointing to a limited background from music classes in school]. When discussing the materials the drums were made of she noted "that's mean, killing baby cows," when the researcher described stillborn calf as a common material for the drum heads. When discussing the different decorative styles used on the drums, she noted that she liked the "etched drums," and that she "did mosaics before" for an art project. She was first to say the riqq "looks exactly like a tambourine". When the zills were introduced, she described the sound they make as "really high pitched" and asked twice if they could play them.

When it was time for the jug drum experiment and the drum was pulled out from its box her eyes grew wide and she let out an audible gasp along with the other participants. She asked "why does it have the hole?" when the experiment in which we put water in the jug was described, and expressed "water can come out" with a confused look on her face. Her hypothesis for what would happen when water was put in was that it would "make a different sound," without further explanation before another participant chimed in. She described the result of the experiment as "weird," (a common term she used in the beginning of the study) continuing to explain that the water caused it to "[not] echo as much".

She could hardly control her excitement when it was time to play the drums the first time. Immediately, she said "I want to try the big one [the researcher's]," then asked if they could have two drums as the playing position was described before again stating she wanted to "try the big one". She had difficulty playing the rhythms correctly - particularly when it came to counting the number of each sound to make in a specific pattern. She had difficulty focusing between 
exercises while instructions and advice were being given, often finding herself unable to keep from tapping the drum. When given the opportunity to try the pattern individually, she volunteered and gave it her best effort. In the closing discussion she noted that she messed up the pattern while playing the drum.

During the closing discussion for lesson 1 she said she learned "there are some cities [as we would know them in the U.S.]," "you can't cross your arms [referring to the discussion on posture]," and requested that we "learn what the flags are [for the countries]". As she was walking out the door to go to recreation time she asked "so what's the country called?", which led to a short discussion and reminder that the Middle East is an area that has a number of countries.

Alyssa was hard to keep focused and difficult to get serious comments from during session 2 [potentially some outside influences unknown to the researcher that contributed to this]. She was particularly interested in asking "if we are going to play instruments" at various times through the session [showing enthusiasm and interest in the activity], and she whined if/when she did not get to play her first choice of instrument right away [potentially an only child, or a child that always gets her way]. However, her objection to using animal skins for instruments was further solidified [likely a love of animals, and/or a strong personal/family belief.

During the opening discussion where we reviewed what they learned/remembered from the previous session, she noted that she "thought it was pretty cool [looking at places in the Middle East]. She noted that looking at those places she saw "a lot of just different" expanding to say "well, they have different buildings than us" when asked to expand on what she meant by 
"different," also noting that she thought "they are a little more advanced [than us]...a little bit higher". She agreed with another participant who said they are "more colorful".

She was one of the first to comment that you "don't point them at people [feet]" during the cultural highlights discussion, and she explained that you "shouldn't do this [touch people's heads," following which she touched various parts of her head/hair and asked if they would be okay to touch. She was concerned about proper sitting posture in the Middle East, particularly in respect to "criss-cross-apple-sauce" and how you should sit in a chair since pointing the bottom of your feet at someone is considered rude. Following this discussion she asked "what else is rude? There is a lot of rude things". She concurred with the other participants in that "the drums" were the most interesting part of the previous session, with her explaining that was because "it was the only thing we got to play".

When it was time to introduce the string instruments, she let out an audible "whoa" as her eyes grew wider when the gopichands were brought forward. Her prediction for what each size would sound like was "the littler the thing is, the bigger [higher] the sound," and she correctly guessed that "paper [parchment]" was on the bottom of the instrument - immediately followed by "I wanna try," and proper identification of a "tuner [peg]". When the researcher asked for hyopotheses of what would happen if both sides of the instrument were moved during playing she asked what a hypothesis was before using her voice to mimic a wave after it was explained (along with other participants). She was impatient as the gopichands were passed around, and she found she was not the first one to get to try them. When it was her turn, she began twisting the peg and jumped as she let out a gasp when the string broke. At which time adrenaline took over and she tried to deflect the blame, hurriedly saying "I didn't know it was that tight...I thought it was the other way... why would you do that [toward another participant]". She blamed 
the participant who had it before her for tightening it too tight and explained she was "gonna unloose it [sic]...I was going to untie it". All throughout the duration of this, the researcher attempted to put everyone at ease by explaining he was not mad, that the instruments were not expensive, and the string could be replaced.

When the ektar's were brought forward she was most fascinated and said "is that a pumpkin?...is that actually a pumpkin?" and expressed "I wanna try the pumpkin" after it was confirmed. "Do they eat the pumpkin rind?" she asked followed by "why do you have to kill a pumpkin" and then said the stick [neck of the instrument] was "probably like just bamboo" when another participant asked what it was made of, expanding to say "everything is bamboo," then saying she thought the membrane was "sheepskin something". After this she asked "what do they make out of humans?", at which time other participants were losing patience with her visually and one verbally by replying "nothing, cuz that's revolting," to which Alyssa said "that's not fair". Before returning to the subject of the broken string, once again trying to deflect the blame to others, when the researcher said we would not be passing around the ektars for everyone to try. When the researcher reiterated that he was not upset about it, she replied "then why do we not get to play [the ektara]?”. When discussing the thin, metal, decorative elements on the ektar she asked what animal the membrane was made of.

When the spike fiddle was introduced, she inquired if the bow was "made of horse hair [like western bows]" mentioning it "kinda seems like a violin" because it's played with a bow, and also mentioned that it was "like a cello or bass" because of the spike on the bottom. She returned to her fascination of the materials the instruments were made of, asking if the body was a gourd and asking "is that sheepskin [the membrane]?" The researcher said that one was made of parchment, but skins can also be used to which she reiterated "cuz they're evil". A second 
participant lost their patience with her at this time replying "no, animals were meant to be eaten and used...they kill them to each, and they're very conservative". Alyssa replied by asking "so do they eat us?", with the participant replying “no, they don't...because how else would you get the vitamins and minerals they need? They don't have the protein that they need in all the plants and some of the plants are only found in certain areas. So they would have to get protein". Alyssa replied to this by saying "Then they can kill themselves," with the first participant to lose their patience interjecting along the way. Alyssa asked "Why do they kill animals, though?", getting increasingly irritated as this conversation moved forward (it was obvious this is a subject she feels passionate about, but the researcher is unsure what it stems from). The researcher moved the conversation to the bow, and explaining how rosin is necessary to produce the sound. Alyssa asked "is that [rosin] made out of animals, too?," and asked "do they kill the horse [in order to get the hair?..that's just being evil" - after which, the researcher asked everyone to calm down and follow directions so they could move on to playing instruments.

Alyssa was not focused during the instrument playing activities, particularly after she asked "can I have the big one [the researcher's drum]?” and being told no with an explanation that that drum sounds different than the others so it helps it to stand out and keep everyone on track. She had difficulty trying her best while playing, and keeping conversations on topic so she was advised once to begin following directions or she would lose the instrument she had. This helped to stem the off-topic conversations, but she was consistently not following the directions when it came to the number of times to play a certain pattern. When this was brought up she said "I'm not counting," and was asked to count from that point on so we could stay together and asked "can we do like ten?" then "we could do twelve" as opposed to the eight that was originally requested (the researcher was not sure why those numbers were preferred). Later in 
the session, she seemed to get more confidence in her playing and asked "can I do one without you [the researcher]?" to which the researcher agreed everyone could do it if they wanted to, but the researcher would mime the playing motions in case they got off track and wanted to correct themselves (she did not know what the word mime meant).

When asked to compare and contrast the wooden and ceramic drums, she said "these are better [pointing to ceramic]...cuz this [ceramic] has a hard case right here, and that's why it makes the tek better". She was curious about the instruments (as she has shown all along) and asked "well, how many of these [drums] do you have?" followed by "how many different kinds of instruments do you have" after the initial question was answered. When asked to compare the metal and ceramic drums she went back and forth initially saying the metal, then deciding the ceramic ones were, but noting that "they [metal ones] look better, though".

Alyssa wasn't quite sure about what a folk song was, building on another participant's response by saying "or we have a song for our nation...like the pledge of allegiance". After listening to the Turkish folk song Katibim she said "that was like...weird" and asked the researcher what country he was from, noting she was unsure because the researcher "knows about them [Middle Eastern people]. Getting back on track she described the song as "like Opera" and "high pitch". Her curiosity about the country of Jordan that popped up a few times first came out during this time, she asked "do you have any songs from Jordan?" (the researcher didn't probe into how/what she knew about Jordan). She also asked "do they have like some things that we have here?" following up with "do they have like stuffed animals?" (potentially trying to make more common connections). She described Katibim as sounding "sad, because it sounds like boring," clarifying later to say "it sounds kind of cool but boring" noting "I just didn't like the music". She pointed out that the heads on the metal drums say "Mid-East," 
inquiring "so, it's from the Middle East?...that's far away" (it should be noted that the researcher had already explained they were from the Middle East). Her silliness crept in again here with the question "do they have turkey in Turkey?". After being told the translation for the song she was confused about what a clerk was, asking "what do they like to talk about...a clerk?" and noting "clerk is a weird name" after being told what a clerk is. She also asked "is there like any social traditions in the Middle East?" after which other participants reminded her of the cultural and social norms that had already been discussed. Still seemingly unsure about what a folk song is she asked "why would she [the singer] put it on itunes [a song about who she loves]?" expanding to say she didn't think they had itunes outside of the U.S.. Other participants were quick to note “just cuz it's in the Middle East doesn't mean they don't have it [itunes]," which expanded to a discussion about if they have Apple products in China after her surprise to realize Apple was not exclusive to the U.S.. She asked "do they have different types of music there [in the Middle East]?" specifically asking about "rock" as her intrigue continued and she asked "what type [of song] was that [Katibim]?" (potentially not recalling this was already discussed because she wasn't fully engaged when that discussion happened or potentially that she is overwhelmed with new information).

"I wanna do the cymbals!" she shouted when they were told they were going to mix together the instruments to accompany the song. Though, it was clear she was not fully paying attention as she said "it's that song again" when the music started playing and we were going to pat/clap the rhythms first before adding the instruments. When asked if they preferred the researcher to play or do the hand motions with them to keep them on track, she interrupted asking "is there like a music video to this [song]?" and asking if they could see one when it was confirmed that there was. After the zills, riqq, and frame drum were introduced, she expressed 
her displeasure in receiving the zills (though she had previously requested them), noting she wanted the "big drums [frame drums]!" several times. As the researcher was trying to clarify the various instrument rhythms with other participants she continued to whine about not receiving the instrument she wanted until the researcher stopped to say that they would be switching so everyone would play every instrument at some point in time, which finally made her happy, until it was time to switch again and she didn't receive the instrument she wanted next (this repeated every time participants were given a different instrument).

During the closing discussion of session 2, she was the first to speak up and said she thought "we learned that bells are the most important [instrument]" before being corrected by another participant who had previously lost his patience with her. She then reiterated that she "didn't like the song" after being asked the most interesting or surprising thing from the day, before getting excited and saying "I wanna play that [pointing to the spike fiddle]...we've never heard them!" before being reminded that the researcher had played it for them. When participants were told they would be going on a virtual field trip to Turkey in the following session, she perked up and exclaimed "we're going to Turkey?!" obviously not sure about the meaning of a virtual field trip.

Alyssa was more calm and agreeable during session 3 than she was during the previous session, (there was no mention of animal skins being used, and instruments were not played so potentially one or the combination was too much for her previously). She was audibly disappointed when she was informed there would be no instrument playing during that session, asking "then what are we doing?". She was first to recall that the folk song from the previous session was from "Turkey" and that it was a "love song". There was a short reminder that one of the strings broke during the previous session, but she was able to move on quickly from that 
subject. Her fascination with videos returned during this session, trying to catch the researcher in a lie by saying "I thought you said we can't see a video," when it was mentioned they would be watching a video to see how the instruments for the day work and what they sound like. She seemed unable to let this idea go, as later in the session she returned to the subject to ask "can you look up that song that we played [last week]?”.

She described the shehnai as looking "hand-made...[of] wood". She described the sound as the video began to play as "weird," "loud," and later like a "koala". She noticed some of the clothing in the video and commented that it "looks like [the clothes] are from America". During a discussion about the sound of the oud in the video, she commented it "sounds a little bit like a guitar". During the wrap-up discussion around this video she said she thought it was "cool, because it kinda sounds loud," noting "I like loud [and] I like the drums.

She perked up and yelled "yay!" when it was stated that they would be watching a video for the mizmar as well, but she commented "these videos are long" before being corrected by another participant about their length, and finally asking "Can we listen to a music video?" (the researcher assumes she meant an MTV-type music video).

She described the reed of the duduk as "bigger" than the others we had seen previously, and that "it kind of looks like a tooth... a shark tooth". She described the sound the duduk makes in the video as sounding like "bedtime music" similar to a "clarinet" and being "loud". She came back to the subject of videos inquiring “do you have any videos with girls in it?", and also asked several questions about "what's your most expensive value [instrument] from the Middle East?". This led the others into a discussion about the price of each instrument that had been used and also research into the price of an oud. 
During the virtual field trip to Turkey the first thing she commented on was "they seem like the same cars [that are in the U.S.]". She commented on seeing "a lot of shoes" (perhaps pointing to not expecting to see shoes), before noted seeing "street vendors," "a motorcycle," and "purses". She mentioned seeing "a slide on top of a roof", which led to a short discussion with the other participants as to why there might be a slide on a roof and if she might have seen it incorrectly. She joined the other participants in expressing their interest in this activity by yelling "noooooo!" when they were asked to put away the iPads for the day. Though she did not say anything during the wrap-up discussion of this activity, she did ask "does the app [we used] cost money?" (potentially expressing interest in using it at home).

Her tendency toward silliness came out a bit again during the opening discussion for the Israeli wedding dance, but she was able to keep it under control and remain on task. When discussing common traditions for weddings in the U.S. she said "when they ask if someone has objections then they shouldn't get married, I raise my hand", followed by giving the bride and groom "cards" and "bath salts" several times (the researcher is not sure if she meant something to be used in the bathtub, or she was commenting on the drug that is prevalent in the area). She later asked "does it [the dance] have a video?...how are we supposed to learn it if there is no video?" (given that this is a common theme for her, it seems likely that she relies a lot on videos to learn/do things) before the researcher explained that he knew the dance, and you can learn dances through written word and/or diagrams as well. She expressed frustration with the dance at first, saying "I can't do it" very quickly after this portion of the session began, and noting "I can't snap" which added to her belief that she could not perform the dance. She was instructed to try her best, and to simply make the hand gesture if she can't snap. She was engaged and 
attentive during the rest of the dance segment of the session, and caught on relatively quickly after her fears were addressed.

During the closing discussion for session 3, she commented that "seeing Turkey on the tablet" was the most interesting thing for her, and she inquired if they could "do it again" and "visit Jordan" in the same manner. She also mentioned it was unexpected that "they were dressed kinda like us" in "t-shirts and Adidas".

As previously mentioned, session 4 was a difficult session based on the fact that it was pajama day for the camp, and they were having a water day during recreation time after camp. All of the participants had difficulty maintaining focus, paying attention, and giving thoughtful responses. The only time everyone was quiet for a fair amount of time was while the researcher was reading the folk tale The Magic Apple as part of the activities. This was disappointing in regard to Alyssa considering her focus had improved during session 3.

During the opening discussion for session 4 she recalled seeing and being surprised by "Burger King," "lots of shoes," and "gas stations" during the virtual field trip to Turkey in session 3. She did, however, engage with another participant on if her (Alyssa's) sitting posture was appropriate for the Middle East.

Alyssa continually lost her focus during the virtual field trip, at one point her interest in going to "Jordan" came up again (the researcher is not sure if there is a significance to Jordan in her life). She had some difficulty getting past the fact that you couldn't navigate through them all as you could during session 3, but she made the observation "this looks like where war is" in one scene she was visiting, and inquired as to "where do these cars park" as she saw a lot of cars but not any parking lots or garages. At one point she ended up at the "Dead Sea," which led her 
to ask where that is located, before she arrived at "Camel Mountain National Park". Her silliness crept back in as she started to proceed the wrong direction on a street and exclaimed "watch out car! I'm going to crash into you!". During the wrap up discussion of this activity she noted seeing the "Dead Sea" was interesting, and she thought it was a "hot climate" based on the landscape.

Alyssa laid down (as did other participants) while listening to The Magic Apple, though she seemed to be listening as she asked a few clarifying questions about the storyline. When it was time to move to the next activity she was the only one who argued "I can't" and had to be asked a few time before she complied.

Her silliness crept out again as participants were learning the dance steps using hands only to Hoy Nergis, where she was slapping her legs hard and complained "it hurts," instead of using the gentle tap the other participants and the researcher were using. She had difficulty catching onto the steps of the dance, similar to the difficulty she showed while learning the first drum pattern - seemingly not counting the steps of the pattern to keep on track. Several small spats broke out between Alyssa and other participants during the dance segment of the session, with various people being accused of different things that upset her. As the session continued, her dancing improved, and she requested they be able to do the routine completely with the proper hand holds even though the researcher mentioned it would make the dance more difficult given the small number of participants.

During the closing discussion for session 4, she mentioned she thought "the last one [virtual field trip from the previous session] was more interesting... because there were more [navigable] cities". Her final reflection was on the fact that they saw "toes without bodies" 
referring to the phantom images that occur with moving people and cameras when the images don't align that were taken at different times.

As previously described, session 5 was held at an earlier time than normal due to the participants taking a trip to the pool immediately after lunch. It was also shortened due to the county Superintendent of Schools reading to the campers just before the session. However, the participants remained much more focused than they were during session 4. Many of the responses, however, were still more limited than they were initially (perhaps the biggest realizations had occurred during the first few sessions, leading to lesser surprise during the later sessions). However, Alyssa was more focused and serious during session 5 than she had been during previous sessions.

During the introduction to the session, Alyssa recalled doing "a virtual field trip" in the previous session. She commented that she could not remember the general idea of The Magic Apple because she has "bad short term memory" but added to another participants' summary by stating "their father wanted them to find something that will bring them happiness and riches," and stated "she didn't think it would come from that [the Middle East]".

Alyssa was very engaged while Joha Makes A Wish was being read. She joined one of the other participants in making relevant commentary and predictions as the story moved forward. At one point she asked "So are they [the stick] granting the wishes for just the opposite of what he [Joha] says?...He should say 'I don't wish for..."'. After the story was finished she commented "that was good", but asked "where is it [the story] from again?" and where the book had been purchased. As she continued to ask questions she asked 'It's a [Middle Eastern] story, but it's in America?" at which point the series of questions led the researcher to understand she 
was confused how a Middle Eastern tale could be written using English words, leading to a short discussion about translations.

Alyssa contributed a little to the discussion about traditions surrounding when children lose teeth in the U.S. compared to in the Middle East by saying "when we lose them we put them under our pillow" and "you get money". She stated the Middle Eastern custom was "different" without further explanation.

Her tendency to not count when playing rhythm patterns came out again while participants were reviewing the sounds and rhythm that was learned in previous sessions, as well as while learning the new rhythm introduced in session 5. After listening to the Israeli Pop song, Lealy Nahari, Alyssa commented "it sounds like they're in a computer," but it was not unexpected for her "because the buildings are so big [that they saw in virtual field trips]" (making connections across activities). She described the song as "kind of like classical, because of how it sounds," expanding to "a little pop, a little classical". She stated she thought it was "a dance, a dance party [song]" and potentially a "love song". When participants were given time to put together a self-created rhythmic pattern to accompany Lealy Nahari she appeared to put very little thought into what she was playing, just making a constant noise. The researcher paused the music every so often to offer guidance and tips on how to create a good ostinato pattern to use as an accompaniment and relayed that they could change their rhythm pattern if they felt it needed changed to which she replied "I don't need to change something". Her pattern did end up changing, and she offered to be first to play solo when it came time to show off their ostinato compositions (to the surprise of the researcher).

During the closing discussion for session 5 Alyssa only noted that "the song [and how it sounds]" was surprising to her. She groaned in displeasure as the other participants asked to do 
the dance from session 4, before leaving for the day, saying "You said [we] weren't doing a dance!". She did, however, express she wanted to "play instruments" and do a "virtual field trip" when the researcher relayed that participants would be able to choose some of the activities for session 6.

When comparing the responses from the initial poll and endpoint poll, Alyssa described the answers from the group to question 1: "Using one word, describe what you think of when you think of the Middle East" she described the answers to be "mostly different answers this time" between the two points. When comparing the answers for question 2: "When you think of music from the Middle East, what do you think of?" she described them as "similar and different" without further explanation. She didn't comment on the answers for the whole group on question 3: "When you think of houses and communities in the Middle East, what do you think of?" but, she said "I changed from a lot different to a little bit different" without further explanation. In regard to question 4: "When you think of popular stories from the Middle East, do you think the storylines, morals, and characters would be similar to ours in the United States, or very different?" she stated that "we changed [overall]". She did not comment on the answers from question 5: "overall, do you think people from the Middle East share a lot of common interests, ideals, and thoughts we have in the United States?".

When discussion the activities during the sessions that may have impacted their thoughts, she was first to speak up and say the "virtual field trips" impacted her. She continued to say "it looks very different [than expected]" noting she didn't expect "the pictures of the big buildings".

In regard to the musical activities, Alyssa said the "tempo was higher [faster, than expected]" and "how it sounded [was surprising]" with no further explanation. 
When asked about the folk stories that were read she replied "they're unique...in a good way". She later interjected "there's one thing about the stories...all the stories revolve around one tiny thing" expanding to say "a jar or an apple... or a stick" saying that it is different than what is done in the U.S., but backtracking when questioned further by saying "they can [revolve around one thing in the U.S.]". The other participants argued this point with her by citing examples from stories they had read during the morning camp, and pointing out that the stories we read from the Middle East had more than one important character or item, one example being The Magic Apple having "3 brothers" and "[an] apple, carpet, and looking glass" which all equated to more than one thing.

After being asked about the most surprising thing from the sessions, she responded "[seeing] lots of shoes and feet" during the virtual field trips with no further comment.

The group unanimously decided they wanted to go on another virtual field trip and play drums for the rest of the session. She first requested to go back to "Turkey," before asking if she could visit "Iran" and "China," with the only thing she mentioned seeing being "a sea".

She was the first to request being able to "make our own" rhythms again on the drums, and volunteered to demonstrate how to make the sounds they had learned. She requested that they be able to play to the "first song we ever heard [Katibim]," and then later a few "new songs" of the Israeli Pop genre. She went back and forth between serious/focused and goofing off with her drum playing, but seemed to genuinely enjoy the music always dancing as she played.

While she had some trouble seeing past the superficial differences between Middle Eastern and U.S. culture on her own, it seems through her comments and interactions that she did develop an understanding of similarities on some level (though maybe not as deep as other 
participants). She seems to have deep-rooted beliefs about animals, and what she would likely deem "animal cruelty", which may have been a mental barrier for her during the sessions where the use of animal skins was discussed (these were the sessions where she was most unfocused and emotional). She seems to have some level of difficulty expressing herself fully in language, often confusing or contradicting herself. The virtual field trips seemed to be the most eye opening for her, as her perception of communities seemed to change from beginning to end and this revelation opened the door for her to (presumably) tie together that the Middle East is a developed, civilized area and allowed her to not be surprised by the existence of modern/electronic music (as she stated herself).

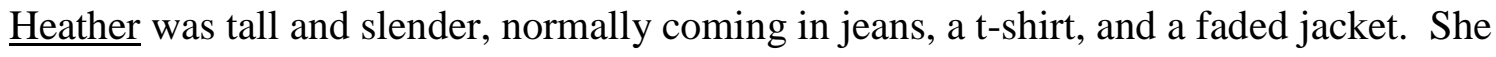
was shy, during the first session she did not say a word but was engaged with a demeanor that read as polite and respectful. During the drumming activities she had difficulty playing the rhythms correctly used a gentle touch that hardly created a sound [maybe her rhythm problems have been pointed out during music classes at school making her apprehensive].

Heather was absent during session 2.

Before session 3 started, Heather engaged in conversation with the others to an extent, but was pretty quiet and reserved as she had been during session 1. She was obviously engaged, always looking toward the researcher through each activity, but she did not offer many verbal comments during the session.

She started to open up for the first time during the research sessions when the wind instruments were being introduced during this session (potentially becoming more comfortable with the researcher). She said she thought the shehnai "looks like a flute," and commented that 
one of the other instruments in the video is seen on "Teen Titans Go!," which the researcher assumed to be a TV show. She described the song played in the shehnai demonstration video as sounding "like music from The Young and the Restless". While she still appeared interested and engaged while the other instruments were introduced, she did not offer any further comments.

She initially had some trouble figuring out how the virtual field trip worked, but was excited at the prospect of using the iPad. Very shortly after she got the app working she exclaimed "look at all these people!" (seemingly surprised that there were so many in the pictures. She then came upon a "Burger King," a point that she repeated 4 times and proved to be one of the most surprising things for all of the participants. She was the first to name one of the streets she was on, "Broadway," which led others to begin naming the streets they were on. This led to a group realization that many of the street names are ones they would recognize in English. During the wrap up discussion for this activity, she said "everything" in response to the question of what the participants were most surprised by.

She didn't offer any further verbal comments during the session, but seemed to enjoy the dance activity. She seemed to pick up on the movements relatively easily, and was smiling as the activity progressed and she gained more confidence in the movements.

Heather was more quiet during session 4 than she was in session 3 (perhaps because she did not feel as comfortable considering most of the participants were unable to focus and she caught onto that frustration).

She made her first comment during the virtual field trip to Israel, where she said there were "a bunch of people by the Dead Sea" which led other participants to try to locate it. Later shouting "This is a pretty view" but did not elaborate on what she was looking at. Her final 
comment during the virtual field trip was that "this is pretty awesome [being able to see different places]".

She joined most of the other participants in laying down while The Magic Apple was read. While she appeared to be attentive as the story was read, she only offered that she thought the story was "kind of like Snow White".

Heather also didn't make any verbal comments while learning the dance to Hoy Nergis. She had some difficulty catching onto the movements, particularly when trying to "mirror" what the researcher was showing. Her face was consistently that of focus, she appeared to be trying her best and continually improved and became more comfortable each time the dance segments repeated.

While she didn't contribute anything to the closing discussion about what was interesting or most surprising about the session's activities, she asked if they would be dancing during the next week. She asked this in a tone of excited anticipation instead of dread, solidifying for the researcher that she was enjoying the dancing activities even with the look of focus on her face throughout.

Heather was more vocal during in her engagement from the start of session 5, but still reserved. She was among the first to speak during the introduction to the session by recalling that they did "dancing" in the previous session, and contributed to the summary of The Magic Apple by stating "someone got a looking glass, a magic carpet, and an apple". She also noted that she would have expected that storyline from the Middle East.

While she did not say anything, she was listening intently to the reading of Joha Makes A Wish, while studying the illustrations carefully. 
She didn't contribute much to the discussion surrounding U.S. and Middle Eastern customs surrounding when children lose teeth, only to comment that "you get money" and note that she gets " $\$ 20$ " when she loses a tooth during a short discussion in which they compared what each of them gets for teeth.

She also didn't have a lot to say about Lealy Nahari, but did agree that "it sounds like they're in a computer," and she did not expect computerized music from the Middle East. She said the song "sounds like classical [mixed with] a little bit country". While she was always engaged, and didn't seem to have problems catching onto rhythms, she was very apprehensive about playing, always tapping the drum ever so gently when they had time to create their own rhythmic pattern to play along with the song. She didn't seem to be entirely comfortable with the idea of making her own rhythm, saying "I want to be last" when what order participants would go in for their solo was being discussed.

During the closing discussion for session 5, she noted the most surprising thing for the day was "the song" without any further explanation. She also was one of the ones who excitedly yelled "yeah!" when asked if the participants wanted to do the dance they had learned during the previous session.

Heather was absent during session 6, but completed the endpoint poll the following day. Since she was not present for the discussion following the endpoint poll, no information is available for her final reflections on how the various activities may have impacted her thoughts and perceptions.

Given her limited verbal interaction during the sessions, it's hard to pinpoint exactly how her perceptions may have evolved. She only directly commented on if anything was surprising or 
expected once, noting the storyline of The Magic Apple was expected from the Middle East. It seems through her increasing involvement and openness as the weeks passed that her comfort with the researcher, the content, the environment, and/or the activities increased over time. She seems to have a fair amount of insecurity and/or anxiety when it comes to playing instruments, so this may potentially have been a barrier that kept her from really digesting information and making connections. Though, she was excited to have the opportunity to dance again in session 5, and noted that the virtual field trip to Israel was "pretty awesome".

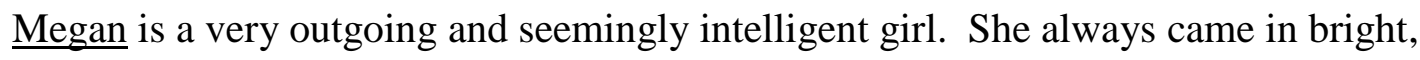
clean clothes and was one of two participants who often spoke first and the most. In the discussion following the initial poll she relayed that her mother often makes Middle Eastern food for the family expanding to say "it's a very interesting culture" [while not certain, this could show an understanding and appreciation within the family of people from other cultures]. Her comments during sessions were often very thorough with a rationale to explain her thoughts.

She stated that her vision of the Middle East had been shaped by school and movies. She explained that "I think a lot of times in movies sometimes [sic], that's all they see from this part of the world. Egypt and stuff like that, it looks old [in movies], so I guess we just kinda thought that all of it was just old," so she was surprised to see a "big city" in the introduction.

As the drums were being introduced and participants were asked if they had played African drums before she said "we went to the museum, and they let us [play them]," and expanded that "one time we went to Disney World, and they have a whole circle of them and people would come out and play [the drums]... it was so very interesting because it looks like the real thing". When participants were asked what they thought the drum heads were made of she replied "skins of some sort? They usually are". Another participant asked why they were made 
of skins she replied "because that's what they have available" and expanded with "certain countries they don't like to kill stuff unless it's already dead" when another participant commented that killing baby cows was mean (stillborn calf skin is a common drum head material) before that participant learned the definition of stillborn.

Megan described the sound of the riqq as "louder" than the western tambourine and not as "high pitched". As the jug drum was taken out of the box before the water experiment, her eyes grow wide and she let out an audible gasp with the rest of the participants. She exclaimed "you blow in it!" before the playing procedure was demonstrated. She hypothesized that the jug would "have a shorter sound" after the water was poured in the jug than it did before. She described the sound after water was poured into the jug as "not as echo-y" as it was when the jug was played before the water was put in. When the zils were pulled out she exclaimed "cymbals, those are mini cymbals!...are those, you put on your fingers?". She described their sound as "bells" and "less loud, and more high pitched" than our western finger cymbals.

As the playing technique for the drums was introduced, one participant suggested they be played with the base of the drum sitting on the floor. Megan replied that it would create "different sounds because it has no bottom, so it doesn't vibrate [when it's on the floor]". The participants were given the ceramic drums to play during this session and she described them as "tiny and cute". She continued to say that the researcher's drum was going to "obviously sound different than [hers] cuz [the researcher's] is bigger". She caught onto the rhythms fairly quickly and volunteered to play the rhythm on her own, only needing a reminder to cup her hand when making the dum sound.

During the closing discussion for session 1 she said she found it interesting "that you weren't allowed to use your left hand [except sanitary purposes]", and that "there are big cities". 
Megan did not seem to be as vocal in session 2 as she was in session 1, but she still showed active engagement and interest through her body language (eye contact with researcher, good posture, etc.). During the introductory discussion she noted that "most people think it's just dry and desert [in the Middle East], but there are still cities". She built on another participant's response of things being "different" by noting "they had to adapt to the environment differently, because they haven't been in that environment, so they do things differently [than we do]". She also mentioned she thought "they're kinda more festive and colorful in display and stuff, especially with roofs and decorations" in that they use different materials and colors than we often do in the U.S.. She also mentioned she remembered the discussion about not pointing the soles of your feet at people, or touching their heads. She agreed with most participants in that "the drums" were the most interesting thing from the previous session, and she was most surprised by "how modern everything is [compared to what she initially thought]".

She was one of the most engaged in discussion surrounding the string instruments. She was among the first to describe the top of the gopichand as "a tuner" and the tuners making them similar to "guitars" and "violins". She was the first to hypothesize that moving the sides of the gopichand would "make it sound like wavy" or "maybe it will sound even higher, maybe" as an alternative. She perked up and exclaimed "I knew it!...it's wavy!" after the researcher played it, in order to determine how it happened she asked "what is the sides made out of?". As the participants were taking turns making sounds on the gophicands she said "it's weird, that sounds so weird," she also tried to assist in calming the participant who broke the string while playing it by saying "you'll just get another styring...it's like a ukulele [in that the strings can be replaced]". As the ektars were introduced she explained to the other participants that it's different than a banjo because "it only has two strings," and she tried to confirm that the body 
would generally be made of pumpkin by asking "so, is that authentic?". When the researcher noted that gopichands and ektars are often played with chants, she tried to explain to the other participants what a chant was by saying "A chant is like a religious, it can be religious, and it just means they talk in rhythm" and used an example from Finding Nemo where "when they get Nemo to swim across the volcano thing [is an example of a chant]". After the ektar was played she said "I can imagine a chant going on [while it was being played]". She was first to say the spike fiddle "looks like a violin," saying it's similar to a violin because "you have the thing where you put...I forget what it's called [while she used her arms to mimic the action of putting rosin on a bow]". She inquired "is that little thing on the bottom to stand it?, it's like a cello". She noted during the discussion on how it does not have frets that she "has a ukulele at home...if I were to not have the frets I would not be able to play anything".

She was the most vocal (and thorough in responses) participant in a discussion with one participant who was very upset that animal skins are used on so many of the instruments. She said "animals were meant to be eaten and used...they kill them to eat, and they're very conservative". She continued by saying "because how else would you get the vitamins and minerals that they need? They don't have the protein that they need in all plants, and some of the plants are only found in certain areas. So they would have to get protein".

She could recall the details on how to play the two sounds they had learned on the drums the previous session, verbally and visually showing the other participants. When reviewing the rhythmic pattern she had no problem in quickly having success in accurately playing the pattern. She did note one time when she got off track but she "played with it until you were done with it, then I got back". She didn't say a whole lot about the drums when participants were asked to compare and contrast each type (this was just after the discussion on animals, so potentially she 
was worked up over that), but noted that the "metal ones are more modern looking" and that she thought they were "the highest of them all cuz of the material".

The group was asked what a folk song was and she was the first to respond by saying "It's like country and old songs... like the original". After listening to Katibim she responded "that was cool!". She described it by saying "I think it sounded really fast" and that "it sounded like they drew out the words [with long notes] that they had and it was really fast and upbeat" and that it "sounds interesting". Later she noted that "sometimes we do [have long notes and drawn out words]". She said "maybe it's religious" when the participants were asked what they thought it was about. She did not find the fact that there are love songs in the Middle East surprising, and said "Yes, it's overflowing" when asked if we have love songs in the U.S.. She thought it was "weird" that this song was a folk song in the Middle East, saying "'their folk [songs] sounds more modern, I think [than those in the U.S.]". While she was active and engaged, and seemingly enjoying playing the various instruments she did not have anything to say while they were accompanying the folk song and learning the various parts [maybe too focused on keeping the parts straight with so many rhythms going on at once].

During the closing discussion of session 2 she noted "I liked the song" as the most interesting thing of the day, making no further comment.

Megan was, again, not as vocal in session 3 as she was during session 1 and didn't offer thorough analyses of thoughts like she had in both the previous sessions. She was among the first to recall the folk song from session 2 being from "Turkey," though she could not recall the exact city it was about, and she was among two who remembered it being a "love song". She also pointed out that we had learned about some new instruments in session 2 . 
Megan was the second to identify that the new instruments for session 3 would be categorized in the "wind" family in the U.S.. During a discussion on double reeds the researcher asked if anyone had learned about the oboe before, Megan replied "yes, at my old school [in a different county] we had music class and we learned about the instruments". She said the shehnai "kind of looks like a clarinet," and was fascinated at double reed and how it is made and how it creates sound. She described the tablahs that were featured in the shehnai video as appearing "like pumpkins". She agreed with the other participants in their initial analysis that the shehnai "sounds weird," expanding later to say "it sounds like a foghorn". She said the song itself made her "feel like a snake" and she "never thought that word would come up". She was amazed at the instrumentalists in the video, saying "it must be really hard [for the shehnai player] to keep the breath," exclaiming "look at his fingers!" [referring to the tablah player], and that "it must take years to learn...it must take a lot of technique". She disagreed with another participant who said the players were just showing off by saying "he can just do it well".

She seemed to really enjoy the song used in the mizmar demonstration video. Shortly after it started she yelled "I love this!," expanding to say "it still sounds different, it sounds like a spy movie"

She described the sound of the duduk as "unrealistic, fantasy-like," adding that "it sounds like [the sound] would come from a much bigger instrument". When the oud began playing in the mizmar demonstration video she commented "now [the song] sounds more Mexican".

She joined most of the others in showing excitement when it was time to begin the virtual field trip by yelling "yeah!", but she didn't have as much to say throughout the activity as the researcher anticipated. The first thing she pointed out was "it shows women with those things [hijabs] on their head". She later mentioned seeing a "taxi," a "bus," "a new house being built 
or something," "random water bottles," and added to the conversation about identifiable street names by mentioning she was on "Kennedy Avenue," followed shortly after with "Diaz Avenue" at which she was surprised to be able to read signs. She joined the others in expressing disappointment that the activity was over by yelling "Noooo!" when participants were asked to put away the iPads. During the wrap-up discussion for the virtual field trip she mentioned she was surprised to see "a lot of stuff there was spelled in English," to see "people with the headcoverings," and "waterbottles [laying around]".

As the Israeli wedding dance was introduced, Megan mentioned "cake," "you dance," and giving "cards" as common U.S. wedding customs with the "electric slide" and "cupid shuffle" being common dances. She described the song as being "very high pitched," and noted that the lyrics "don't rhyme" after the translation was read. Her good sense of rhythm and coordination that showed during instrumental activities clearly translated to the dance. She perfected the moves quickly, saying "that was easy" after the first time going through it. She seemed to enjoy the dance, smiling and moving elegantly during the whole performance.

She didn't say a whole lot during the closing discussion for session 3, but she was quick to point out that it was surprising that "a lot of the signs were in English". She agreed with other participants in that she did not expect to see people dressed "kinda like us" particulary in "Adidas, like the shoe".

Megan had difficulty keeping on-task during session 4, and particularly had difficulty giving serious, insightful responses during the virtual field trip during this session - a much different personality than was seen in the previous sessions. As mentioned with the other participants, session 4 was a difficult session based on the fact that it was pajama day for the camp, and they were having a water day during recreation time after camp. All of the 
participants had difficulty maintaining focus, paying attention, and giving thoughtful responses; but Megan more than this others. The only time everyone was quiet for a fair amount of time was while the researcher was reading the folk tale, The Magic Apple, as part of the activities.

During the introductory discussion and review of the previous session, Megan only recalled seeing "a rainbow" during the virtual field trip to Turkey in the previous session. She did, however, engage in a conversation with another participant on whether that participant's sitting style would be appropriate based on the information they had learned about feet and posture in previous sessions.

She had the most difficulty focusing during the virtual field trip to Israel during this session. She found herself very distracted by phantom images, particularly "disembodied toes" and "disembodied feet" that occur during the image collection process when you have moving people and moving vehicles and the images don't line up when put together. She commented on seeing these numerous times during the session, and burst out into laughter that also distracted the other participants. When she was able to focus on other things she was seeing she noted being "by the sea," and "literally in the ocean". She was excited when she found a point where she could once again navigate the images like in the previous session instead of just panning one area. She was quite confused at one point when she was describing a spot that she was exploring that she was seeing a beach that was "like frozen" but that it was "not sand, though" but she couldn't determine what it was if it was not sand. She also described seeing what she thought was "an island in the sky," which was a hilltop with clouds around the base making it appear to float. During the wrap-up discussion for this activity she noted there "was a lot of beaches," "a lot of disembodied toes," "lots of stone [laying around and used on buildings]," and said she suspected the climate was "hot" based on the landscape. 
She joined most of the others in laying down as The Magic Apple was read. She was attentive and quiet during the reading, and was the first to respond with what the moral of the story was by saying “don’t be selfish”. Another participant suggested the story was like Snow White, Megan took it a different direction by saying it was "kind of like Snow White, but reversed because the apple saves her instead of killing her".

While Megan continued to have difficulty maintaining focus while learning the moves to Hoy Nergis, she did catch on quickly noting "it got easier now" when we switched from just hand movements to foot movements. After discussing the hand gestures that would go along with the dance she was one of the most vocal in wanting to do it with the hand motions, even after being told it would make it more difficult given how few people we had participating.

Megan did not offer any verbal comments during the closing discussion for day 4, which was unlike her during previous sessions. Likely she was too excited for water day that followed at the park to focus.

Megan was absent during sessions 5 and 6, but completed the endpoint poll the following day. Since she was not present for the discussion following the endpoint poll, no information is available for her final reflections on how the various activities may have impacted her thoughts and perceptions.

Megan came in with a pretty open mind about Middle Eastern people and culture, but did comment on several things throughout the sessions that were surprising to her and often had thorough responses for why people of the Middle East may have done things differently, or when she had a different opinion than another participant. She was surprised to see modern, developed cities in the virtual field trips, based on the picture that movies and the media often paint, and 
noted that she thought they were "more festive and colorful in display and stuff" than the U.S. She noted several surprising things during the virtual field trips including seeing a "taxi," a "bus," "a new house being built," "random water bottles," a number of signs that were written in English, and that people were dressed "kinda like us". She mentioned that she thought the folk song "sounds more modern" than those common in the U.S. (though, that may be purely due to the recording - though it is an older one at this point). She also built a connection to The Magic Apple by describing it as a "reverse Snow White".

Chloe was quiet, reserved, and very timid much of the time - particularly for the first few sessions. Though she seemed to always pay attention, she did not seem to want to make eye contact. When she did speak, her voice had a lisp with very child-like enunciation below the norm for her age (potentially a sign of speech/language difficulty in school and/or the home). She had poor posture, faded and worn jeans with a t-shirt and a jacket during most of the sessions, and greasy brown hair. She always brought part of her lunch with her to the sessions [which were after lunch], and started to point out the various food items she brought with her before the sessions began after the first week. The food was always a piece of fruit or something otherwise pre-packaged so it could easily make it home [potentially a sign of a lack of food in the home].

During the discussion following the initial poll she did not say anything out loud, but raised her hand in agreement with other participants that her vision of the Middle East was formed through TV and movies. During the jug drum experiment, she described the sound after water was introduced as "different" with no further explanation.

She seemed to have no sense of rhythm, having great difficulty with the pattern being taught in the first session. She was focused and attempting to make the rhythm, but with little 
success. It was during this period that she spoke the most [although off-topic] stating "I made a string instrument", and explained "you take a container and a few strings with a piece of wood, and it's like a guitar" when asked what kind of string instrument it was that she made.

She did not contribute any comments during the closing discussion of session 1.

Prior to the start of data collection on session 2, Chloe was engaged in discussions with other participants. She seemed more comfortable in the environment, but didn't say anything during the session. She was still timid, but, made a little more eye contact with the researcher. She played her instruments lightly and was not always accurate, but tried her best and got back on track with direction from the researcher. She smiled much of the time while playing instruments, and appeared happy to be able to switch to different instruments throughout the session (though, she got off track with each of them no matter the difficulty of the rhythm).

Chloe really came out of her shell in session 3, saying more than most of the other participants that are usually very vocal (perhaps because of increasing comfort with the researcher, and a feeling of safety and respect for opinions within the environment). It should be noted, however, that not all of her comments were directly (only semi-related) to the topic that was being discussed at each point.

During the opening discussion she was first to recall that one of the instruments we looked at during session 2 looked like a "violin or cello". During this time she also showed excitement over the prospect of watching videos during this session saying "I love videos!," and she placed herself very near the computer screen each time a video was played.

The first example of a semi-related comment was made as the wind instruments were being introduced. As the material they were made of was identified as wood she mentioned the 
fact that her "grandpa has bamboo trees" (though the researcher was happy she was feeling comfortable enough to start sharing). As double reeds were first explained, in reference to the shehnai, she commented that the "end [of the reed] looks like a " $\mathrm{v}$ ". The shehnai demonstration video included an oud player which Chloe said "looks like a guitar," as well as a tablah player which led her to inquire if they were "made of pumpkins" due to their shape. She said the shehnai sound was "weird" expanding to say "[it] sounds like a type of deer or something" then later "an elephant," or that it "sounds like it was Egyptian," or like a "cool elk". She was the first to point out people wearing "Adidas" in the video that was used.

She said she thought the mizmar "looks like a flute," and was excited to learn a demonstration video was going to be played for that instrument as well. She described the sound of the mizmar as "different" and the song as sounding like "running away in spy movies".

She seemed uncertain about what to think in regard to the duduk. She raised an eyebrow and said "Whaaaaat?" when it was brought out, and inquired further as to how the double reed works (it's much easier to see with the large reed the duduk uses). She described the sound of the duduk as like it was "from a scary movie".

Chloe joined in the excitement of the others when the virtual field trip was introduced. She had some difficulty navigating the iPad at first, but seemed to enjoy the activity once she got to the right place. She didn't comment a lot on what she was seeing as the activity went along, but did comment on seeing "people running in the street," "people with the thing [hijab] over their head," and seeing a "coffee place". During the wrap up discussion for the activity she said she was surprised by "everything," particularly noting the "people with the thing over their head". 
During the introduction to the Israeli wedding dance, Chloe agreed with other members when they said "kiss" and "dance songs" as common traditions at U.S. weddings. After listening to the song once she said it "sounds like a snake". She had difficulty with the movements for the dance, never quite getting them all correct by the end of the session, though she had a focused look on her face showing she was trying to get it right.

Chloe didn't offer any verbal comments during the closing discussion for session 3.

Chloe seemed to be the least distracted, and one of the most vocal, during session 4 when it came to on-topic comments. She was the first to comment during the introduction to the session recalling that they did "dancing" during the previous session. She also commented on seeing "Burger King" in the virtual field trip to Turkey before asking "are we gonna do it [virtual field trip] again? (expressing excitement and interest in that activity).

After getting assistance on how to spell Israel from the researcher, the first thing Chloe commented on during the virtual field trip for this session was that she "found people in the desert!" before she expressed confusion about where she was. Shortly after she exclaimed "I can move, yea! I'm in a desert" followed by "I found an ocean!" when she found a place that was navigable instead of just a 360 image. She was most excited when she said "I found people...I think I'm at the Grand Canyon!" before another participant told her that the Grand Canyon is on a different continent. Chloe pointed out seeing a "big building," and that she thought she "found Florida...it might not be but it looks like Florida [because of the palm trees]". During the wrapup discussion for the activity she noted seeing "palm trees" and "beaches... it looked like Florida!". She thought the climate must be "hot" because of the landscape and its similarity to Florida in certain places. 
She did not lay down to listen to The Magic Apple like the other participants did, but she was attentive and engaged. When the book was introduced she noted that she "has an apple" and that "the apple [in the book] is magic". After the reading was complete Chloe was the first to speak by saying "the father wanted them to get married", and responded "I want them both" to another participant who had stated the father wanted happiness and riches for his sons. Before other participants had chimed in, she said she did not think there were stories like The Magic Apple in the U.S..

Chloe didn't say a lot while learning the moves to Hoy Nergis, but showed excitement that the dance centered around a story of "marriage!". After the researcher explained that girls would be wearing skirts while this dance was performed, she commented "I don't like skirts". She never quite got the moves down, but, she gave it her best shot and was always engaged.

Chloe did not offer any verbal comments during the closing discussion for session 4.

Chloe continued coming out of her shell during session 5, certainly making comments more frequently than in the previous sessions. Her first comments were to contribute to the summarizing of The Magic Apple, by saying "he [the father] gave them an apple...a magic apple!" and adding to another participant's response about saving the princess by adding the detail about going "on the magic carpet" finishing with "and the little man, the little boy with the apple married the princess" (based on her comments throughout the sessions, she seems to enjoy romance and fairytales since she brightens up the most when those subjects come up).

She didn't make any comments while the new story, Joha Makes A Wish, was being read, but she was actively listening and engaged with the illustrations. 
During the discussion comparing Middle Eastern and U.S. customs surrounding when children lose teeth, she extended the conversation about how the teeth are put under pillows in the U.S. by saying "cuz you lose it and sometimes we often get close to 2 or 3 [teeth] and you get bigger stacks of money". This prompted a short discussion where the participants compared how much money they receive for each tooth. She agreed with other participants in that it was "different" than the custom in the U.S. before another participant expanded on that thought.

Chloe initially said that "she forgot" what the rhythm was that they had previously learned on the drums, but quickly recalled "tek" as one of the sounds after another participant remembered dum. She was extremely focused while trying to learn the new rhythm, but never quite perfected it. At one point she had a pained look on her face, prompting the researcher to ask if she was okay to which she replied "I'm confused" at which point the researcher changed methods to try to assist her in being successful. She described the interlude section of Lealy Nahary by saying it "sounds Asian," but mentioned she thought "the song was good" and she especially liked the introduction part by vocalizing the melodic line in that section. After the translation was read she gasped and whispered "a romantic date" reinforcing for the researcher that she enjoys those types of songs and stories.

Chloe didn't say anything during the closing discussion for session 5, but joined some of the other participants in yelling “yeah!" when participants were asked if they wanted to do the dance they had learned during session 4 before they left.

Chloe didn't say much during session 6, though she did state "mine's going to be different [answers]" as the endpoint poll was explained and they were informed it would contain the same questions as the first poll they took. She didn't contribute to the discussion where each question was analyzed to see if there was a change in the types of answers that each question 
received, but she did participate in the discussion surrounding another participant's suggestion that the folk tales centered around one small thing by offering examples from the Middle Eastern stories. When the participants were asked what was most surprising or interesting throughout the sessions she initially said "I don't know" and was told she could think about it and tell us if she thought of something later, she did later say "everything was surprising" but did not elaborate with specifics.

As previously mentioned, the participants unanimously decided to go on another virtual field trip and to play the drums before the end of the session. As the participants were getting their iPads ready Chloe asked if she could go to "Asia" before they were told they had to stick to somewhere in or around the Middle East. When another participant asked if they could go to Iraq she stated "that's where they have fights at...do they have wars there?" before stating "I want to go to Iran," then "Iraq," followed by "Georgia" before she asked where else she could go and the researcher suggested "Afghanistan". She was the most on-task during this activity noting that she saw "a wall," "powerlines," "cars and palm trees," "a medical clinic," a "playground," and "a bridge" at her various stops.

During the drumming portion of session 6, she was the first to request that they be taught a new sound to make on the drum. She was otherwise quiet and focused on creating ostinato patterns to go with the songs.

It took some time for Chloe to open up and participate in discussions. Particularly when she first started opening up, her comments didn't give much guidance as to where her thoughts were other than relating the materials of the instruments and the sounds they made to sounds and materials she was familiar with. The only time time she really expressed that something was surprising or unexpected to her was during the virtual field trips. During these sessions she 
noted that she was surprised by "everything" especially "people with the thing over their head [hijab]," also noting "Burger King," "a coffee place," and the resemblance to "Florida" at various times.

\section{Observer \& Site Supervisor Surveys}

Due to scheduling issues, surveys of the observer and the camp supervisor were conducted via e-mail, with follow-up questions not receiving responses by the time of this writing.

The observer was given a survey to get a second set of observations from the sessions. This observer was chosen because he was not a direct employee involved in the camp, but is an employee of the coordinating group that provides recreation time for the camp participants after

camp hours are finished. He was selected by default due to being the only one that was supposed to be available for each of the sessions. It should be noted that he was unexpectedly late on day 3, and absent for days $4 \& 5$. Due to this fact, his responses are not as meaningful as originally planned in the study design.

His responses were as follows:

1. How frequently did the students participate in other activities that involved different cultures throughout this camp (including literature, art, music, dance, etc.)?

They were in a different program than what I worked, so I'm not sure of the activities they did when they weren't at the playgrounds in the afternoon.

2. How in depth were the discussions surrounding those activities in regard to the other culture? 
N/A

3. What were some of the most interesting or notable things you witnessed (from the students) through the activities in the study?

I noticed how their opinions changed from before the program started.

4. Were there continued discussions about the activities after I left the classroom each week?

They would tell the kids at the park what they learned about.

5. If so, what were the nature of those discussions?

[No Response]

In order to get a better idea of the nature of the overall camp activities and how they may have corresponded to the activities in the research project, the camp supervisor was given a survey. He periodically peeked into the research sessions, but had significant time with the participants during the camp activities each day.

His responses were as follows:

1. How frequently did the students participate in other activities that involved different cultures throughout this camp (including literature, art, music, dance, etc.)?

Students participated daily in other multicultural activities. These interactions were primarily though works of children's literature. Some examples of multicultural texts that were read include: The Great Kapok Tree, Masai and I, and It Takes a Village. 
Additionally, students would complete art, writing, and drama activities involving those texts.

2. How in depth were the discussions surrounding those activities in regard to the other culture?

The nature of [the camp] is that of a reading program. Accordingly, when a multicultural book was chosen for the book of the day, the entire day's activities involved the story, and so the center of discussion for the day became multicultural.

3. What were some of the most interesting or notable things you witnessed (from the students) through the activities in the study?

The most notable aspect of the study that I observed was how interested and open minded the students were throughout the study. I will discuss this in more in the next few questions.

4. Were there continued discussions about the activities after I left the classroom each week?

Yes, every week and even after the program ended.

5. If so, what were the nature of those discussions?

The students were very eager to share with me what they had learned. They wanted to play music for me, discuss what they read, and describe the virtual field trips they went on. Those students who attend [my school] were excited to share what they learned with their classmates when school started for the fall. They showed them the instruments, how 
to play them, and told them were they were from. I let two of the students lead the class in one of the activities they learned during the summer study. 


\section{Chapter 5}

\section{$\underline{\text { Analysis }}$}

Now that the data related to each activity have been described, giving a more detailed portrait of the participant reactions and researcher observations for each type of activity, the data sources are combined to answer the research questions (Table 1).

Table 1

Data Used to Answer Research Questions

\begin{tabular}{|l|l|}
\hline \multicolumn{1}{|c|}{ Question } & \multicolumn{1}{|c|}{ Data Used } \\
\hline $\begin{array}{l}\text { Question 1: What impact, if any, does student } \\
\text { activity in Middle Eastern customs have on } \\
\text { the students' ideas or beliefs about the region } \\
\text { and people? }\end{array}$ & $\begin{array}{l}\text { Anonymous poll questions 1, 2, 3, \& 5; audio } \\
\text { recordings/transcripts; field notes. }\end{array}$ \\
\hline $\begin{array}{l}\text { Question 2: What impact, if any, do virtual } \\
\text { field trips to the Middle East have on } \\
\text { students' ideas or beliefs about the region and } \\
\text { people? }\end{array}$ & $\begin{array}{l}\text { Anonymous poll questions 1, 2, 3, \& 5; audio } \\
\text { recordings/transcripts; field notes. }\end{array}$ \\
\hline $\begin{array}{l}\text { Question 3: Is there a notable overall shift in } \\
\text { opinions about people of Middle Eastern } \\
\text { origin, or the region itself after participation } \\
\text { in the aesthetic experiences and discussions? }\end{array}$ & $\begin{array}{l}\text { Anonymous poll questions 1-5; audio } \\
\text { recordings/transcripts, observer/supervisor } \\
\text { surveys; field notes. }\end{array}$ \\
\hline
\end{tabular}

The researcher repeatedly listened to the students' ideas expressed during their participation in this study, repeatedly examined the transcripts of the discussions, repeatedly examined his field notes, written observations and student portraits. These data sources provided a rich and descriptive picture of how the student participants reacted to the Middle Eastern lesson activities throughout the 5 weeks of the study. Full portraits of the student participants combined with the field notes, poll input, observational notes, transcripts and audio recordings informed 
this research about students' perceptions of Middle Eastern cultures during participant in a 5 week study of these cultures incorporating music, dance, and virtual field trips.

\section{$\underline{\text { Research Question } 1}$}

What impact, if any, does student activity in traditional Middle Eastern customs have on the students' ideas or beliefs about the region and people?

Once the descriptive data from all sources had been examined, it seems to paint the portrait of elementary students who exhibited shifting reactions to Middle Eastern cultures while participating in the 5 weeks of lesson activities related to these cultures. There appears to be a shift in the overall tone of the responses. The initial survey data included "war" as the one word they think of when they think of the Middle East in question 1 it was absent in the endpoint interview. Initially, students provided more superficial comments about Middle Eastern cultures including ideas such as "food," "different," "countreys [sic]," and "cool". Word choices provided by the students after participating in the lesson activities were more about the categories they had found interesting throughout each session including "clothes," "unique," "culture," and "colorful" with the only carryover being "different". Before participating in the lesson activities, students described their thoughts surrounding Middle Eastern music as "classic," "fast upbeat drums," "It is difrit [sic]," and "It well sound dirferent from ourhers [sic]". Once students had participated in the lesson activities, they included increased knowledge of content and emotional reactions to what they had experienced describing "Drumming music," "Love songs," "Kind,of,ashun, and,different,songs [sic]," "fast. Upbeat," and "Different. Cool. Unique".

At the outset of the study, students were very similar in their reactions to the Middle Eastern cultural stories by describing them as "Very different". Once students had participated in 
the music, dance, storytelling, and virtual field trips during the study lesson activities, they were similar in their descriptions that our stories and theirs are "similar".

Upon starting the study, all the student participants reported that they didn't believe they shared a lot of common interests, ideals, and thoughts with people in Middle Eastern cultures. It is notable that a couple of the participants during the ending discussion noted that they thought people in Middle Eastern cultures were similar to them in some ways, for instance, "because they don't want their children to get hurt, like we do" and that "They may do things differently, but they have similar goals as us". The descriptive data yields student reactions that provide a thorough explanation for cultural differences such as an explanation that "they are exposed to different things, so they adapt differently [than us]".

The data collected through the cultural highlight discussions, musical, and folk tale portions of the sessions are most applicable to this specific question. Notable observations by participants of things they didn't expect during the cultural highlight activities included musicians wearing "modern clothing" in the video examples (Adidas, jeans, t-shirts); participants noted similarities between what we do when children lose teeth and what they do wrapping it in cotton before throwing it into a garden or body of water for good luck - noting it was "a different way, but kind of similar" and "kinda similar cuz they're wrapping it in cotton and keeping it safe" and "getting money is kind of good luck".

Participants were surprised by the content and sound of some of the musical examples used during the sessions. Overall, they found the music to be "cool," and "interesting," with an overall favorable sound. They discussed how the music was "more fast," "a lot higher," and "different than expected". One participant found the mixture of instruments and the way they make their music "kind of amazing". Participants were particularly surprised by the Israeli Pop 
sound, and that it sounded "like music I would listen to" and "like an American song". Though they did note that they weren't surprised that there were songs centered around love in the Middle East.

Within the folk tales, participants were surprised to find similar morals, characters and personal aims depicted. The storylines were described as "unique...in a good way," and not expected from stories originating from the Middle East. The storyline of one book was described by participants as a "reverse Snow White," with the father in the story wanting "happiness for the sons".

\section{$\underline{\text { Research Question } 2}$}

What impact, if any, do virtual field trips to the Middle East have on students' ideas or beliefs about the region and people?

Once the descriptive data from all sources had been examined, it seems to paint the portrait of elementary students who exhibited shifting reactions to Middle Eastern cultures while participating in the 5 weeks of lesson activities related to these cultures. There appears to be a shift in the overall tone of the responses. Participants exhibited a shift of the language used to describe their thoughts on houses and the communities in the Middle East. Participants mostly used housing descriptions like those we would find in undeveloped countries, or in our own history books. Descriptions included "Mudhouses," "Small tent like structures," "tie pies [sic] triangle shape," "belong difrit [sic]," and "veliges [sic] and small houses". Endpoint data descriptions were more consistent our own communities, describing them as "cities and villages," "Pretty similar to what we have in America," "Townhouses. Apartments," with the two 
students describing them as "a little bit different" and "Old,houses, and, like,a,city,but,looks,beat,up [sic]".

Throughout the virtual field trips participants frequently pointed out things they did not expect to see in the Middle East. These included people driving "the same cars we do," "street vendors," "Burger King," a "coffee place," many signs “spelled in English," "people dressed like us," "streets" that look like ours, "parking lots," and noted that they weren't surprised by the tall buildings due to their introduction during day 1. Elementary students who participated in the lesson activities incorporating Middle Eastern music, dance, stories, and virtual field trips exhibited a changing description of their perceptions of many different aspects of Middle Eastern culture from the beginning to the end of the 5 week study.

\section{$\underline{\text { Research Question } 3}$}

Is there a notable overall shift in opinions about people of Middle Eastern origin, or the region itself after participation in the aesthetic experiences and discussions?

Once the descriptive data from all sources had been examined, it seems to paint the portrait of elementary students who exhibited shifting reactions to Middle Eastern cultures while participating in the 5 weeks of lesson activities related to these cultures. There appears to be a shift in the overall tone of the responses. Descriptive data indicate that there does seem to be a change in the students' descriptions of their perceptions of many different aspects of Middle Eastern culture, with more positive language included at the end of the lesson activities. This change is also noted by the observer in his response that "I noticed how their opinions changed from before the program started". 
This change is also noted in the camp supervisor's responses discussing how "interested and open minded the students were throughout the study" and that the participants were "very eager to share with me what they had learned" and to "share what they learned with their classmates when school started for the fall". When the descriptive data was examined, it became evident that there was a lot more that the participants were surprised by or was unexpected than was expected from the beginning. Items that participants noted as "unexpected" largely had to do with how people live in the Middle East noting the mixtures of "types of people," seeing "people dressed like us," and the fact that there were "cities and all that kind of stuff", and the participants “didn't think they were as developed as they are," as was discovered through the virtual field trips and musical videos. The similar storylines of folk tales, and traditional customs like what they do when children lose their teeth were also found to be surprising to the participants. Students participating in the 5 weeks of lesson activities incorporating Middle Eastern music, dance, songs, stories, and virtual field trips exhibited more positive descriptions of their perceptions of Middle Eastern culture.

\section{Contextualization}

An in-depth description of Narrow Hollow Elementary School and its surrounding community is necessary to get a larger, more detailed picture of the study and the societal influences that came into play.

Narrow Hollow Elementary School is located in the southern portion of Sunrise County, WV, which is located in north-central West Virginia. As previously described Sunrise County, WV, had a population of 69,099 during the 2010 Census of which $96 \%$ were white (U.S. Census Bureau, 2010), with a median household income of $\$ 43,987$ (U.S. Census Bureau, 2014), and 16.7\% of individuals living below the poverty level. Narrow Hollow, WV, during the 2010 
Census had a population of 496 people (Census, 2010), of which $95.8 \%$ were white, with a median household income of $\$ 53,250$ (Census, 2014), with $8.7 \%$ of individuals living below the poverty level.

During the 2016 U.S. Presidential Primary $77.05 \%$ of Republican votes in Sunrise County went to Donald Trump with Ted Cruz coming in second with $8.54 \%$ (West Virginia Secretary of State, 2016a). Bernie Sanders received 49.09\% of Democratic votes for Sunshine County in the Presidential Primary, with Hillary Clinton receiving 38.27\% of the votes (West Virginia Secretary of State, 2016a). Donald Trump received $67.06 \%$ of the votes in the General Election, with Hillary Clinton receiving $27.52 \%$ of the votes (West Virginia Secretary of State, 2016).

Narrow Hollow, WV is a rural town not far off the interstate, about 15 minutes south of the closest developed retail area (grocery stores, shopping, restaurants). While driving through Narrow Hollow, you pass a number of seemingly abandoned structures in various states of disrepair, overgrown empty lots, a single gas station that has a small children's recreation area behind it, and no stop lights to be seen. The area surrounding the school has several narrow streets that lay closely together. Lived-in homes are primarily older mobile homes or early $20^{\text {th }}$ century constructions with a number of boarded up windows, mismatched patchwork siding and boards presumably covering damage, as well as mismatched home additions that appear to be self-constructed.

Narrow Hollow Elementary School was originally built as Narrow Hollow High School in the early $20^{\text {th }}$ century. It is located on top of a hill, with a single-lane drive leading to the rear of the building where the employee parking lot is located. Students are dropped off at the bottom of the hill and have to walk up a long, uneven, windy staircase that is in various states of 
disrepair to the front entrance. The building has a very unique layout inside, consisting of a central area that houses the combined music room/library that is separated from the combined teachers work room/stage area by an accordion style wall on the upper level with the gym located underneath these areas on the lower level. Around these features is a series of multilevel staircases. On each landing area of the side staircases is the doorway into 1-2 classrooms.

The majority of students were dropped off to the camp by parents driving older model vehicles. Most parents fit the stereotype outsiders have of WV residents - primarily overweight, seemingly blue-collar workers wearing dirty t-shirts, worn jeans, and ball-caps. The exceptions being one student who was dropped off by his professionally dressed aunt in a newer car, and one student dropped off by her professionally dressed mother in a newer car. It was observed during the sign-in process (when the information about this study was also given) that several of the parents, primarily fathers, did not know how to spell their child's name as well as what grade they were in.

The activities for this study were conducted in the combined library/music room. This room has a wall of bookcases on either side of the room, a bookcase along the rear exterior wall, and bookcases creating a " $U$ " on the front left of the room, 6 circular tables, a desk along the accordion wall, and an old-fashioned green chalkboard on a rolling easel. An LCD projector is situated on a cart that the classroom teacher projects on the wall above one of the tall bookcases. The room was cluttered with boxes and miscellaneous materials as it was the preparation area for the camp instructors. 


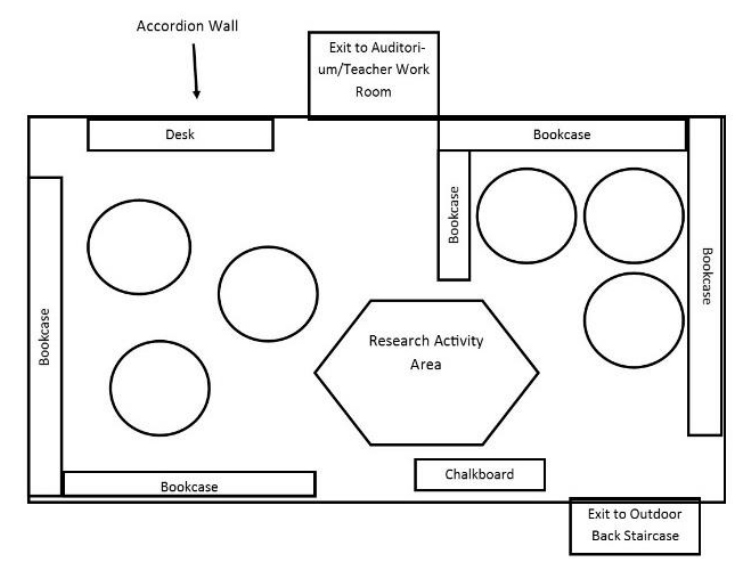

Figure 11: Narrow Hollow Elementary School Library/Music Room Diagram

Initially, it was difficult to get in touch with the right administrative leaders of the cooperating state-run summer camp. Initial contact was attempted with the county coordinator through e-mail. After not receiving a reply for several weeks, the researcher was given contact information for the state-level director who quickly came on board and scheduled a meeting between himself, the county coordinator for Sunrise County, the state-level camp curriculum director, and the researcher to discuss the needs of the study.

The idea surrounding this research project received enthusiasm from everyone present in the initial meeting, with everyone in agreement that the topic is timely and important. It was acknowledged, however, that parent buy-in may be difficult considering the demographics that the camp serves. The Sunshine County camp functions in two parts each day. Before lunch, participants are led through the state-approved curricula that is intended to maintain or increase reading levels through summer break. After lunch participants are given recreation time until their parents pick them up at $5 \mathrm{pm}$. After discussing the needs for the study it was decided the lessons for the study would be delivered to those participants who returned consent and assent 
forms after lunch, and then would join the others at recreation time after the lessons were finished. A specific site was also suggested based on the site supervisor's background in music, which also happened to be a new site for the year. The site supervisor turned out to be a gentleman that student taught under the researcher; which was somewhat troublesome as there were a number of issues during that time in regard to planning, leadership, and classroom management. It was also agreed that one of their employees would serve as the lesson observer. In order to facilitate the distribution of parent consent and participant assent forms, and allow questions to be answered for the parents the state-level director and county supervisor said they would plan a game night that would also function as a meet and greet where I would come in and discuss the research project and be available to answer questions and address concerns. Signatures were then obtained from the state-level director, county supervisor, and the Superintendent of Sunshine County Schools since the study would be conducted on school property. The IRB protocol was then created and submitted for review and approval.

Initial enthusiasm and reliable communication waned, however, as the IRB process progressed and the time to begin the study drew near. It became evident that there were communication breakdowns between the various levels. The curriculum coordinator and county supervisor stopped responding to calls and messages left with secretaries, as well as e-mails concerning the project - particularly the meet and greet/game night they originally said they would plan. A call was made to the state-level director, who relayed he understood the curriculum coordinator and county supervisor were working with the site supervisor to plan it. The curriculum coordinator made a call to the researcher to relay that further communication should go through the site supervisor as he had all of the information. 
Contact was made with the site supervisor, who was aware that my project would be taking place but had no details in regard to the needs of the study. By this time it was the week before the camp was to begin, and there was no time to put together the meet and greet/game night as promised. The county coordinator suggested the best way for the researcher to get the information out was to meet the parents when they dropped the kids off the first day. With the site supervisor's input it was decided Wednesday from 12:30-1:30 would be the best time to conduct the research each week, so the researcher would need to distribute the consent/assent forms on the first Monday and collect the forms and begin the research on Wednesday.

Upon arriving at the site early on the first day of the camp, it was clear that the site supervisor had not improved in the way of leadership from his time during student teaching. The researcher walked in to find volunteers wandering around not sure where to go or what to do, with the supervisor walking around aimlessly with the volunteers asking the researcher where they should go or what they should do. The researcher was able to pause the supervisor to ask when the kids would arrive, and where sign in would take place, to which he said they should arrive at $8 \mathrm{am}$ and be dropped off at the bottom of the hill to sign in with other employees. The researcher wandered around the building to try to find the other employees who would be signing the kids in. Inside the gym there were a couple employees and kids already waiting for the day to start. The employees what the sign in process was so as to best try put together the plan for talking with parents, to which they said they didn't know and were waiting for directions.

Eventually, the researcher made his way down the stairs to the bottom of the hill to wait for parents to begin drop-offs. The first kids arrived before the employees walked down with the sign-in books. During drop-off time some parents dropped their kids off in the parking lot across 
the street, some while stopped in the street at the bottom of the hill, and others on the side street that runs behind the building. Some got out of their cars, some did not. Some had multiple kids, some only one. With this setup there was only opportunity to spend a couple seconds maximum with each parent in order to ask what grade their child was in to determine eligibility and then tell them about the project. The parents were given a short talk on the researcher and were informed that after they had a chance to read the information letter they could contact the researcher with any questions, and return the forms signed the following Wednesday if their child was allowed to participate. When signing kids in, some parents had to have their children sign the papers for them as they didn't know how to spell and/or write the child's name, these same parents and a few more also didn't know what grade their child was in. In all, 25 consent and assent forms were distributed for the eligible students.

On the first day of data collection the researcher arrived to find that 5 eligible participants had returned consent and assent forms. The county supervisor and state curriculum coordinator apologized for the low number, expressing they wished they could have gotten more participation but knew it would be an uphill battle given the topic and demographic of the community we were in. They relayed that they had received a number of complaints from parents that this subject was allowed to be addressed, but did not give direct quotes or reasons that were given. The researcher requested that if any more came forward that they direct them to him directly, as he had hoped those complaints would be directed to him anyway as asked in the informational letter so questions could be answered, and he would have the direct information about complaints for my write-up. The observer was also assigned at this time, by default. Due to staffing issues there was only one person who was going to be at that site every day, every 
week. The researcher explained the project to him and allowed him to read the informational letter, he agreed to serve as the observer and signed the consent form.

Communication issues continued during various periods of the study. The observer was late on day 3 because he "forgot" about where he needed to be, though, before he arrived the students were on better behavior than they had been in the previous sessions and then they were after he arrived. The researcher wonders if this has something to do with him normally having playground duty so they associate him with "play time". On day 4 the researcher arrived to find that the observer had decided to go on vacation. They planned for a last-minute stand-in observer whom also read and signed the consent form. She relayed the original observer "is bored and hates his job in general", which was a red flag for me as to the quality of the reflection that would be received from him following the completion of the study. On day 5 the researcher received a text from the site supervisor saying they needed to move my time so the Superintendent of Schools could read to the kids, but they were also going to the pool right after lunch so it needed to be early. It was agreed that the session would go from 11:00-12:00 so the session could still go its normal hour and the participants be on time for lunch. The researcher arrived at the site to set up and found the Superintendent was late, so the research session didn't get to start until about 11:20. The participants were also more rambunctious, and less open to talking than they were previously - likely given the fact they were going to the pool and any excitement like that for elementary students fosters that type of behavior. While we were waiting on the Superintendent to begin the site supervisor relayed that they decided to cut the program a week short to save money, so I couldn't finish the following week. The researcher was supposed to leave town for the weekend the following morning, but moved his plans so the last session could take place the following day to gather the endpoint data and do the final 
activities. A couple students were absent on various days, as is expected with kids this age over a period of time; unfortunately two of them were absent on the final day of data collection. Their responses were recorded in the final poll under the supervision of the site supervisor, unknown to me until after it was completed. Their final responses are included in the data for the study, but naturally could not participate in the discussion following the final poll to gather more detailed information about their responses and thoughts.

Following the completion of the study, the researcher had planned to do a follow-up interview with the observer to gather observations from another perspective. Given the fact that the researcher desired information on the other activities they were doing throughout the camp, it was also decided to interview the site coordinator who was overseeing all that work. Neither were available for formal surveys, so an e-mail was sent with the questions to each of them. A month went by with no reply, even with reminder e-mails. Given the importance of this information to the write-up, an e-mail was sent to the county coordinator who quickly replied and asked that the messages be sent again with him copied so he could make them sit down and reply. This method was successful in getting responses, but follow-up questions for more information were not answered after the initial response.

\section{$\underline{\text { Discussion }}$}

This study aimed fill a gap within previous literature that does little to explore student perceptions and understandings of the Middle East and its people. This study was designed to explore how the combination of musical and cultural activities from the Middle East, as well as virtual field trips to the region begin to break down some of the prejudice against people of Middle Eastern heritage. 
The study followed the guidance of previous researchers, as it was built using an interdisciplinary approach to give participants deeper understanding that music and dance alone would not allow (Banks, 1988). It aimed to bring to focus the common characteristics of our cultures by retaining the values of cultures through class activities, while empowering the students to construct common themes and connections (Banks, 1988; Cantarelli Vita, 2016; Janzen, 1994; Pizzillo, 1983; Tiedt \& Tied, 1990) to assist the students to "not only develop appreciation for the perspectives of others, but sustain a value-tolerant acceptance of diverse cultural understandings, belief systems, customs and (perhaps) sociopolitical traditions" (Janzen, 1994, p.10).

The qualitative research approach used in the study, along with the researcher being a participant-observer allowed greater insight into the thought processes of the participants throughout the research period from beginning to end. The ethnographical approach was necessary for the researcher to "describe and provide interpretations about the culture of a group or system" (Hays \& Singh, 2012, p.60).

The data proved consistent with Banks (1998) in concluding that participant understandings of the Middle East is, overall, positively impacted through participation in the combination of musical and cultural activities and virtual field trips that center around the region, as well as other researchers who find that properly designed multicultural education can positively impact student perceptions of “the other” (Aboud, 2003; Cristol \& Gimbert, 2008; Katz, 2003; Vietz \& Hildebrandt, 2009). If you take each category within the data matrix alone, you would still notice a change in participant thoughts on the Middle East and its people to varying degrees. However, taken as a whole participants had a more holistic change in thought patterns that one type of activity alone could not provide. 


\section{$\underline{\text { Barriers }}$}

In developing a study that was focused on aiming to increase understanding of a group of people who are widely misjudged and frequently the receivers of unwarranted acts of prejudice, I knew it would likely be an uphill battle. This proved to be the case given the limited number of participants who were allowed to return their signed consent and assent forms. Complicating this matter further was a number of communication breakdowns that occurred throughout the planning, permissions, and implementation process at all levels that made it difficult - and often impossible - to carry out the study as originally planned from participant recruitment to final data collection.

I was unable to distribute information about the study in the manner that was originally planned between myself and the state and county leadership given communication breakdowns. For this reason, I had limited contact time with each guardian to explain the project. While the information sent home with the guardians had a thorough explanation letter and my personal contact information, I did not receive any calls with questions or concerns, and only had 5 consent and assent forms returned (out of 25 distributed). While guardians were instructed in the letter to contact the researcher with questions or concerns, it was not until arriving at the site on the first day of data collection that I learned that the camp supervisor, as well as the county coordinators, received a number of complaints that children were allowed to be presented lessons

of this nature. Another factor that may have played into this was the fact that some of the guardians were observed as not being able to read or write while signing in their children to the camp, and some didn't know what grade(s) their child(ren) were in.

A factor that may have played into the data collection include inconsistency of the schedule. What was supposed to be a 6-week camp unexpectedly turned into a 5-week camp, 
which required sessions 5 and 6 to be on days right next to each other. There were also some last minute camp schedule changes and special activities that required time changes, and some shortened sessions. As is normal with this age group, the participants were particularly hard to keep focused on those days with the extra excitement of their normal routine being disrupted which did result in less substantial data being collected on those days.

The gentleman chosen to be the observer was selected by his employer solely on the basis that he was the only person that was supposed to be there every day due to county-wide staffing issues. This observer ended up being late for one session (due to a last minute schedule change), and absent for two full sessions. He did observe the first and last session so he was able to see where their thoughts began and ended, but he had some limitation of knowledge on the process between.

\section{Implications}

The findings of this study further solidified the value of cross-curricular, cross-cultural learning units in providing students with a better understanding of peoples that are different from themselves as discussed by Banks (1988). Even with two of the participants not being completely shut out from Middle Eastern culture (one being a military child whose parents talk about their time there, and the other whose mother makes Middle Eastern food frequently), the participants discovered a number of things they did not expect through the activities.

The virtual field trips proved to be the activity that created the most discussion between participants. I suspect this is because participating in musical activities and reading books is fairly commonplace in schools today, and likely the largest portion of their "multicultural education". While virtual field trips are not hard to coordinate in a modern classroom, they are 
likely less common. This activity provided a novelty for the students, and also gave them a different perspective about the Middle East. Yes, it is important and interesting to listen to music from a region, play the instruments, and read their stories. However, allowing students to "walk" the streets of the region, see the people on the streets, view the landscape, and explore their communities takes it to a whole new level by allowing students to interact with the interface and establish relationships between location, culture, and events (Adam \& Mowers, 2010; Cook, et al, 2016; Davinroy \& Williams, 2015). I imagine it takes the learning from more of a "theoretical" perspective to a more "real" perspective by allowing them to see with their own eyes. You could sense the interest in the students given the fact that they had already been playing and dancing with music that was originally from these areas of the world. It gave them a sense of purpose, almost a grounding to build on while they toured the areas virtually.

\section{Limitations and Future Research}

This study provided insight into how the combination of musical \& cultural activities, folk tales, and virtual field trips enhance student understanding of the Middle East. While the design and findings provide a good starting point, future work could be helpful in understanding the impacts of these activities on a larger scale individually, as well as centering on other cultures.

In regard to transferability, qualitative research findings are largely context-bound (Moffa, 2016). This study was focused on students in a rural community with a predominantly low socio-economic population, and had a small sample size. While the results should be transferable to other rural areas with similar demographics as the one this study was conducted in, the results are not generalizable. The findings of the study could be further solidified with replication in various settings, particularly if larger sample sizes could be acquired. 
It should be pointed out, as is found in the survey response by the camp supervisor, the participants did participate in other multicultural activities and discussions during the normal camp sessions. Given that the researcher was not present during those lessons, and follow-up questions sent to the camp supervisor did not receive responses, the nature of those discussions and how they may have impacted this study are not known.

Future researchers should consider using a different introduction to the study following the initial data poll. While the introduction used in this study was effective in breaking down their preconceived ideas of what communities and houses look like in the Middle East, it was almost too much too soon. Meaning, they were handed these photographs of various prominent places (Dubai, pyramids, etc.), and didn't have to rely on the virtual field trips and self-discovery to make those connections. However, it should be noted that other connections were made through the insights the students had during the virtual field trips, so it may have also been helpful that the initial "a-ha" moment had already occurred so they could focus on the other things they were seeing.

If participants are allowed to explore places of personal interest during the virtual field trip in the last session, it might be helpful for future researchers to create some guidelines for things participants might find during their adventures. While there is value in self-exploration, it may have been helpful if the participants had some sort of "scavenger hunt" type activity that was generic enough to be applicable to most environments they were viewing to help keep their attention focused to discovery and reflection.

Future researchers may also benefit from doing data collection through a program with fewer levels of authority to limit communication breakdowns between the channels. This was one of the biggest headaches throughout this process. Planning and implementation discussions 
throughout this study would take place between the researcher and state and county level leadership sometimes synchronously, and others asynchronously with the camp supervisor coming in toward the end of the planning stages. Frequently, when communication was asynchronous there was a disconnect between the various channels. Consistently, there were breakdowns between the county level leadership and the camp supervisor, as well as between all levels of leadership and myself when there were changes to the camp schedule that impacted the schedule of the study. These breakdowns led to frequent last minute changes to the original plan and two unexpectedly shortened sessions. Future researchers may want to seek out a site or program that would have more consistency in scheduling and activities to avoid the schedule changes, and natural participant attentiveness issues at this age when there are changes in their normal routine.

Future researchers would also benefit from being able to identify responsible observer(s) on their own in order to be their second set of eyes for the study. The observer and camp supervisor for this study were given by default, and weren't very reliable with getting back survey questions in a timely manner - even with multiple attempts over several weeks. Followup questions were sent seeking further explanation based on the initial responses, but not received within the time needed to prepare this document.

Ensuring this study is planned and implemented with an initial parent and student meeting to hand out consent/assent forms would likely be very beneficial to aid in a larger sample size. This was in the original study design, but due to the communication breakdowns didn’t end up happening in the end. What was planned as a well-organized informational meeting, turned into flagging down parents dropping off their children on two streets and in one parking lot. This led to a rushed explanation of the project, and little to not time to have a 
discussion with the parents to answer questions and quell any fears. Particularly with projects that center around controversial topics like this one, that discussion and explanation are likely necessary in order to silence any unwarranted assumptions the guardians may have had.

Organizing an occasion to talk to the parents of the participants on one or two occasions may be helpful in gathering information about why the parents allowed their child to participate and if and why they thought it was an important subject for their children. This may also allow a deeper look into the background knowledge and understanding of the student in relation to cultural differences and understanding. If these discussions happen toward the end of the research period, the researcher may also be able to get deeper insight into any potential evolution of perceptions that the participants had throughout the research period based on discussions that were held at home outside of the research sessions. 


\section{References}

Aboud, F. E. (2003). The formation of in-group favoritism and out-group prejudice in young children: Are they distinct attitudes? Developmental Psychology, 39(1), 48-60.

Adam, A., \& Mowers, H. (2007). Got the world on a screen: Google Earth serves up more than a geography lesson. School Library Journal, 53(4), 40-42.

Adamy, J. \& Overberg, P. (2015). Census Bureau weighs Mideast category. The Wall Street Journal. Retrieved from: https://www.wsj.com/articles/census-bureau-weighs-mideastcategory-1450483703

Agid, S., \& Rand, E. (2007). Teaching beyond “tolerance". Radical Teacher, 80, 2-5.

Ajjawi, R., \& Tai, J. (2016). Undertaking and reporting qualitative research. The Clinical Teacher, 13, 175-182.

Amankwaa, L. (2016). Creating protocols for trustworthiness in qualitative research. Journal of Cultural Diversity, 23(3), 121-127.

American Psychological Association. (2008). Report of the APA task force on the implementation of the multicultural guidelines. Retrieved from: https://www.apa.org/about/policy/multicultural-report.pdf

Arab American Institute. (2014). Demographics. Retrieved from: http://www.aaiusa.org/demographics

Armstrong, N., \& Tinker, C. (2008). From the outside looking in: How an awareness of difference can benefit the qualitative research process. The Qualitative Report, 13(1), 5360. 
Axtell, R. E. (1998). Gestures: The Do's and Taboos of Body Language Around the World. New York: John Wiley \& Sons, Inc.

Baer, A. L., \& Glasgow, J. N.(2010). Negotiating understanding through the young adult literature of Muslim cultures. Journal of Adolescent \& Adult Literacy, 54(1), 23-32.

Banks, J. (1988). Multiethnic education: Theory and practice. Boston: Allyn and Bacon.

Banks, J.A. (1993). Multicultural education: Historical development, dimensions, and practice. Review of Research in Education, 19, 3-49.

Banks, J.A. (2006). Improving race relations in schools: From theory and research to practice. Journal of Social Issues, 62(3), 607-614.

Banks, J.A. (2013). The construction and historical development of multicultural education, 1962-2012. Theory into Practice, 52, 73-82.

Bar-Tal, D. (1996). Development of social categories and stereotypes in early childhood: The case of "The Arab" concept formation, stereotype and attitudes by Jewish children in Israel. International Journal of Intercultural Relations, 20(3/4), 341-370.

Bartolome, S. J. (2013). The virtual field experience: An immersive approach toward multicultural music education. Kodaly Envoy, 39(2), 14-18.

Belt, D. D. (2016). Anti-Islam discourse in the United States in the decade after 9/11: The role of social conservatives and cultural politics. Journal of Ecumenical Studies, 51(2), 210-223.

Bennett, C. (2001). Genres of research in multicultural education. Review of Educational Research, 71(2), 171-217. 
Bhatia, K., Premadasa, K, \& Wijetunge, T. (2016). Using cellphones as virtual clickers in a mathematics classroom. The Electronic Journal of Mathematics and Technology, 10(3), $165-177$.

Bindewald, B., \& Rosenblith, S. (2014). Between mere tolerance and robust respect: Mutuality as a basis for civic education in pluralist democracies. Educational Theory, 64(6), 589606.

Blood, E. (2010). Effects of students response systems on participation and learning of students with emotional and behavioral disorders. Behavioral Disorders, 35(3), 214-228.

Blood, E. \& Gulchak, D. (2012). Embedding “Clickers” into classroom instruction: Benefits and strategies. Intervention in School and Clinic, 48(4), 246-253.

Bos, W., Tibboel, D., Tromp, K., \& Pinxten, W. (2013). Educational paper: Ethical aspects of clinical research with minors. European Journal of Pediatrics, 172, 859-886.

Brandt, R. (1994). On educating for diversity: A conversation with James A. Banks. Educational Leadership, 51(8), 28-31.

Bruna, K. R., \& Sabry, N. S. (2007). Learning from the experience of Muslim students in American schools: Towards a proactive model of school-community cooperation. Multicultural Perspectives, 93(3), 44-50.

Bush, A. (2013). Minding the gap: Approaches to addressing the Middle East within the social sciences. International Journal of Contemporary Iraqi Studies, 7(3), 199-218.

Campbell, P.S.(2014). Teaching a multicultural experience: Music, culture, and pedagogy. The Orff Echo, 46(2), 10. 
Campbell, P. \& Beegle, A. (2003). Middle eastern expansion on cultural diversity in music education. Music Educators'Journal. 90(1), 21-30.

Cantarelli Vita, J. (2016). Listening to their voices: An ethnographic study of children's values and meaning ascribed to learning world music in elementary school general music (Master's thesis). West Virginia University. Available from ProQuest Dissertation and Theses database. (UMI No. 10110170)

Carter, N., Bryant-Lukosius, D., DiCenso, A., Blythe, J., \& Neville, A. J. (2014). The use of triangulation in qualitative research. Oncology Nursing Forum, 41(5), 545-547.

Castro, A. J, Field, S. L., Bauml, M., \& Morowski, D. (2012). “I want a multicultural classroom": Preparing social studies teachers for culturally diverse classrooms. The Social Studies, 103, 97-106.

Chandler, C., Hamm, R.M., Hudson, J.C., Smith, E. M., \& Tucker, P. (2010). Assessing changes in medical student attitudes toward non-traditional human sexual behaviors using a confidential audience response system. Sex Education, 10(1), 37-45.

Charles, J., \& Stevens, R. (2005). Preparing teachers to teach tolerance. Multicultural Perspectives, 7(1), 17-25.

Cobb, C. (2012). Throwing out the culturally unresponsive cookie cutter: Collaborations, concessions, and curricula in a Ramadan music accommodationtion. Canadian Journal of Action Research, 13(3), 3-18.

Cohen, H.A. (2016). America's unique constitutional framework and the fit of Islam. Journal of Equmenical Studies, 51(2), 174-188. 
Conaway, W.A., \& Morrison, T. (2006). Kiss, Bow, or Shake Hands. Massachusetts: Adams Media.

Connelly, L. M. (2016). Understanding research: Trustworthiness in qualitative research. Medsurg Nursing, 25(6), 435-436.

Cook, L.A., Bell, M.L., Nugent, J., \& Smith, W.S. (2016). Global collaboration enhances technology literacy. Technology and Engineering Teacher, February, 20-25.

Cristol, D. \& Gimbert, B. (2008). Racial perceptions of young children: A review of literature post-1999. Early Childhood Education Journal, 36, 201-207.

Crotty, M. (2015). The Foundations of Social Research. Australia: Allen \& Unwin.

Damm, R. J. (2006). Education through Collaboration: Learning the Arts while Celebrating Culture. An Elementary School—University Partnership Provides Valuable Multicultural Music Education Experience for Elementary Future Educators. Music Educators Journal, 93(2), 54.

Davinroy, T.C., \& Williams, A. (2015). Teachable Moment: Google Earth takes us there. Change, 47(1), 62-65.

Derr, A. M., Taryn, L., \& Moylan, C.A. (2015). Increasingly mobile: How new technologies can enhance qualitative research. Qualitative Social Work, 14(1), 36-47.

Devers, K.J., \& Frankel, R.M. (2000). Study design in qualitative research -2: Sampling and data collection strategies. Education for Health, 13(2), 263-271.

Dodsworth, E., \& Nicholson, A. (2012). Academic uses of Google Earth and Google Maps in a library setting. Information Technology \& Libraries, 31(2), 102-117. 
Dresser, N. (2005). Multicultural Manners: Essential Rules of Etiquette for the $21^{\text {st }}$ century. New Jersey: John Wiley \& Sons, Inc.

Dunham, Y., Stepanova, E.V., Dotsch, R., \& Todorov, A. (2015). The development of racebased perceptual categorizations: skil color dominates early category judgements. Developmental Science, 18(3), 469-483.

El-Atwani, K. (2015). Envisioning multicultural education development in U.S. Islamic schools in life of reviewed literature. Multicultural Perspectives, 17(3), 145-151.

Emara, M. (2017). Islamophobia: Historical roots and expected outcomes. Islam Today, 34, 3346.

Emerson, R. M., Fretz, R. I., \& Shaw, L.L. (2011). Writing ethnographic fieldnotes. Chicago: University of Chicago Press.

Fawcett, B., \& Hearn, F. (2004). Researching others: Epistemology, experience, standpoints, and participants. Social Research Methodology, 7(3), 201-218.

Fraser, J.W. (2014). The school in the United States: A documentary history. New York, NY: Routledge.

Freitag, M., \& Rapp, C. (2015). Teaching tolerance? Associated diversity and tolerance formation. Political Studies, 63, 1031-1051.

Gibson, M. (1984). Approaches to multicultural education in the United States: Some concepts and assumptions. Anthropology \& Education Quarterly, 1(1), 94-119.

Glock, C.Y., Wuthnow, R., Piliavin, J.A. \& Spencer, M. (1975). Adolescent prejudice. New York,NY: Harper and Row. 
Hailey, S.E. \& Olson, K.R. (2013). A social psychologist's guide to the development of racial attitudes. Social and Personality Psychology Compass, 7(3), 457-469.

Hall, B. (2013). Adapting outdated content standards: Complications of teaching the Middle East in the California k-12 setting. International Journal of Contemporary Iraqi Studies, 7(3), 169-197.

Hays, D.G., \& Singh, A.A. (2012). Qualitative Inquiry in Clinical and Educational Settings. New York, NI: The Guilford Press.

Heiligman, D. (2006). Celebrate Diwali with Sweets, Lights, and Fireworks. Washington, D.C.: National Geographic Company.

Hellawell, D. (2006). Inside-out: Analysis of the insider-outsider concept as a heuristic device to develop reflexivity in students doing qualitative research. Teaching in Higher Education, 11(4), 483-494.

Hildebrandt, E.J., \& Vietze, D.L. (2009). Multiculturally conscious parenting: Promoting peace and teaching tolerance to young children. Encounter: Education for Meaning and Social Justice, 22(4), 33-37.

Hindley, M. (2007). Feature: Soldier of fortune: John Smith before Jamestown. Humanities: The Magazine of the National Endowment for Humanities, 28(1). Retrieved from: https://www.neh.gov/humanities/2007/januaryfebruary/feature/soldier-fortune-john$\underline{\text { smith-jamestown }}$

Hoffman, D. (1996). Culture and self in multicultural education: Reflections on discourse, text, and practice. American Educational Research Journal, 33(3), 545-569. 
Hoffman, A. R. (2012). Performing Our World: Affirming Cultural Diversity through Music Education. Music Educators Journal, 98(4), 61-65. Doi:10.1177/0027432112443262

Humphreys, J. T., \& Wang, J. (2009). Multicultural and popular music content in an American music teacher education program. International Journal of Music Education, 27(1), 1936.

Hutson, J.H. (2002). The founding fathers and Islam: Library papers show early tolerance for Muslim faith. Library of Congress Information Bulletin. Retrieved from: https://www.loc.gov/loc/lcib/0205/tolerance.html

Hwang, C., Lacroix, D., \& Usova, T. (2012). Mobile response systems: A fast and easy interactive tool. Feliciter, 58(3), 119-121.

Jackson, L. (n.d.) The new assimilationism: The push for patriotic education in the United States since September 11. Journal for Critical Education Policy Studies, 8(1), 109-136.

Janzen, R. (1994). Melting pot or mosaic? Educational Leadership, 51(8), 9-11.

Johnson, L, \& Lamb, A. (2010). Virtual expeditions: Google Earth, GIS, and geovisualization technologies in teaching and learning. Teacher Librarian, 37(3), 81-85.

Johnston, D.L.(2016). American evangelical islamophobia: A history of continuity with a hope for change. Journal of Ecumenical Studies, 51(2), 224-235.

Katz, P. A. (2003). Racists or tolerant multiculturalists? How do they begin? American Psychologist, 58(11), 897-909. 
Kenan, S. (2005). Reconsidering peace and multicultural education after 9/11: The case of educational outreach for muslim sensitivity curriculum in New York City. Educational Sciences, Theory and Practice, 5(1), 172-180.

Kliebard, H. M. (2004). The struggle for the American curriculum. New York, NY: RoutledgeFalmer.

Kundrat, S. (1993). Fun with the doumbek instructions \& 50 rhythm variations from One amateur to another. Mid-East Mfg. Co.

Lester, E. (2012). Teaching for religious tolerance in Modesto: Just enough, but not too much. Phi Delta Kappan, 93(4), 38-43.

Lincoln, Y. S., \& Guba, E.G. (1985). Naturalistic inquiry. Newbury Park, CA: Sage Publications.

Lowe, J.L., \& Matthew, K.I. (2004). Neal-Schuman Guide to Celebrations and Holidays Around the World. New York: Neal-Schuman Publishers.

Mason, E. (2010). Multicultural Music Represented in Current Elementary Music Textbooks: A Comparative Study of Two Published Music Series. Update: Applications Of Research In Music Education, 28(2), 29-41.

McKinley, W. (1900). Decision on the Philippines. Digital History: Using New Technologies to Enhance Teaching and Research. Retrieved from: http://www.digitalhistory.uh.edu/disp_textbook.cfm?smtID=3\&psid=1257

Meyer, L. (2016). Students explore the earth and beyond with virtual field trips. THE Journal, $43(3), 22-25$. 
Middle East Policy Council. (n.d.). What is the Middle East? Retrieved from: http://teachmideast.org/articles/what-is-the-middle-east/

Miles, M.B., Huberman, A.M., \& Saldaña, J. (2014). Qualitative data analysis: A methods sourcebook. Thousand Oaks, CA: Sage Publications.

Miqdad, M.I. (2015). Islam and the rejection of violence. Palestine-Israel Journal of Politics, Economics, and Culture, 20(4/1), 33-39.

Moffa, E. D.(2016). The impact of rural contexts on citizenship education (Doctoral dissertation). West Virginia University. Available from ProQuest Dissertations and Theses database. (No. 10246312)

Moore, J.R. (2009). Why religious education matters: The role of Islam in multicultural education. Multicultural Perspectives, 11(3), 139-145.

National Coalition for Core Arts Standards. (2014). National core arts standards-dance. Retrieved from: http://www.nationalartsstandards.org/sites/default/files/Dance\%20at\%20a\%20Glance\%2 0-\%20new\%20copyright\%20info.pdf

National Coalition for Core Arts Standards. (2014). National core arts standards-music. Retrieved from: http://www.nationalartsstandards.org/sites/default/files/Music\%20at\%20a\%20Glance\%2 Orev\%209-22-16.pdf

National Coalition for Core Arts Standards. (2014). National core arts standards-theatre. Retrieved from: 
http://www.nationalartsstandards.org/sites/default/files/Theatre\%20at\%20a\%20Glance\% 20-\%20new\%20copyright\%20info.pdf

National Committee on Science Education Standards and Assessment. (1996). National science education standards. Retrieved from: http://www.csun.edu/science/ref/curriculum/reforms/nses/nses-complete.pdf

National Council for the Social Studies. (2010). Curriculum standards for social studies. Retrieved from: https://www.mhschool.com/socialstudies/2009/teacher/pdf/ncss.pdf

Naumenko, E.A., \& Naumenko, O.N. (2016).. Pedagogical experience on formation of tolerant and multicultural consciousness of students European Journal of Contemporary Education, 17(3), 335-343.

Nelson, M.L., \& Quintana, S.M. (2005). Qualitative clinical research with children and adolescents. Journal of Clinical Child and Adolescent Psychology, 34(2), 344-356.

Nethsinghe, R. (2013). The Notion of Authenticity in Multicultural Music: Approaching Proximal Simulation. International Journal of Multicultural Education, 15(2), 1-15.

Okoye-Johnson, O. (2011). Does multicultural education improve students' racial attitudes? Implications for closing the achievement gap. Journal of Black Studies, 42(8), 12521274.

Orsborn, C. (2016). Shoulder to shoulder with American Muslims: What the interreligious community is doing to combat anti-Muslim bigotry in America. Journal of Ecumenical Studies, 51(2), 257-263. 
Pascale, L.M. (2011) Sharing songs: A powerful tool for teaching tolerance and honoring culture. General Music Today, 25(1), 4-7.

Pew Research Center. (2012). Arab-American population growth. Retrieved from: http://www.journalism.org/2012/11/28/arabamerican-population-growth/

Pew Research Center. (2012a). Arab-American Media.Retrieved from: http://www.journalism.org/files/legacy/Arab\%20American\%20Media\%20Report.pdf

Pew Research Center. (2015). The future of world religions: Population growth projections, 2010-2050. Retrieved from http://www.pewforum.org/2015/04/02/religious-projections$\underline{2010-2050 /}$

Pizzillo, J.J. (1983). Intercultural studies. Dubuque, Iowa: Kendall/Hunt.

Rauf, I.F.A.(2016). The relationship between the Muslim world and the United States and the root of islamophobia in America. Journal of Ecumenical Studies, 51(2), 189-197.

Robinson, M. (2010). Crossing Borders: Adding Cultural Diversity to Music Education Expands Horizons for All. Teaching Music, 18(3), 38-40.

Saladin, C.S. (2016). From Thomas Jefferson to Donald Trump: The recurring Muslim xenoarchetype in American politics and government. Augustana College,online submission.

Saldaña, J. (2013). The coding manual for qualitative researchers. London: Sage Publications Ltd.

Samuelson, R. (2002). John Quincy Adams on the war we are in. Claremont Review of Books, 3(1). Retrieved from: http://www.claremont.org/crb/article/john-quincy-adams-on-thewar-we-are-in/

Sanders, J., \& Tavakol, M. (2014). Quantitative and qualitative methods in medical education research. Medical Teacher, 36, 838-848. 
Shatara, L. H. (2007). A teacher's power: A Muslim child's perspective. Multicultural Perspectives, 9(1), 50-52.

Shon, H., \& Smith, L. (2011). A review of Poll Everywhere audience response system. Journal of Technology in Human Services, 29, 236-245.

Siddiqui, S. (2016). Through the looking glass: Reflecting Muslim narratives in children's literature. The California Reacher, 49(4), 10-14.

Sleeter, C. \& Grant, C. (1987). An analysis of multicultural education in the United States. Harvard Educational Review, 57(4), 421-444.

Social Psychology Network. (n.d.). Understanding prejudice: Christopher Columbus: The untold story. Retrieved from: http://www.understandingprejudice.org/nativeiq/columbus.htm

Souhami, J. (2015). Rama and the demon king: An ancient tale from India. London: Frances Lincoln Children's Books.

Tarr, R. (2006). Using 'Google Earth' in the history classroom. History Review, December, 2627.

Tatum, B.D. (2007). Can we talk about race?And other conversations in an era of school resegregation. Boston, Massachusetts: Beacon Press.

The Editors of the Encyclopaedia Britrannica. (2007). Council of Clermont. Retrieved from: https://www.britannica.com/event/Council-of-Clermont

Tiedt, P., \& Tiedt, I.M.(1990). Multicultural teaching: A handbook of activities, information, and resources. Boston: Allyn and Bacon

Urban, W. \& Wagoner, J. (2014). American Education: A History. New York: Routledge.

U.S. Census Bureau. (2010). 2010 Demographic Profile Data. Retrieved From: https://factfinder.census.gov/faces/tableservices/jsf/pages/productview.xhtml?src=bkmk

U.S. Census Bureau. (2014). 2011-2015 American Community Survey 5-Year Estimates. Retrieved from: https://factfinder.census.gov/faces/tableservices/jsf/pages/productview.xhtml?src=bkmk

U.S. Congress. (1790). Naturalization Act of 1790. Retrieved from: http://library.uwb.edu/Static/USimmigration/1\%20stat\%20103.pdf 
U.S. Congress. (1921). Emergency Quota Act of 1921. Retrieved from: http://loveman.sdsu.edu/docs/1921EmergencyQuotaAct.pdf

U.S. District Court for the District of Massachusetts. (1944). Ex Parte Mohriez, 54 F. Supp. 941. Retrieved from: https://law.justia.com/cases/federal/districtcourts/FSupp/54/941/1739378/

Walker, C.A. (2015). Social constructionism and qualitative research. The Journal of Theory Construction \& Testing, 19(2), 37-38.

Wan, G. (2006). Teaching diversity and tolerance in the classroom: A thematic storybook approach. Education, 127(1), 140-154.

Weidknecht, M. K. (2009). Multicultural Music Education: Building an Appreciative Audience. Online Submission.

West Virginia Department of Education. (2003). $21^{\text {st }}$ century dance content standards and objectives for west 157irginia schools. Retried from: https://wvde.state.wv.us/policies/p2520.9.pdf

West Virginia Department of Education. (2008). $21^{\text {st }}$ century music education content standards and objectives for west 157irginia schools. Retrieved from: https://wvde.state.wv.us/policies/p2520.10.pdf

West Virginia Department of Education. (2008). $21^{\text {st }}$ century theatre content standards and objectives for West Virginia schools. Retrieved from: https://wvde.state.wv.us/policies/p2520.11.pdf 
West Virginia Department of Education. (2016). Next generation content standards and objectives for science in West Virginia schools. Retrieved from: http://apps.sos.wv.gov/adlaw/csr/readfile.aspx?DocId=26574\&Format=PDF

West Virginia Department of Education. (2016). West Virginia college and career readiness standards for social studies. Retried from: http://apps.sos.wv.gov/adlaw/csr/readfile.aspx?DocId=29936\&Format=PDF

West Virginia Secretary of State. (2016). Election results center. Harrison County results, general election November 8, 2016. Retrieved from: http://services.sos.wv.gov/apps/elections/results/results.aspx?year=2016\&eid=23\&county $=$ Harrison

West Virginia Secretary of State. (2016a). Election results center. Harrison County results, primary election May 10, 2016.Retrieved from: http://services.sos.wv.gov/apps/elections/results/results.aspx?year=2016\&eid=22\&county =Harrison

Woodrow Wilson International Center for Scholars. (n.d.). US Presidential candidates on ISIS, extremism. Retrieved from: https://www.wilsoncenter.org/article/us-presidential$\underline{\text { candidates-isis-extremism }}$ 


\section{Appendix A}

The lesson sessions within this study can be mapped to the following WV and National Standards:

The included lessons align to the following standards:

National Common Core Science Standards:

3-PS2-1, 4-ESS2-1: Cause and effect relationships are routinely identified

3-PS2-2, 4-PS3-2, 5-PS1-3: Make observations and/or measurements to produce data to serve as the basis for evidence for an explanation of a phenomenon or a test design solution.

3-PS2-3: Ask questions that can be investigated based on patterns such as cause and effect relationships.

4-PS3-2: Make observations to provide evidence that energy can be transferred from place to place by sound, light, heat, and electric currents.

National Council for the Social Studies Standards:

I. Culture- Social studies programs should include experiences that provide for the study of culture and cultural diversity so that the learner can:

a. explore and describe similarities and differences in the ways groups, societies, and cultures address similar human needs and concerns.

c. describe ways in which language, stories, folktales, music, and artistic creations serve as expressions of culture and influence behavior of people living in a particular culture. 
II. People, Places, \& Environments- Social studies programs should include experiences that provide for the study of people, places, and environments so that the learner can:

a. construct and use mental maps of locales, regions, and the world that demonstrate understanding of relative location, direction, size, and shape.

b. Interpret, use, and distinguish various representations of the earth, such as maps, globes, and photographs.

IX. Global Communications- Social studies programs should include experiences that provide for the study of global connections and independence.

a. Explore ways that language, art, music, belief systems, and other cultural elements may facilitate global understanding or lead to misunderstanding.

\section{Dance- National Core Arts Standards:}

Anchor Standard 7: Perceive and Analyze Artistic Work

DA: Re.7.1.3.b. Demonstrate and explain how one dance genre is different from another, or how one cultural movement practice is different from another.

DA: Re.7.1.4.b. Demonstrate and explain how dance styles differ within a genre or within a cultural movement practice.

DA: Re.7.1.5.b. Describe, using basic dance terminology the qualities and characteristics of style used in a dance from one's own cultural movement practice. Compare them to the qualities and characteristics of style found in a different dance genre, style, or cultural movement practice, also using basic dance terminology. 
Anchor Standard 9: Apply Criteria to Evaluate Artistic Work

DA: Re.9.1.3 Select movements from specific genres, styles, or cultures. Identify characteristic movements from these dances and describe in basic dance terminology ways in which they are alike and different.

Anchor Standard 11: Relate Artistic Ideas and Works with Societal, Cultural, and Historical Context to Deepen Understanding

DA: Cn11.1.3a. Find a relationship between movement in a dance from a culture, society, or community and the culture from which the dance is derived. Explain what the movements communicate about key aspects of the culture, society, or community.

DA: Cn11.1.4a. Select and describe movements in a specific genre or style and explain how the movements relate to the culture, society, historical period, or community from which the dance originated.

DA: Cn.11.1.5a Describe how the movement characteristics and qualities of a dance in a specific genre or style communicate the ideas and perspectives of the cultural, historical period, or community from which the genre or style originated.

Music- National Core Arts Standards:

Anchor Standard 2: Organize and Develop Artistic Ideas and Work

MU.Cr.2.1.3a Demonstrate selected musical ideas for a simple improvisation or composition to express intent, and describe connection to a specific purpose and context. 
MU.Cr.2.1.4a Demonstrate selected and organized musical ideas for an improvisation, arrangement, or composition to express intent, and explain connection to purpose and context.

Anchor Standard 4: Select, Analyze, and Interpret Artistic Work for Presentation

MU.Pr4.3.3a Demonstrate and describe how intent is conveyed through expressive qualities (such as dynamics, tempo, and timbre).

MU.Pr4.3.4a Demonstrate and explain how intent is conveyed through interpretive decisions and expressive qualities (such as dynamics, tempo, and timbre).

MU.Pr4.3.5a Demonstrate and explain how intent is conveyed through interpretive decisions and expressive qualities (such as dynamics, tempo, timbre, and articulation/style).

Anchor Standard 5: Develop and Refine Artistic Techniques and Work for Presentation

MU.Pr5.1.3b. Rehearse to refine technical accuracy, expressive qualities, and identified performance challenges.

MU.Pr5.1.4b. Rehearse to refine technical accuracy and expressive qualities, and address performance challenges.

MU.Pr5.1.5b. Rehearse to refine technical accuracy and expressive qualities to address challenges, and show improvement over time.

Anchor Standard 6: Convey Meaning through the Presentation of Artistic Work MU.Pr6.1.3a. Perform music with expression and technical accuracy. 
MU.Pr6.1.4a. Perform music, alone or with others, with expression and technical accuracy, and appropriate interpretation.

MU.Pr6.1.5a. Perform music, alone or with others, with expression, technical accuracy, and appropriate interpretation.

Anchor Standard 11: Relate Artistic Ideas and Works with Societal, Cultural, and Historical Context to Deepen Understanding

MU.Cn11.0.3a. Demonstrate understanding of relationships between music and the other arts, other disciplines, varied contexts, and daily life.

MU.Cn11.0.4a. Demonstrate understanding of relationships between music and the other arts, other disciplines, varied contexts, and daily life.

MU.Cn11.0.5a. Demonstrate understanding of relationships between music and the other arts, other disciplines, varied contexts, and daily life.

Theatre- National Core Arts Standards:

Anchor Standard 1: Generate and Conceptualize Artistic Ideas and Work

TH.Cr1.1.3c. Collaborate to determine how characters might move and speak to support the story and given circumstances in a drama/theatre work.

TH.Cr1.1.4c. Imagine how a character might move to support the story and given circumstances in a drama/theatre work.

Anchor Standard 3: Refine and Complete Artistic Work 
TH.Cr3.1.3a. Collaborate with peers to revise, refine, and adapt ideas to fit the given parameters of a drama theatre work.

Anchor Standard 11: Relate Artistic Ideas and Works with Societal, Cultural, and Historical Context to Deepen Understanding

TH.Cn11.2.3a. Explore how stories are adapted from literature to drama/theatre work.

TH.Cn11.2.5a. Analyze commonalities and differences between stories set in different cultures in preparation for a drama/theatre work.

West Virginia Science Standards:

Energy

S.4.GS.2. Make observations to provide evidence that energy can be transferred from place to place by sound, light, heat, and electric currents.

West Virginia Social Studies Standards:

Civics

SS.3.1. Identify and explain the following commonly-held American democratic values, princles, and beliefs: Diversity, Rule of Law, Family Values, Community Service, Justice, and Liberty.

Geography

SS.3.14. Label maps to demonstrate knowledge of map skills.

SS.4.9. Document the effects of and explain how people adapted to geographic factors on the following: transportation routes, settlement patterns and population density, culture (e.g., 
jobs, food, clothing, shelter, religion, government, etc.), interactions with others (local and national).

SS.5.19 Display information on maps, globes, geographic models and in graphs, diagrams and charts (e.g. designing map keys and legends, etc.).

West Virginia $21^{\text {st }}$ Century Theatre Standards:

Standard 2: Acting

TH.O.LI.2.05. Communicate responsibly and respectfully in ensemble efforts and during critique.

Standard 4: Directing

TH.O.LI.4.03. Research and analyze information related to the historical, cultural, and social context of a play.

Standard 5: Making Meaning through Connections

TH.O.LI.5.06. Explore cultural, historical, and symbolic clues in dramatic texts and determine the practicality of the information to assist in making artistic choices for use in informal and formal productions.

West Virginia Music Content Standards:

Performing

MU.O.GM3-5.1.04. Perform syncopated patterns

MU.O.GM3-5.1.15. Sing or play instruments, following the cues of a conductor

Exploring 
MU.O.GM3-5.2.21. Evaluate their own musical performances.

Creating

MU.O.GM3-5.3.03. Given a theme, create variations on that theme.

Relating

MU.O.GM3-5.4.01. Collaborate with others in a musical play.

MU.O.GM3-5.4.05. Sing and interpret foreign language songs from global cultures.

MU.O.GM3-5.4.09 Identify and discuss tone production for instruments and voices.

$\underline{2{ }^{\text {st }} \text { Century West Virginia Dance Content Standards: }}$

D.O.LI.2.01. Identify and practice locomotor and nonlocomotor/axial movements with an awareness of alignment.

D.O.LI.2.02. Identify and practice steps and patterns from several different dance styles/traditions.

D.S.LI.4. Students will examine and demonstrate dance from various cultures and historical periods.

D.O.LI.4.01. Perform and report on the history of culturally diverse dances.

D.O.LI.7.01. Create a group interdisciplinary project based on a theme identified by the group. 


\section{$\underline{\text { Appendix B }}$}

Researcher Compiled Map - Session 1

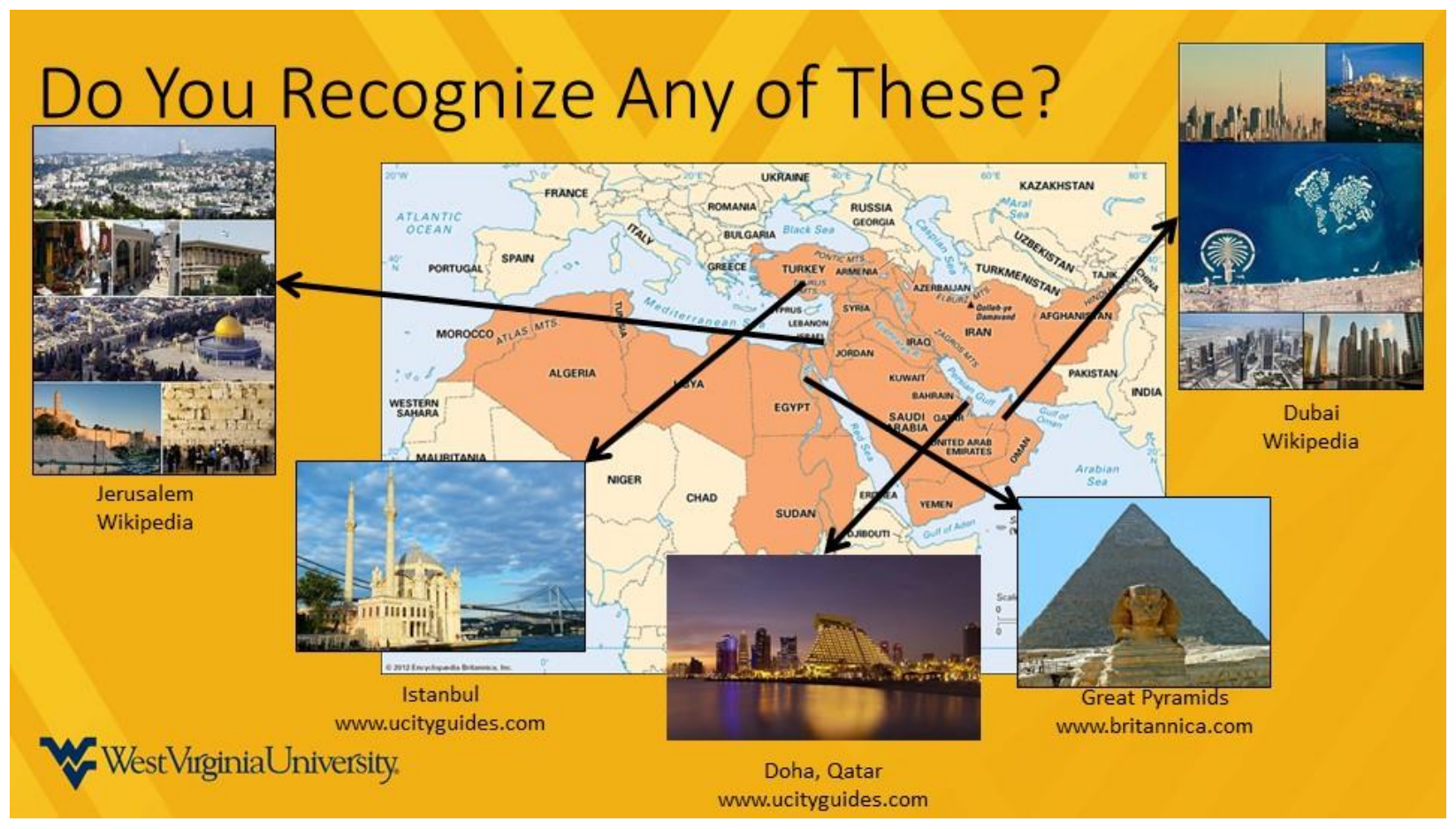




\section{Appendix C}

\section{Parent Consent Letter}

WestVirginiaUniversity:

COUEGE OF EDUCATION AND HUMWN SERMCES

Dear Participent Guardien:

This letter is to request permission for your child to participste in a research study that serves to enhance perceptions of Middle Eastern people \& Culture through music, dance, cultural sctivities, folk literature, and virtual field trips. This is the dissertation project of lason Noiand, a doctoral candidate in the College of Education and Human Services at West Virginia University. This project will not touch on religion, but aim to focus on common traits and themes we have in our cultural activities and daily lives.

As o participont, your child will portiojpste in six lessons once week throughout that will include anonymous virtual polls, music, dance, cutural activities, fosk literature, snd virtusl field trips. These lessons will be approximately one hour to one hour snd fifteen minutes in length and will be sudio recorded to accurstely represent the voices and discussions hesrd throughout the lessons.

Your child's invoivement in this project will be confidential. Information obtained ouring the lessons and observations will be reported with their identity kept strictly confidential. Participation is completey voluntary, your child can stop participation at any time without pensity. This study offers no grester risks then any normal dsily activities during

The institutionsl Review board of West Virginia University has approved this project.

I hope you will allow your child to participste in this study, ss it will contribute to the better knowledge of the Middle Esst and mulicultural education in schools. If you will sllow your child to be a port of this study, please sign the assent form your child should complete snd return it to me. Should you have any questions about this letter or the research project, please feel free to contact Jason Nolsnd at $304 \quad$ or by e-mail st janolandefemix.wvu.edu.

Thank you for your time and help with this project.

Sincerely.

Jason Noland 


\section{$\underline{\text { Appendix D }}$}

\section{Participant Assent Letter}

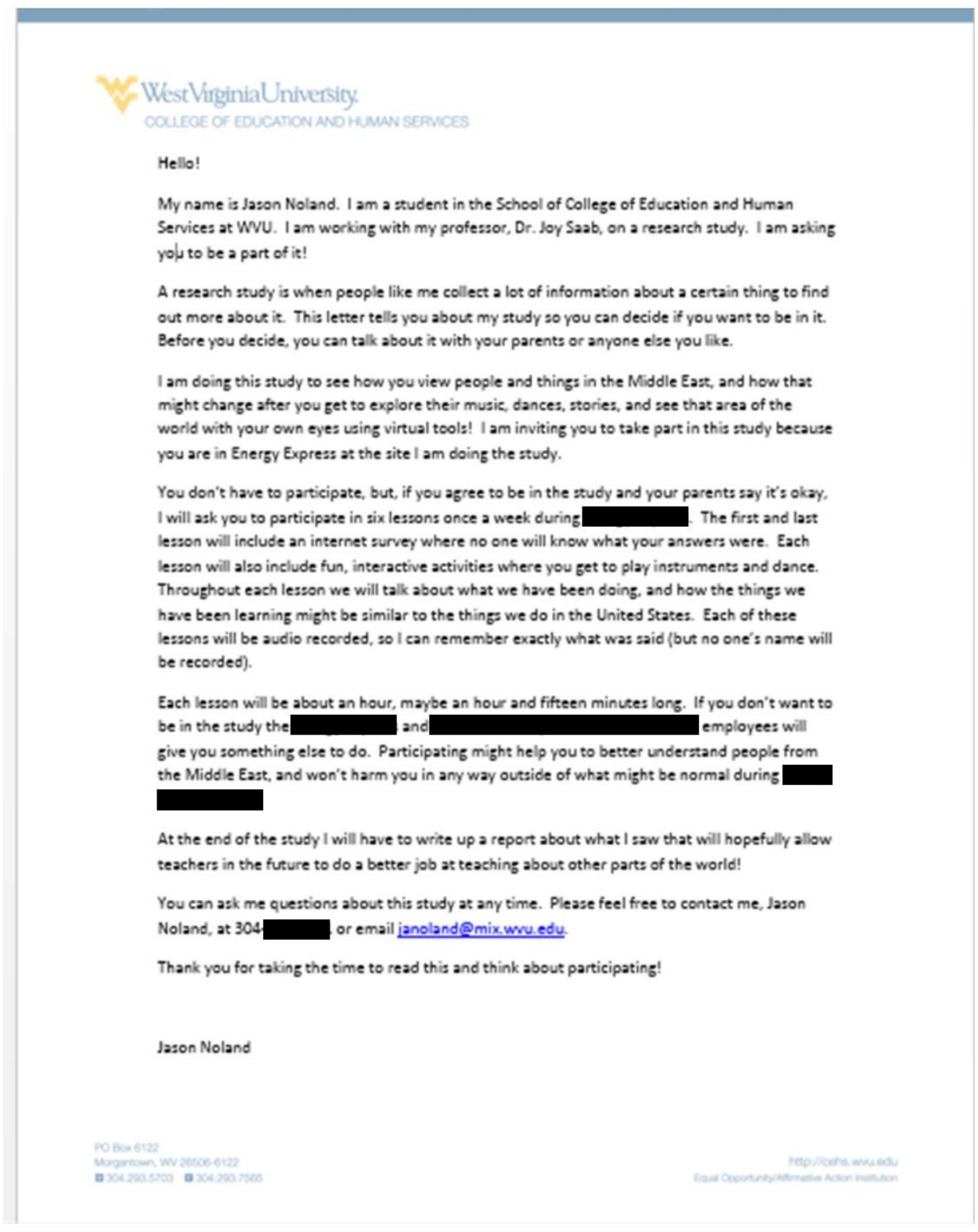




\section{$\underline{\text { Appendix E }}$}

Observer Consent Letter

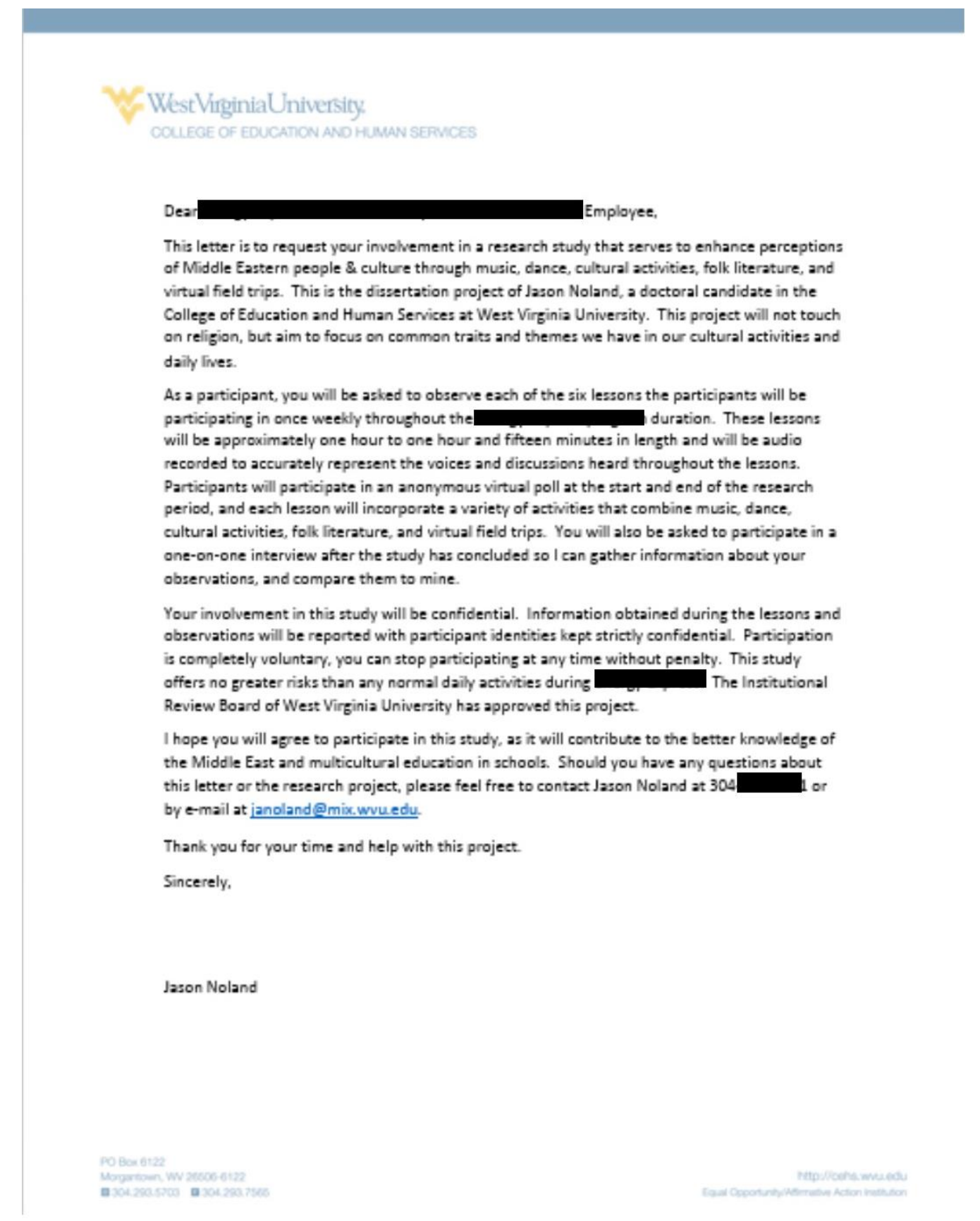




\section{Appendix F}

Sample Data Matrix Excerpts

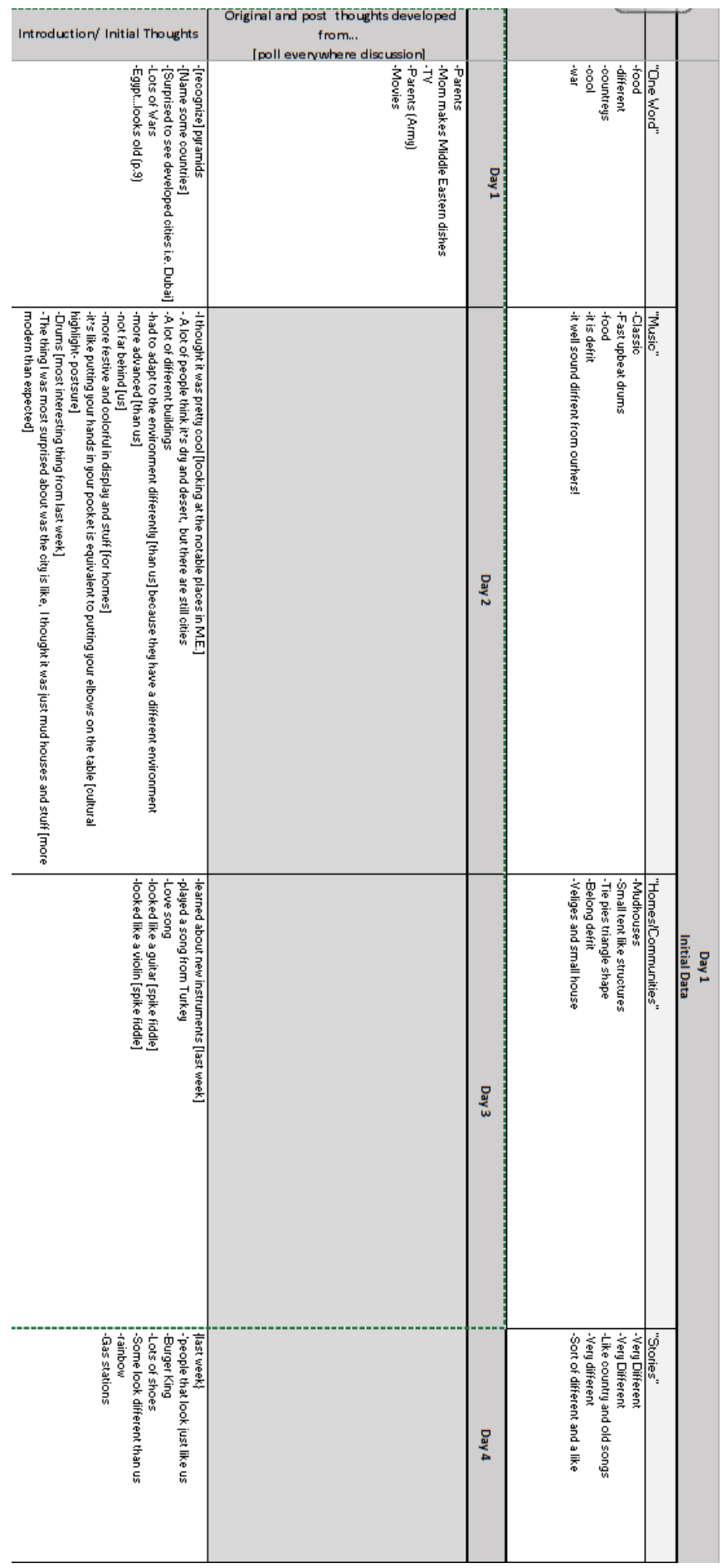




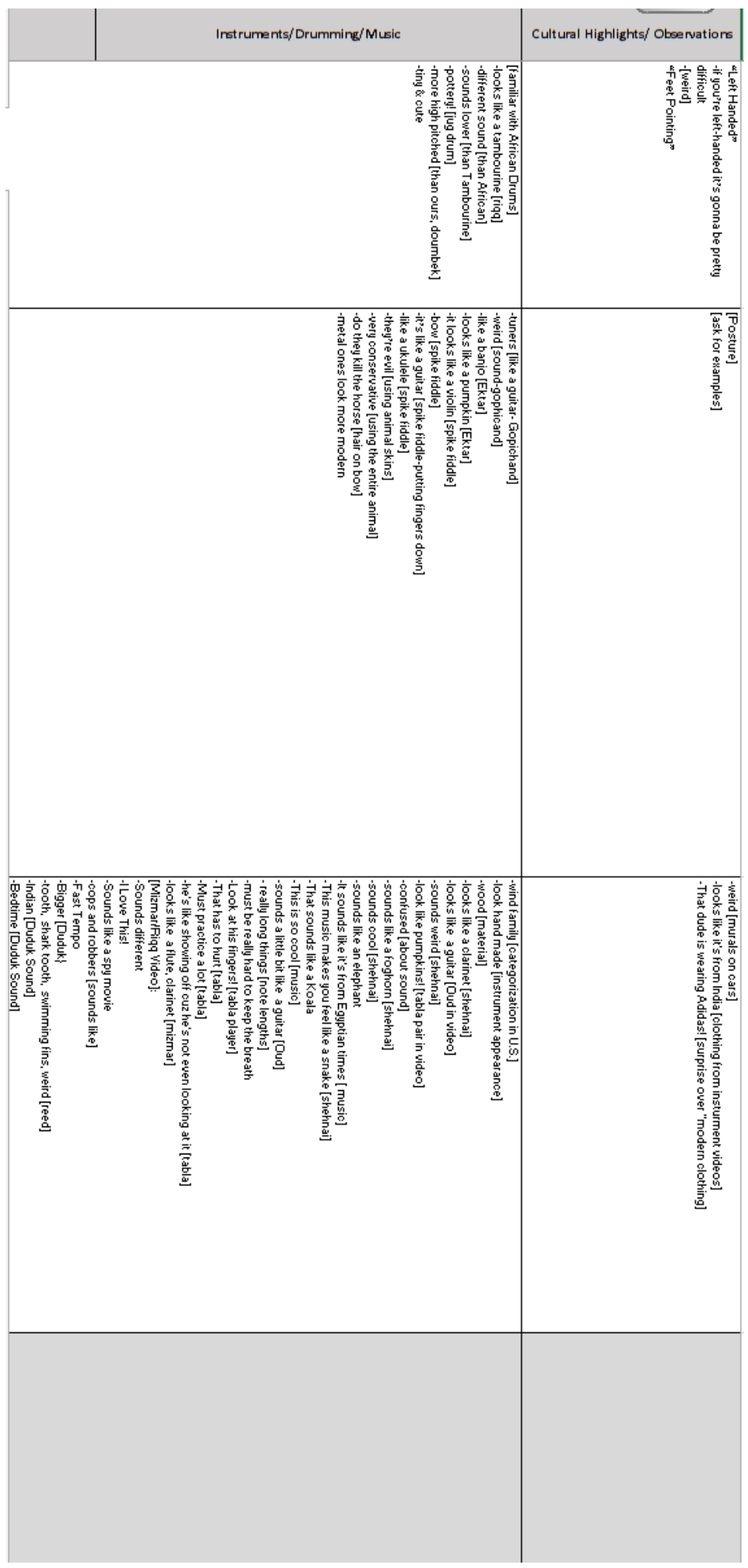




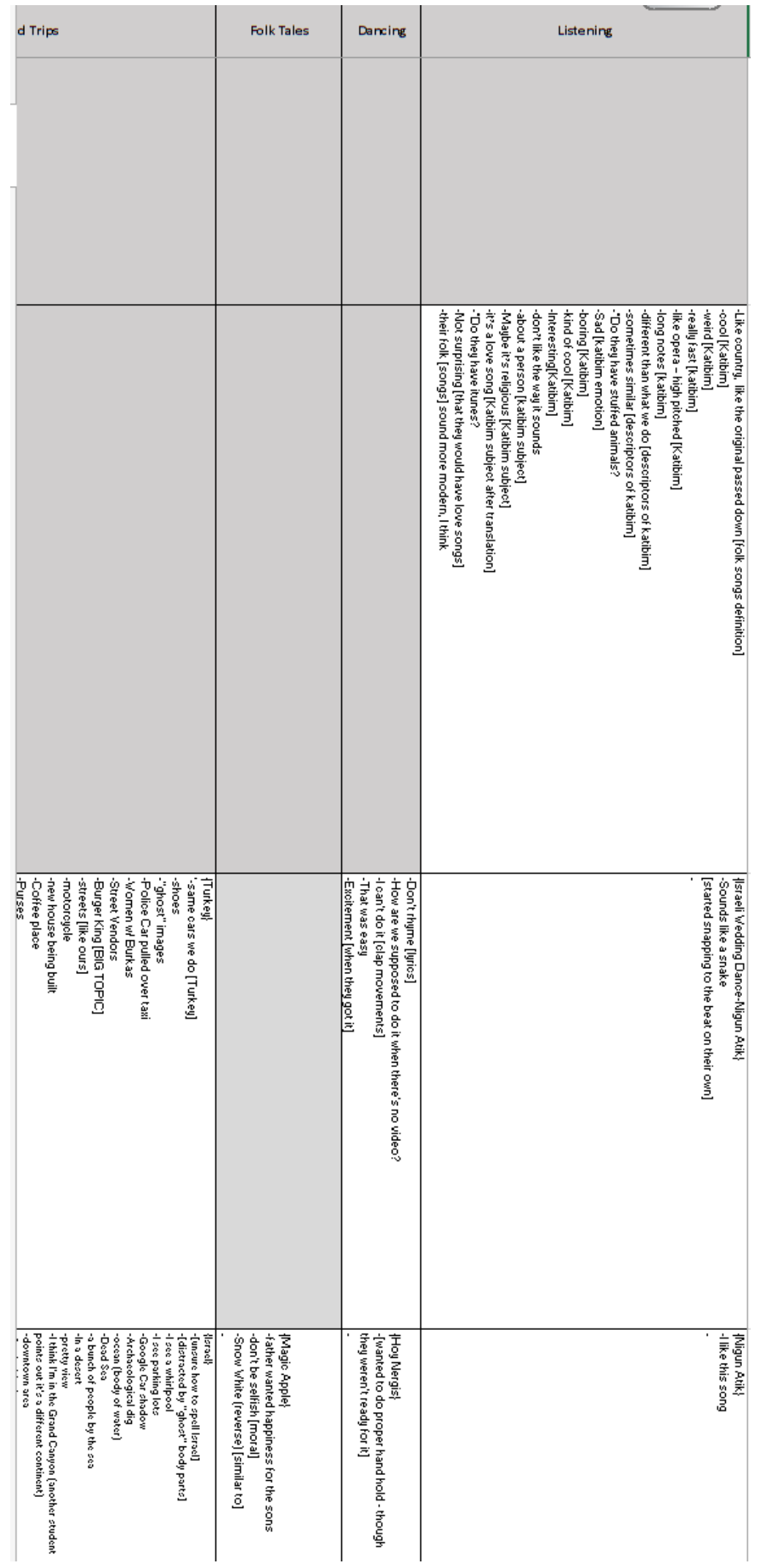




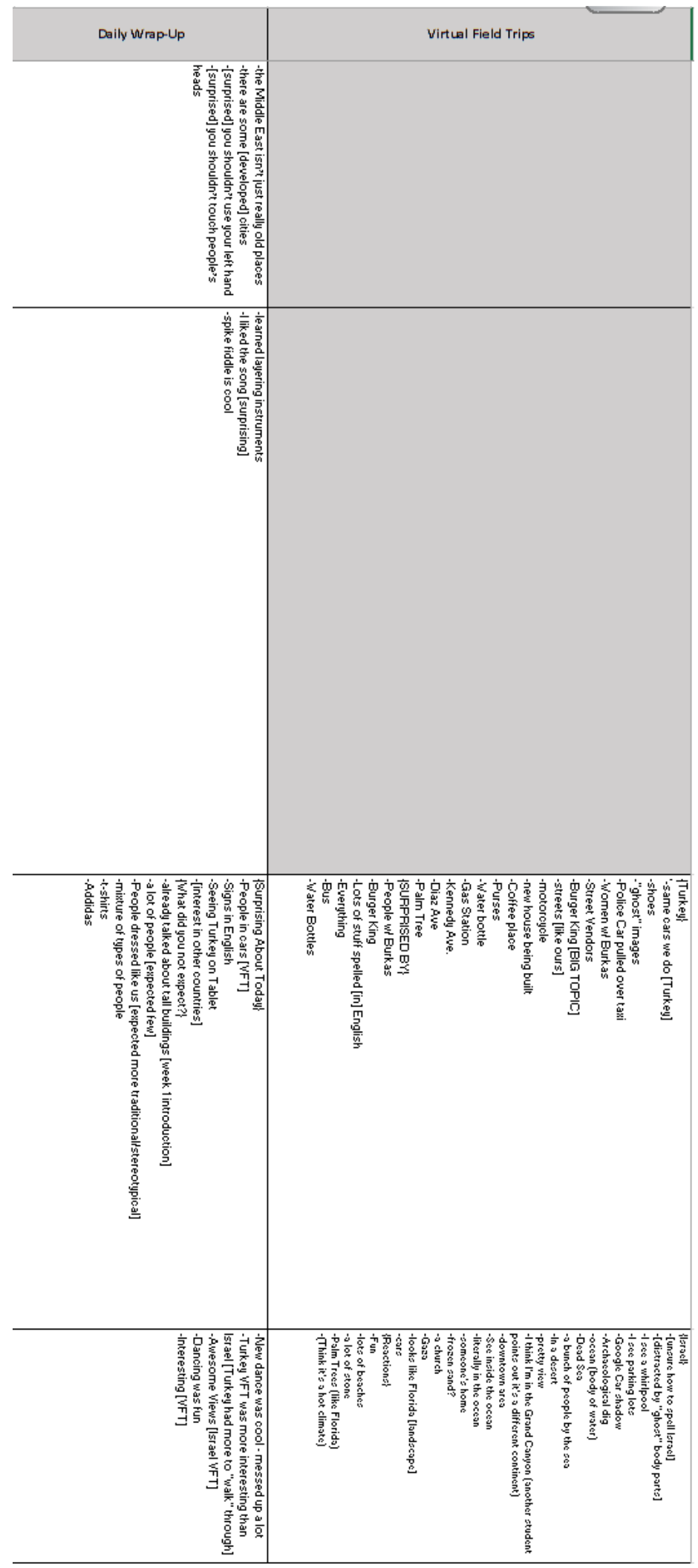




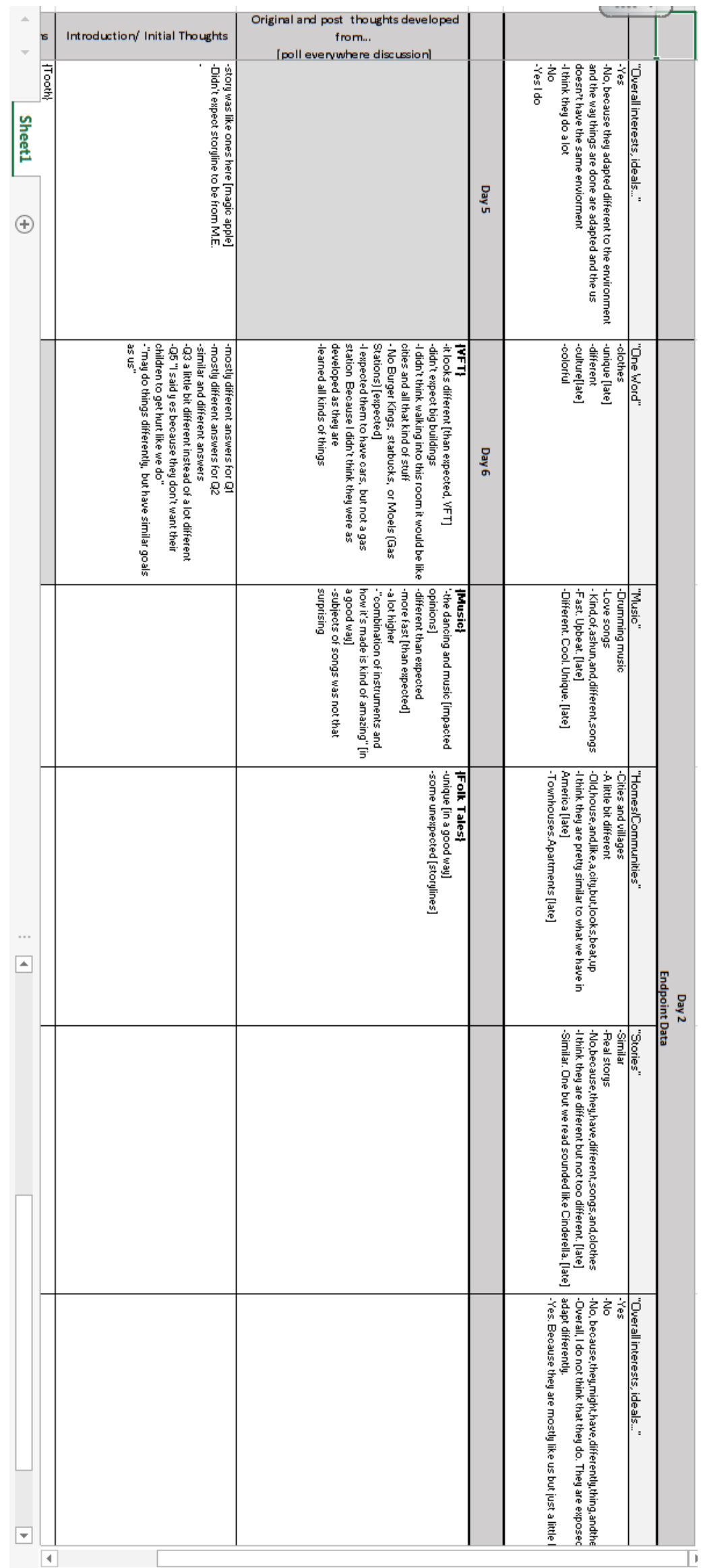




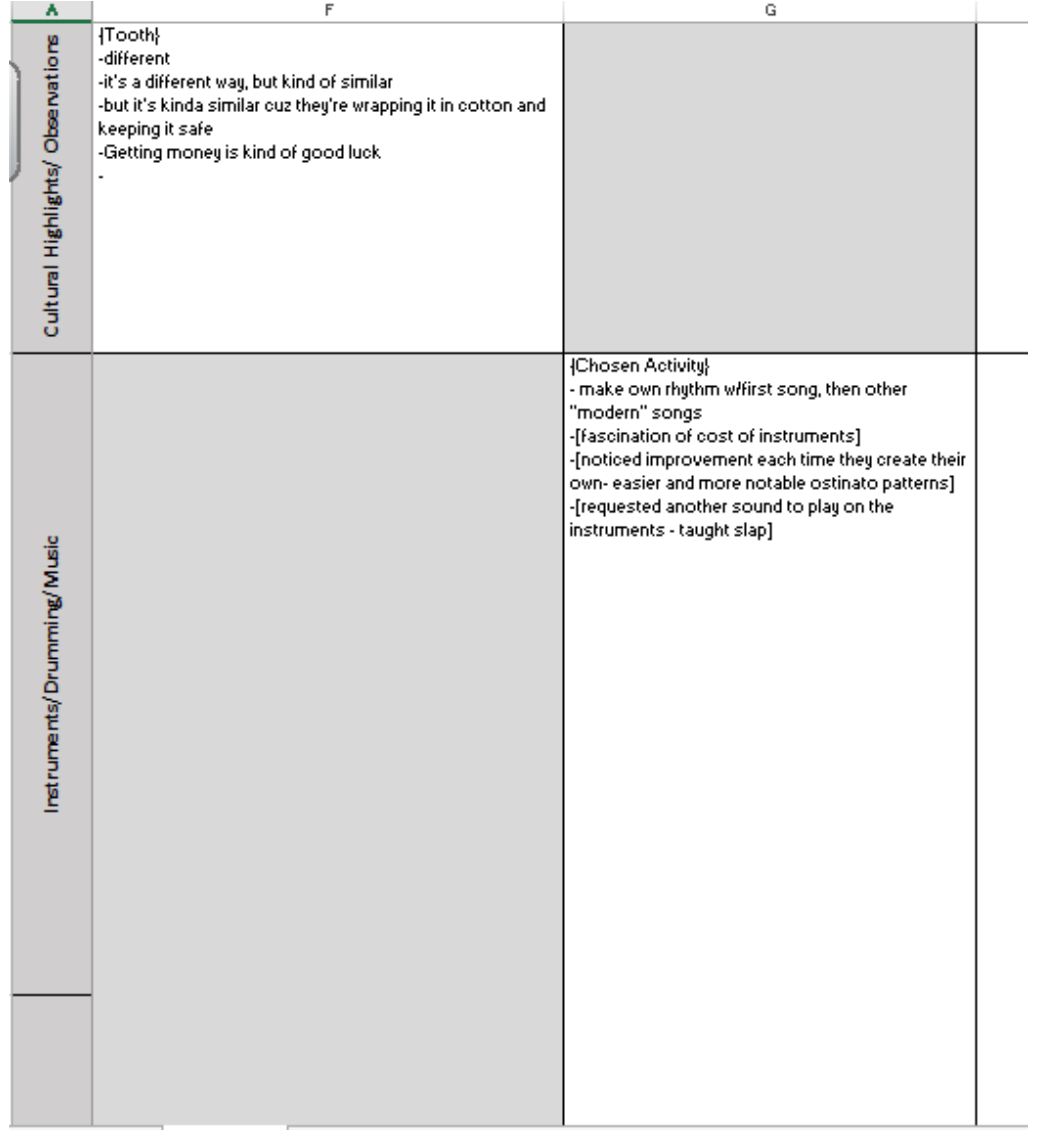




\begin{tabular}{|c|c|c|}
\hline A & $F$ & G \\
\hline 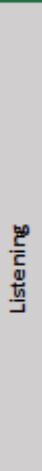 & $\begin{array}{l}\text { \{Title...\} } \\
\text {-Sounds like an American Song } \\
\text {-sounds like music l like to listen to } \\
\text {-Sounds Asian [Instrument interlude] } \\
\text {-Sounded American btc of the kind of music it is } \\
\text {-The beat [American] } \\
\text { - How it sounds [American] } \\
\text {-(didn't expect] Computerized sound } \\
\text { - - some expected computerized sound brc of modern } \\
\text { buildings) } \\
\text {-Song was good } \\
\text {-liked instrumental interlude } \\
\text {-it's like a pop song } \\
\text {-classical mixed with a little bit of pop } \\
\text {-classical, a little bit country } \\
\text {-sounds like a happy song } \\
\text {-sounds like a dance party song } \\
\text {-Love song [after translation] }\end{array}$ & $\begin{array}{l}\text {-one [new song] reminded of ocean breeze } \\
\text {-another [new song] reminded of Alvin and the } \\
\text { Chipmunks }\end{array}$ \\
\hline$\frac{\frac{2}{g}}{8}$ & & \\
\hline $\begin{array}{l}\frac{y}{\frac{y}{10}} \\
\frac{10}{5} \\
\frac{\partial}{0}\end{array}$ & $\begin{array}{l}\text {-good book [Joha] } \\
\text {-[didn't expect that storyline from the M.E.] } \\
\text {-[story was like stories we have here] } \\
\text {-"So are they granting the wishes for just the opposite of } \\
\text { what he says?" } \\
\text {-It got huge [hypothesis of what happened next] } \\
\text {-he'll take it [hypothesis] }\end{array}$ & $\begin{array}{l}\text {-unique...in a good way } \\
\text {-revolve around one tiny thing } \\
\text {-storylines were unempected from Middle East }\end{array}$ \\
\hline $\begin{array}{l}\frac{8}{2} \\
0\end{array}$ & & $\begin{array}{l}\text { 1Chosen Activity\} } \\
\text {-[one student requested Iran] } \\
\text {-[One student requested Syria] } \\
\text {-[one student requested Armenia] } \\
\text {-[One student visited Georgia] } \\
\text {-[jumping around countries] } \\
\text { IDENTIFIED: } \\
\text {-a wall } \\
\text {-powerlines } \\
\text {-sea } \\
\text {-car } \\
\text {-Palm Trees } \\
\text {-medical clinic }\end{array}$ \\
\hline
\end{tabular}




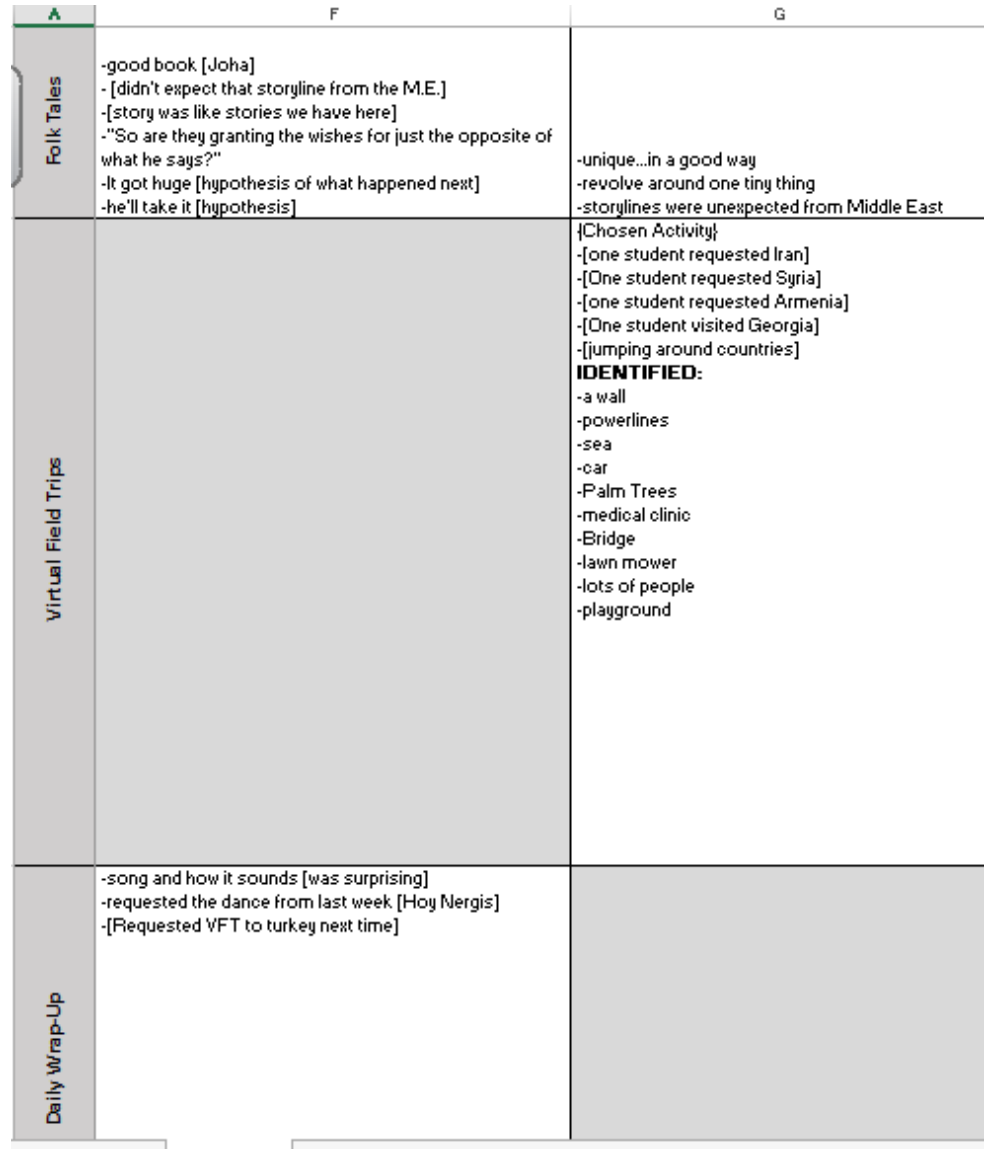




\section{$\underline{\text { List of Tables }}$}

Table 1: Data Used to Answer Research Questions.....................................123 


\section{$\underline{\text { List of Figures }}$}

Figure 1: Initial Data Question 1 Responses............................................56

Figure 2: Initial Data Question 2 Responses........................................57

Figure 3: Initial Data Question 3 Responses.......................................57

Figure 4: Initial Data Question 4 Responses........................................5

Figure 5: Initial Data Question 5 Responses.......................................58

Figure 6: Endpoint Data Question 1 Responses....................................66

Figure 7: Endpoint Data Question 2 Responses...................................67

Figure 8: Endpoint Data Question 3 Responses..................................67

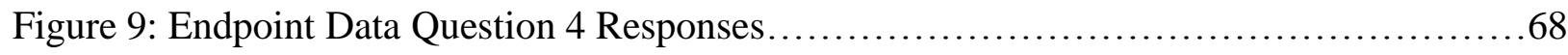

Figure 10: Endpoint Data Question 5 Responses...................................68

Figure 11: Narrow Hollow Elementary School Library/Music Room Diagram................131 